O infinito na matemática 
SERVIÇO DE PÓS-GRADUAÇÃO DO ICMC-USP

Data de Depósito:

Assinatura:

\section{O infinito na matemática}

\section{Bruno Andrade Borges}

Orientador: Prof. Dr. Américo López Gálvez

Dissertação apresentada ao Instituto de Ciências Matemáticas e de Computação - ICMC-USP, como parte dos requisitos para obtenção do título de Mestre Programa de Mestrado Profissional em Matemática. VERSÃO REVISADA

\section{USP - São Carlos}

Janeiro de 2015 
Ficha catalográfica elaborada pela Biblioteca Prof. Achille Bassi e Seção Técnica de Informática, ICMC/USP, com os dados fornecidos pelo(a) autor(a)

O infinito na matemática / Bruno Andrade Borges;

B732i orientador Américo López. -- São Carlos, 2015. $89 \mathrm{p}$.

Dissertação (Mestrado - Programa de Pós-Graduação em Mestrado Profissional em Matemática em Rede Nacional) -- Instituto de Ciências Matemáticas e de Computação, Universidade de São Paulo, 2015.

1. Infinito. 2. Infinito potencial e infinito actual. 3. Cardinalidade. I. López, Américo, orient. II. Título. 


\section{Dedicatória}

Dedico este trabalho a minha esposa, com amor, admiração e gratidão por sua compreensão, carinho, presença e incansável apoio ao longo do período de elaboração deste trabalho. 


\section{Agradecimentos}

Agradeço primeiramente a Deus por me dar a vida, saúde e capacidade.

Gostaria de agradecer também:

Ao Prof. Dr. Américo López Gálvez, pela atenção e apoio durante o processo de definição e orientação que muito me ensinou, contribuindo para meu amadurecimento científico e intelectual.

Ao PROFMAT, pela oportunidade de ampliar meus conhecimentos e, de certa forma, contribuir para o crescimento científico do meu país.

À Faculdade de Filosofia, Ciências e Letras de Ribeirão Preto e o Instituto de Ciências Matemáticas e de Computação de São Carlos, pela oportunidade de realização do curso de mestrado.

À CAPES, pela concessão da bolsa de mestrado e pelo apoio financeiro para a realização desta pesquisa.

Por fim, agradeço imensamente minha família por todo o apoio prestado, pela paciência enorme e pelas palavras de incentivo nos momentos difíceis. 


\section{Resumo}

BORGES, B. A. O infinito na matemática. 2014. 79f. Dissertação (Mestrado) Faculdade de Filosofia, Ciências e Letras de Ribeirão Preto, Universidade de São Paulo, Ribeirão Preto, 2014.

Nesta dissertação, abordaremos os dois tipos de infinitos existentes: o infinito potencial e o infinito actual. Apresentaremos algumas situações, exemplos que caracterizam cada um desses dois tipos. Focaremo-nos no infinito actual, com o qual discutiremos alguns dos desafios encontrados na teoria criada por Cantor sobre este assunto. Mostraremos também sua importância e a diferença entre este e o infinito potencial. Com isso, buscamos fazer com que o professor compreenda adequadamente os fundamentos matemáticos necessários para que trabalhe, ensine e motive apropriadamente seus alunos no momento em que o infinito e conjuntos infinitos são discutidos em aula. Desta forma, buscamos esclarecer os termos usados e equívocos comuns cometidos por alunos e também professores, muitas vezes enganados ou confundidos pelo senso comum.

Palavras-chave: Infinito; infinito potencial; infinito actual; conjuntos enumeráveis; cardinalidade. 


\section{Abstract}

BORGES, B. A. Infinity in mathematics. 2014. 79f. Dissertação (Mestrado) Faculdade de Filosofia, Ciências e Letras de Ribeirão Preto, Universidade de São Paulo, Ribeirão Preto, 2014.

In this dissertation, we will discuss the two types of infinities: the potential infinity and the actual infinity. We will present some situations, examples that characterize each of these two types. We will focus on the actual infinity, with which we will discuss some of the challenges found in the theory created by Cantor on this subject. We will also show its importance and the difference between this and the potential infinity. Thus, we seek to make teachers properly understand the mathematical foundations necessary for them to work, teach and properly motivate their students at the time the infinity and infinite sets are discussed in class. In this way, we seek to clarify the terms used and common mistakes made by students and also teachers, so often misguided or confused by common sense.

Keywords: Infinity; potential infinity; actual infinity; countable sets; cardinality. 


\section{Sumário}

\section{Lista de Figuras}

1 Introdução $\quad$ p. 12

2 Motivação $\quad$ p. 13

2.1 Aquiles e a tartaruga . . . . . . . . . . . . . . . . . p. 13

2.2 Hotel de Hilbert - "Estamos sempre lotados, mas sempre temos um quarto para você". . . . . . . . . . . . . . . . . . . . p. 14

2.3 Somas infinitas . . . . . . . . . . . . . . . . . p. 15

3 O infinito pelos estudantes: Um questionário $\quad$ p. 22

4 O Infinito potêncial e o infinito Actual p. 26

5 Conceitos nescessários para estudar o infinito actual p. 31

5.1 Um pouco de história . . . . . . . . . . . . . . . p. 31

5.2 Algumas noções básicas . . . . . . . . . . . . . . . . . . . . . . . . p. 32

5.3 Conjuntos Finitos, Infinitos Enumeráveis e Não Enumeráveis . . . . . p.38

5.4 Cardinalidade . . . . . . . . . . . . . . . . p p 44

5.5 O cubo e o intervalo de reta tem o "mesmo número de elementos". . . . p. p1

5.6 Observações Gerais . . . . . . . . . . . . . . . . . . . p. 62

6 O símbolo $\infty \quad$ p. 64

$\begin{array}{llr}7 & \text { Uma proposta didática } & \text { p. } 66\end{array}$ 
7.1 Número de elementos . . . . . . . . . . . . . . . . . p. 67

7.2 O infinito como um "número" grande? . . . . . . . . . . . . . . p 69

7.3 "Contando" o infinito . . . . . . . . . . . . . . . . . . p. 71

7.4 Diferença entre o infinito potencial e actual . . . . . . . . p. p 75

8 Conclusão $\quad$ p. 78

$\begin{array}{lr}\text { Referências } & \text { p. } 79\end{array}$

$\begin{array}{lr}\text { Apêndice A } & \text { p. } 80\end{array}$

$\begin{array}{lr}\text { Apêndice B } & \text { p. } 83\end{array}$

$\begin{array}{lr}\text { Apêndice } \mathbf{C} & \text { p. } 87\end{array}$ 


\section{Lista de Figuras}

1 Soma infinita das distâncias percorridas. . . . . . . . . . . . . . p. 14

2 Quadrado de área 2 dividido ao meio. . . . . . . . . . . . . p. 15

3 Metade do quadrado dividido ao meio. . . . . . . . . . . . p. 16

4 Metade da metade do quadrado dividido ao meio. . . . . . . . . . p. p. 16

5 Metade da metade ... do quadrado dividido ao meio. . . . . . . . . p. 16

6 Soma infinita da série harmônica. . . . . . . . . . . . . p p. 17

7 Aproximação da área da circunferência por polígonos. . . . . . . . . . . p. 27

$8 \quad$ Gráfico da função $f: \mathbb{R}-\{0\} \rightarrow \mathbb{R}$ dada por $f(x)=\frac{1}{x} \ldots \ldots$. . . . . 28

9 Retas paralelas no plano cartesiano. . . . . . . . . . . . . . . p. 29

10 Retas paralelas em perspectiva. . . . . . . . . . . . . . . . p. 29

11 Quadrado de lado $1 \mathrm{~cm} \ldots \ldots \ldots \ldots$. . . . . . . . . . . . . . . . . . . . .

12 Produto cartesiano $A \times B \ldots \ldots \ldots \ldots \ldots$ p. 33

13 Gráfico da função $f: \mathbb{R}-\{1\} \rightarrow \mathbb{R}-\{2\}$ dada por $f(x)=\frac{2 x+1}{x-1}$. . . . $\quad$ p. 36

14 Gráfico da função $f: \mathbb{R} \rightarrow \mathbb{R}$ dada por $f(x)=x^{2} \ldots \ldots$ p. 36

15 Gráfico da função $f(x)=2 x \ldots \ldots \ldots \ldots$ p. . . . . . . . . . . . . . . . . .

16 Enumeração dos números inteiros. . . . . . . . . . . . . . . . p. 42

17 Enumeração dos números inteiros sem o zero. . . . . . . . . . . . . p. 43

18 Segmentos $\overline{A B}$ e $\overline{C D} \ldots \ldots \ldots \ldots \ldots$ p. 46

19 Função $f: \overline{A B} \rightarrow \overline{C D} \ldots \ldots \ldots$. . . . . . . . . . . . . . 46

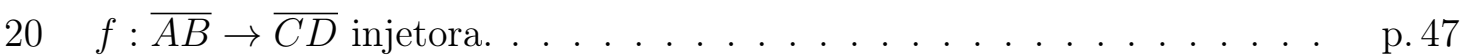

21 Gráfico da função $f:\left(-\frac{\pi}{2}, \frac{\pi}{2}\right) \rightarrow \mathbb{R}$ dada por $f(x)=t g(x) \ldots \ldots$ p. 49

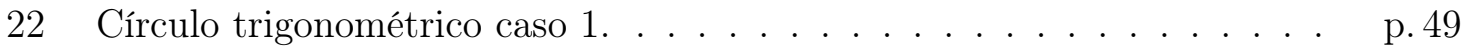


23 Círculo trigonométrico caso $2 \ldots \ldots \ldots \ldots \ldots$ p. . . . . . . . . . . .

24 Triângulos retângulos. . . . . . . . . . . . . . p. p . 50

25 Segmento, quadrado e cubo unitários. . . . . . . . . . . p. 51

26 Símbolo romano para representar números grandiosos. . . . . . . . . . p. 64

27 Ômega, última letra do alfabeto grego. . . . . . . . . . . p. 65 


\section{Introdução}

Neste trabalho discutimos várias situações dentro da matemática envolvendo o infinito. São situações que, a princípio, são estranhas e que vão contra nosso senso comum, mas são explicadas matematicamente mostrando que possuem uma solução. Em seguida, falamos um pouco sobre o infinito de diversas maneiras, trazemos exemplos da diferença entre o infinito potencial e o infinito actual e algumas reflexões (indagações) sobre o tema.

Dedicamos uma parte do nosso trabalho a um questionário para alunos do $8^{\circ}$ e $9^{\circ}$ ano do Ensino Fundamental e alunos do $1^{\circ}$ e $3^{\circ}$ ano do Ensino Médio com o objetivo de buscar entender como esses alunos lidam com questões que envolvem o infinito. Foram aplicadas quatro questões, previamente selecionadas e iguais para todas as turmas.

Traremos brevemente um pouco do contexto histórico do surgimento da teoria dos conjuntos para entendermos melhor o surgimento da necessidade de "vários" infinitos, e nos situarmos no tempo cronológico dos acontecimentos. Veremos que é uma teoria relativamente recente para a história da matemática e que ainda há muito para se estudar.

Com a intenção de entender o infinito actual desenvolveremos a parte teórica e conceitos necessários sobre conjuntos, funções, conjuntos finitos, conjuntos infinitos enumeráveis, conjuntos infinitos não enumeráveis e cardinalidade. Faremos alguns exemplos de conjuntos infinitos de "tamanhos" iguais, diferentes, e situações que vão contra nosso senso comum; mais precisamente: provaremos que é possível ter conjuntos de dimensões diferentes mas com o mesmo "tamanho". Traremos também algumas curiosidades do possível surgimento do símbolo $\infty$.

Por fim, para encerrarmos essa dissertação, concluímos com uma proposta didática com exemplos de situações para que professores possam usar e motivar seus alunos falando do infinito de uma forma mais acessível e simples, porém coerente com a teoria formal, expandindo a curiosidade e o conhecimento sobre o infinito que ainda é pouco estudado e muitas vezes usado de forma equivocada. 


\section{Motivação}

Para motivar nosso trabalho, já ilustrando e despertando a curiosidade pelo infinito, vamos falar de algumas situações em que o infinito tem um papel relevante. Veremos como ao considerar o infinito, certas situações parecem contradizer nosso censo comum.

\subsection{Aquiles e a tartaruga}

Nesse paradoxo, Zenão, filósofo grego, propôs um problema intrigante que desafia o movimento contínuo e toda nossa intuição. Em resumo, o problema diz que em uma corrida entre duas pessoas, de velocidades diferentes, em que a mais lenta começa a uma distância de vantagem para a mais rápida, a mais rápida nunca alcançará a mais lenta.

Eis o problema: Uma corrida entre Aquiles, um herói grego, e uma tartaruga, em que a tartaruga começa com 100 metros de vantagem e sempre com a metade da velocidade de Aquiles. Assim, quando Aquiles atingir os 100 metros, a tartaruga terá andado 50 metros. Quando Aquiles andar mais 50 metros, a tartaruga terá andado mais 25 metros. Continuando com esse raciocínio infinitamente, Aquiles nunca alcançará a tartaruga. Ou seja, por mais que Aquiles corra, em um mesmo período de tempo, por menor que seja, sempre haverá um espaço entre Aquiles e a tartaruga. Então, para Aquiles alcançar a tartaruga, ele terá que percorrer a distância entre ele e a tartaruga, e para isso, levará um certo tempo. Nesse tempo, a tartaruga percorrerá uma nova distância, mesmo que muito pequena, essa distância impedirá que Aquiles alcance a tartaruga, assim, Zenão conclui que Aquiles não alcançará a tartaruga, mesmo sendo mais rápido que ela.

É claro que essa conclusão vai contra o senso comum. Então, o que há de errado com o pensamento de Zenão? Se pensarmos o problema como se Aquiles fosse percorrer uma distância de $A$ a $B$, e que ele sempre percorrerá a metade da distância que falta para chegar ao ponto $B$, podemos escrever o espaço percorrido por ele a cada período de tempo pela série $\sum_{n=1}^{\infty} 100\left(\frac{1}{2}\right)^{n-1}$, onde $n \in \mathbb{N}$ é o período de tempo, ou seja, uma progressão 
geométrica infinita de razão $\frac{1}{2}$ cuja soma converge e é dado por $\frac{100}{1-\frac{1}{2}}=200$.

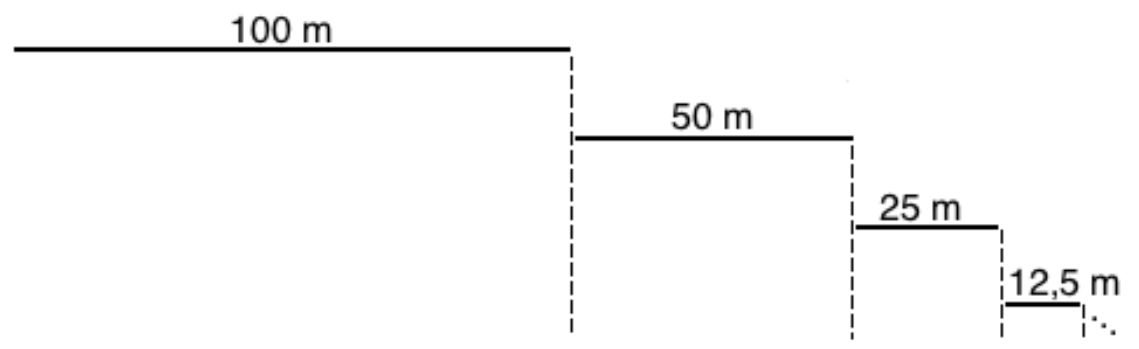

Figura 1: Soma infinita das distâncias percorridas.

Assim, a soma infinita das distâncias percorridas por Aquiles converge para 200 metros, que é a distância final percorrida por ele. Se Aquiles disputar com a tartaruga uma corrida de mais de 200 metros tendo o dobro da velocidade da tartaruga, ele irá ultrapassála quando completarem 200 metros de corrida, confirmando assim o senso comum de que o mais rápido irá ultrapassar o mais lento, desde que haja distância suficiente para isso.

Uma outra situação curiosa é conhecida como o paradoxo do Hotel de Hilbert.

\subsection{Hotel de Hilbert - "Estamos sempre lotados, mas sempre temos um quarto para você".}

Considere um hotel com infinitos quartos e numerados pelos números naturais. Certa noite, o hotel está com todos os quartos ocupados com um hóspede. Normalmente, seria impossível o hotel hospedar mais um hóspede. Porém, chega um novo hóspede e o recepcionista o recebe e lhe informa que é capaz de lhe arrumar um quarto. Ele pede que o hóspede do quarto um vá para o quarto dois, o hóspede do quarto dois vá para o quarto três, e assim por diante, ou seja, o hóspede do quarto $n$ vai para o quarto $n+1$, já que os quartos estão numerados pelos números naturais e todo número natural tem um sucessor. Assim, o recepcionista acomoda o novo hóspede no quarto um. Mais tarde, chega um ônibus com infinitos hóspedes para se acomodarem no hotel. O recepcionista sem nenhuma dúvida os recebe e lhes informa que é capaz de achar quartos para todos. Ele pede para que cada hóspede do quarto $n$ vá para o quarto $2 n+1$. Desse modo apenas os quartos de números ímpares estarão ocupados, deixando os quartos de número par desocupados para os novos hóspedes. Então o recepcionista pede para que os novos hóspedes formem uma única fila e para que o hóspede da posição $i$ vá para o quarto $2 i$, onde $i \in \mathbb{N}$. Logo em seguida, chegam infinitos ônibus, um depois do outro, com infinitos hóspedes em cada 
ônibus para se hospedarem no hotel. Rapidamente o recepcionista os recebe e lhes comunica que é capaz de acomodar cada um em um quarto. Ele pede para o hóspede já acomodado no quarto de número $n$ ir para o quarto de número $2 n+1$, liberando assim todos os quartos de números pares. Deste modo, ele pede para que o novo hóspede $i$ do ônibus $j$ se acomode no quarto $2^{i+1}(2 j+1)$.

Como os quartos do hotel estão numerados pelo conjunto dos números naturais, e a quantidade de hóspedes que chegam para se hospedar no hotel também é enumerado pelo conjunto dos números naturais; então, o que o recepcionista faz nos dois primeiros casos é encontrar uma relação biunívoca entre o conjunto dos números naturais para acomodar os novos hóspedes. Na terceira situação, o recepcionista precisa encontrar uma relação biunívoca de $\mathbb{N} \times \mathbb{N}$ em $\mathbb{N}$ para acomodar todos os novos hóspedes, cada um em um quarto.

\subsection{Somas infinitas}

Veremos agora outros exemplos em que o infinito cumpre um papel relevante.

\section{Exemplo 2.3.1. Séria Geométrica.}

Vamos considerar a seguinte soma de infinitos termos

$$
1+\frac{1}{2}+\frac{1}{4}+\ldots+\frac{1}{2^{n}}+\ldots
$$

Se perguntarmos qual seria o valor dessa soma infinita, teríamos das mais diversas resposta, como: infinito, não existe, a soma não tem fim, etc. Porém, sabemos que não é verdade nenhuma dessas respostas. O resultado dessa soma é 2. Podemos verificar de duas maneiras, uma geométrica e outra algébrica. Fazendo pelo primeiro modo, vamos considerar um quadrado de área igual a 2. Dividindo-o ao meio, temos dois triângulos iguais de área 1 como na figura 2.

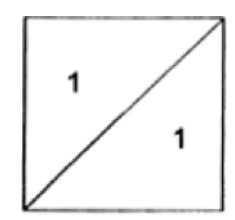

Figura 2: Quadrado de área 2 dividido ao meio.

Agora, dividindo um dos triângulos ao meio como na figura 3, obtendo dois triângulos de área $\frac{1}{2}$. 


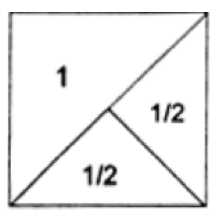

Figura 3: Metade do quadrado dividido ao meio.

Desse modo, fazendo o mesmo procedimento, dividindo ao meio, um dos triângulos de área $\frac{1}{2}$, obtemos outros dois triângulos de área $\frac{1}{4}$.

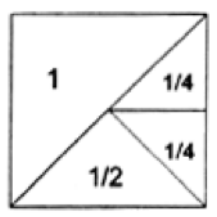

Figura 4: Metade da metade do quadrado dividido ao meio.

Assim, se continuarmos dividindo sempre um dos triângulos obtidos da divisão anterior ao meio, chegaremos como na figura 5.

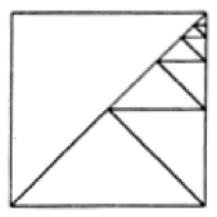

Figura 5: Metade da metade ... do quadrado dividido ao meio.

A soma das áreas dos triângulos da figura 5 é igual a área do quadrado de área 2 da figura 2. Por mais que continuemos a divisão dos triângulos restantes, eles sempre irão compor a área do quadrado. Portanto, a soma

$$
1+\frac{1}{2}+\frac{1}{4}+\ldots+\frac{1}{2^{n}}+\ldots=2
$$

Fazendo pelo modo algébrico, é fácil perceber que a soma

$$
S=1+\frac{1}{2}+\frac{1}{4}+\ldots+\frac{1}{2^{n}}+\ldots
$$

é a soma infinita de uma progressão geométrica de razão $\frac{1}{2}$. Sabemos que a soma da série geométrica infinita $a_{1}, a_{2}, a_{3}, \ldots$ de razão $q$, para $0<q<1$, é dada por

$$
S=a_{1}+a_{2}+a_{3}+\ldots=\frac{a_{1}}{1-q} .
$$


Da equação (2.1), temos que $a_{1}=1$ e $q=\frac{1}{2}$, então

$$
S=\frac{1}{1-\frac{1}{2}}=2 \text {. }
$$

Exemplo 2.3.2. Série Harmônica.

Considere agora a soma $1+\frac{1}{2}+\frac{1}{3}+\frac{1}{4}+\frac{1}{5}+\ldots$ de infinitos termos. Essa soma é conhecida como série harmônica; dada por $\sum_{n=1}^{\infty} \frac{1}{n}$.

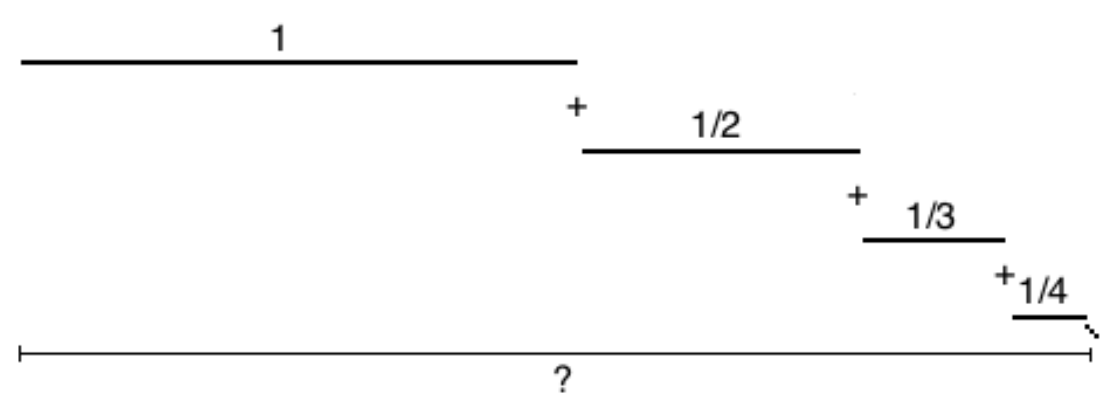

Figura 6: Soma infinita da série harmônica.

Podemos pensar, em um primeiro momento, que o resultado dessa soma não deve ser um número muito grande, pois estamos somando 1 com muitas outras frações menores que 1 e que estão cada vez mais perto do zero. Mas será que nossa intuição está certa e conseguiremos calcular o valor dessa soma? A resposta é não! Veremos:

Vamos tomar a soma infinita e agrupar alguns termos da seguinte forma

$$
\begin{gathered}
1+\frac{1}{2}+\frac{1}{3}+\frac{1}{4}+\frac{1}{5}+\frac{1}{6}+\frac{1}{7}+\frac{1}{8} \ldots \\
=1+\frac{1}{2}+\left(\frac{1}{3}+\frac{1}{4}\right)+\left(\frac{1}{5}+\frac{1}{6}+\frac{1}{7}+\frac{1}{8}\right)+\left(\frac{1}{9}+\frac{1}{10}+\ldots+\frac{1}{16}\right)+\ldots
\end{gathered}
$$

Observe que:

$$
\begin{aligned}
\left(\frac{1}{3}+\frac{1}{4}\right) & >\frac{1}{4}+\frac{1}{4}=\frac{1}{2} \\
\left(\frac{1}{5}+\frac{1}{6}+\frac{1}{7}+\frac{1}{8}\right) & >\frac{1}{8}+\frac{1}{8}+\frac{1}{8}+\frac{1}{8}=\frac{1}{2} \\
\left(\frac{1}{9}+\frac{1}{10}+\ldots+\frac{1}{16}\right) & >\frac{1}{16}+\frac{1}{16}+\ldots+\frac{1}{16}=\frac{1}{2}
\end{aligned}
$$

e assim por diante. 
Então, a série harmônica

$$
\sum_{n=1}^{\infty} \frac{1}{n}=1+\frac{1}{2}+\frac{1}{3}+\frac{1}{4}+\frac{1}{5}+\ldots>1+\frac{1}{2}+\frac{1}{2}+\frac{1}{2}+\ldots .
$$

Como a série infinita $1+\frac{1}{2}+\frac{1}{2}+\frac{1}{2}+\ldots$ diverge, então temos que a série infinita $1+\frac{1}{2}+\frac{1}{3}+\frac{1}{4}+\frac{1}{5}+\ldots$ também diverge. Para mais detalhes sobre a divergência da série, veja o apêncide $\mathrm{A}$.

Com a ajuda de um computador podemos verificar que a soma dessa série para $n=$ 31557600 ultrapassa 17, e não para de crescer a medida que aumentamos $n$, mesmo que muito lentamente. Para maiores detalhes, recomendamos a leitura de Ávila (1996).

Neste exemplo podemos pensar que a soma da série harmônica é infinito? É o infinito um número?

Os próximos dois exemplos mostrarão porque infinito não pode ser considerado um número, ou mais precisamente, não segue a álgebra usual dos números inteiros.

Exemplo 2.3.3. Suponhamos que infinito seja um número, denotado por $S$, e trabalharemos algébricamente com ele. Claramente podemos escrever

$$
S=1+2+2^{2}+2^{3}+2^{4}+\ldots
$$

Colocando 2 em evidência a partir do segundo termo temos

$$
S=1+2\left(1+2+2^{2}+2^{3}+\ldots\right)=1+2 S,
$$

então, $S=-1$. Absurdo, pois $S>0$, logo, este exemplo nos mostra que o infinito não pode ser considerado como um número.

Exemplo 2.3.4. Considere o conjunto dos números inteiros positivos ímpares $A=\{1,3,5, \ldots\}$ e o conjunto dos números inteiros positivos pares $B=\{2,4,6, \ldots\}$. Vamos supor que o infinito seja um número denotado por $I$. Sabemos que ambos os conjuntos $A$ e $B$ possuem infinitos elementos, ou seja, $I$ elementos. Também sabemos que o conjunto dos números naturais $\mathbb{N}$ é a união disjunta dos conjuntos $A$ e $B$ e que possui infinitos elementos. Desse modo, os infinitos elementos de $A$ mais os infinitos elementos de $B$ daria os infinitos elementos de $\mathbb{N}$, ou seja, $2 I=I$, o que implicaría que $I=0$.

Exemplo 2.3.5. Vejamos agora uma soma finita $\sum_{k=0}^{n}(-1)^{k}=1+(-1)+1+(-1)+\ldots+$ (-1). Como são finitos termos, em algum momento sua soma terá fim e seu resultado será 
um número que dependerá do número de termos $n$. Se $n$ for um número par o resultado será 0 , se $n$ for um número ímpar o resultado será 1 . Mas e a soma infinita $\sum_{k=0}^{\infty}(-1)^{k}=$ $1+(-1)+1+(-1)+\ldots$ ? Como são infinitos termos, não sabemos quando a soma "termina". Note-se que se fizermos dois arranjos dessa soma: $(1-1)+(1-1)+(1-1)+\ldots$ de modo que o resultado daria 0 , e $1-(1-1)-(1-1)-(1-1)-\ldots$ de modo que o resultado daria 1 , portanto, não dá para afirmar o valor da soma infinita $1+(-1)+1+(-1)+\ldots$. Em outras palavras, as séries divergem.

Um outro exemplo curioso onde o infitino nos deixa intrigados, é o fato de mudarmos apenas a ordem dos números de uma soma infinita e o resultado ser alterado. Como assim? Vamos considerar a soma infinita convergente. A convergência desta soma infinita pode ser vista em Guidorizzi (2002, p.29).

$$
S=1-\frac{1}{2}+\frac{1}{3}-\frac{1}{4}+\frac{1}{5}-\frac{1}{6}+\frac{1}{7}-\ldots=\ln 2
$$

Multiplicando-a por $\frac{1}{2}$, temos

$$
\frac{1}{2} S=\frac{1}{2}-\frac{1}{4}+\frac{1}{6}-\frac{1}{8}+\frac{1}{10}-\frac{1}{12}+\frac{1}{14}-\ldots=\frac{1}{2} \ln 2
$$

Somando zeros, temos

$$
\frac{1}{2} S=0+\frac{1}{2}+0-\frac{1}{4}+0+\frac{1}{6}+0-\frac{1}{8}+0+\frac{1}{10}+0-\frac{1}{12}+0+\frac{1}{14}-\ldots=\frac{1}{2} \ln 2
$$

Somando (2.3) com (2.5) membro a membro, temos

$$
\frac{3}{2} S=1+0+\frac{1}{3}-\frac{1}{2}+\frac{1}{5}+0+\frac{1}{7}-\frac{1}{4}+\ldots=\frac{3}{2} \ln 2
$$

Reescrevendo (2.6) retirando os zeros, temos

$$
\frac{3}{2} S=1+\frac{1}{3}-\frac{1}{2}+\frac{1}{5}+\frac{1}{7}-\frac{1}{4}+\ldots=\frac{3}{2} \ln 2
$$

que é a mesma soma infinita de (2.3) com apenas os termos reagrupados de forma diferente, porém o resultado de (2.7) é aproximadamente 1,035 e o resultado de (2.3) é aproximadamente 0,69 .

Com todos esses exemplos, podemos perceber diferentes modos como o infinito aparece. Por exemplo, na história de Aquiles e a tartaruga vimos que podemos sempre tomar uma distância cada vez menor da anterior, quantas forem necessárias, ou seja, infinitas vezes. Ainda na mesma situação, essas quantidades tomadas eram infinitamente pequenas (cada vez menores), onde sempre havia uma distância menor a ser tomada. Já no 
Hotel de Hilbert, além do infinito aparecer como na história de Aquiles e a tartaruga, onde sempre era possível acomodar mais hóspedes, o infinito aparece como um todo, uma quantidade infinita de quartos e pessoas.

Nosso principal objeto de estudo serão os conjuntos infinitos. Como no exemplo do Hotel de Hilbert, podemos dizer que tínhamos um conjunto infinito formado pelos quartos do hotel e outro conjunto infinito formado pelos hóspedes que iam chegando para hospedar-se no hotel. Queremos comparar o "tamanho" entre conjuntos infinitos. Mas como isso é possível? Não podemos contar a quantidade de elementos desses conjuntos um a um. Para compararmos dois conjuntos, iremos utilizar de associação entre dois conjuntos no sentido de conseguirmos associar cada elemento de um conjunto a um único elemento de outro conjunto e vice-e-versa. Se soubermos a quantidade de elementos de um certo conjunto e pudermos associá-los com os elemento de um outro conjunto, então saberemos que esses conjuntos possuem a mesma quantidade de elementos. Veja os exemplos a seguir.

Exemplo 2.3.6. Quando vamos a um jogo de futebol, se quisermos saber quantos torcedores há no estádio, não iremos contar cada torcedor presente, não é? Iremos chegar a resposta por associação. Sabendo o número total de lugares no estádio e percebendo que o estádio está todo lotado, ou seja, não há nenhum lugar vazio, podemos associar cada lugar no estádio a um único torcedor presente. Então, se o estádio tiver um lugar, terá um torcedor, se tiver dois lugares terá dois torcedores, se tiver três lugares terá três torcedores, e assim por diante. Não importa a quantidade de lugares no estádio, sempre conseguiremos encontrar o número de torcedores presentes. Podemos concluir que o número de torcedores presentes é igual ao número de lugares desse estádio. Associamos cada lugar do estádio a cada torcedor presente.

Um outro exemplo que podemos usar é o seguinte:

Exemplo 2.3.7. Durante o Carnaval, imagine uma rua inteiramente tomada por foliões; se cada pessoa ocupa meio metro quadrado, podemos estabelecer a quantidade de pessoas presentes associando cada meio metro quadrado dessa rua a uma pessoa. Então, dependendo da quantidade de metros quadrados de tal rua teremos a quantidade de pessoas presentes pulando carnaval.

Voltando na situação do Hotel de Hilbert, o recepcionista do hotel conseguiu associar cada quarto do hotel a um hóspede diferente, ou seja, ele conseguiu estabelecer uma relação entre cada elemento de cada conjunto, de modo que cada hóspede tinha seu 
próprio quarto. Com isso podemos comparar a quantidade de elementos entre conjuntos infinitos, pois se conseguirmos estabelecer uma relação, ou seja, associar cada elemento de um conjunto a um único elemento de outro conjunto, podemos dizer que esses conjuntos possuem o mesmo "tamanho" ou a mesma quantidade de elementos.

Para entendermos melhor os diferentes tipos de infinito, falaremos um pouco mais no capítulo 4 sobre o infinito potêncial e o infinito actual. 


\section{$3 \quad O$ infinito pelos estudantes: Um questionário}

Neste capítulo traremos os resultados e algumas reflexições de um questionário aplicado a alunos do $8^{\circ}$ e $9^{\circ}$ ano do Ensino Fundamental e alunos do $1^{\circ}$ e $3^{\circ}$ ano do Ensino Médio.

Foram elaboradas quatro questões que envolvessem a ideia do infinito potencial e do infinito actual, para sabermos como os alunos, em diferentes níveis escolares, lidam com essas diferenças. Não foi dado nenhuma explicação anterior ao questionário sobre o assunto.

As perguntas foram as seguintes:

1. Quantos números existem entre 0,18 e 0,6 ?

2. Qual é o maior número entre 0 e 1 , desconsiderando o 1 ?

3. Existe algum número entre 2,9 e 3? Se sim, qual é?

4. Descreva com suas palavras o que você acha que é o infinito.

Queríamos com a primeira questão ver se o aluno perceberia a possibilidade de sempre acrescentar uma casa decimal a mais entre os números 0,18 e 0,6, ou seja, um processo de iteração sem fim.

Na segunda questão, o processo de iteração usado anteriormente daria a possibilidade do aluno perceber que sempre é possível encontrar um número maior que o candidato ao maior número entre 0 e 1 excluíndo-se o 1.

Para aqueles que não perceberam a infinidade dos números decimais, colocamos a terceira questão para fazê-los pensar a respeito e refletirem melhor sobre o assunto e suas respostas anteriores. 
Por fim, queríamos saber o que os alunos pensam sobre o infinito, se eles tem alguma ideia matemática formada sobre o assunto, ou apenas o senso comum.

Nas tabelas a seguir estão as respostas dadas pelos alunos a essas questões.

\begin{tabular}{|c|c|c|c|}
\hline Questão & Ano escolar & Respostas & Número de alunos \\
\hline & \multirow{3}{*}{ 8 Ano } & Infinitos & 16 \\
\hline & & 42 & 3 \\
\hline & & Muitos & 1 \\
\hline & \multirow{8}{*}{ 9읏 Ano } & Infinitos & 2 \\
\hline & & 17 e 5 & 2 \\
\hline & & Nenhum & 1 \\
\hline & & 0,6 & 1 \\
\hline & & 13 & 1 \\
\hline & & $0,18-0,6=0,12$ & 1 \\
\hline & & 5 & 1 \\
\hline & & 0,42 & 1 \\
\hline & \multirow{3}{*}{ 1ㅇ.M. } & Infinitos & 19 \\
\hline & & 2 & 1 \\
\hline & & 5 & 1 \\
\hline & \multirow{6}{*}{ 3ㅇ. E.M. } & Infinitos & 11 \\
\hline & & 42 & 2 \\
\hline & & 42 com duas casas decimais & 1 \\
\hline & & 13 & 1 \\
\hline & & 0 & 1 \\
\hline & & Muitos & 1 \\
\hline & \multirow{9}{*}{ 8ㅇ Ano } & Infinito & 5 \\
\hline & & $0,999 \ldots$ & 2 \\
\hline & & Não tem & 2 \\
\hline & & 0,9 & 1 \\
\hline & & 1 & 1 \\
\hline & & 0,99 & 1 \\
\hline & & Não tem, pois é infinito & 1 \\
\hline & & 0,999 & 1 \\
\hline & & 46 ou 47 & 1 \\
\hline & \multirow{4}{*}{ 9o Ano } & 0,9 & 4 \\
\hline & & 0,99 & 3 \\
\hline & & Infinitos & 2 \\
\hline & & 0 & 1 \\
\hline & \multirow{3}{*}{ 1으. E.M. } & $0,999 \ldots$ & 15 \\
\hline & & 0,9 & 1 \\
\hline & & 1,01 & 1 \\
\hline & \multirow{4}{*}{ 3으.M. } & $0,999 \ldots$ & 13 \\
\hline & & 0,99 & 2 \\
\hline & & 0 & 1 \\
\hline & & 0,001 & 1 \\
\hline & \multirow{6}{*}{ 8 Ano } & Infinitos & 12 \\
\hline & & 2,99 & 3 \\
\hline & & Não, é infinito & 1 \\
\hline & & $2,999 \ldots$ & 1 \\
\hline & & Não & 1 \\
\hline & & 92 e 93 & 1 \\
\hline
\end{tabular}




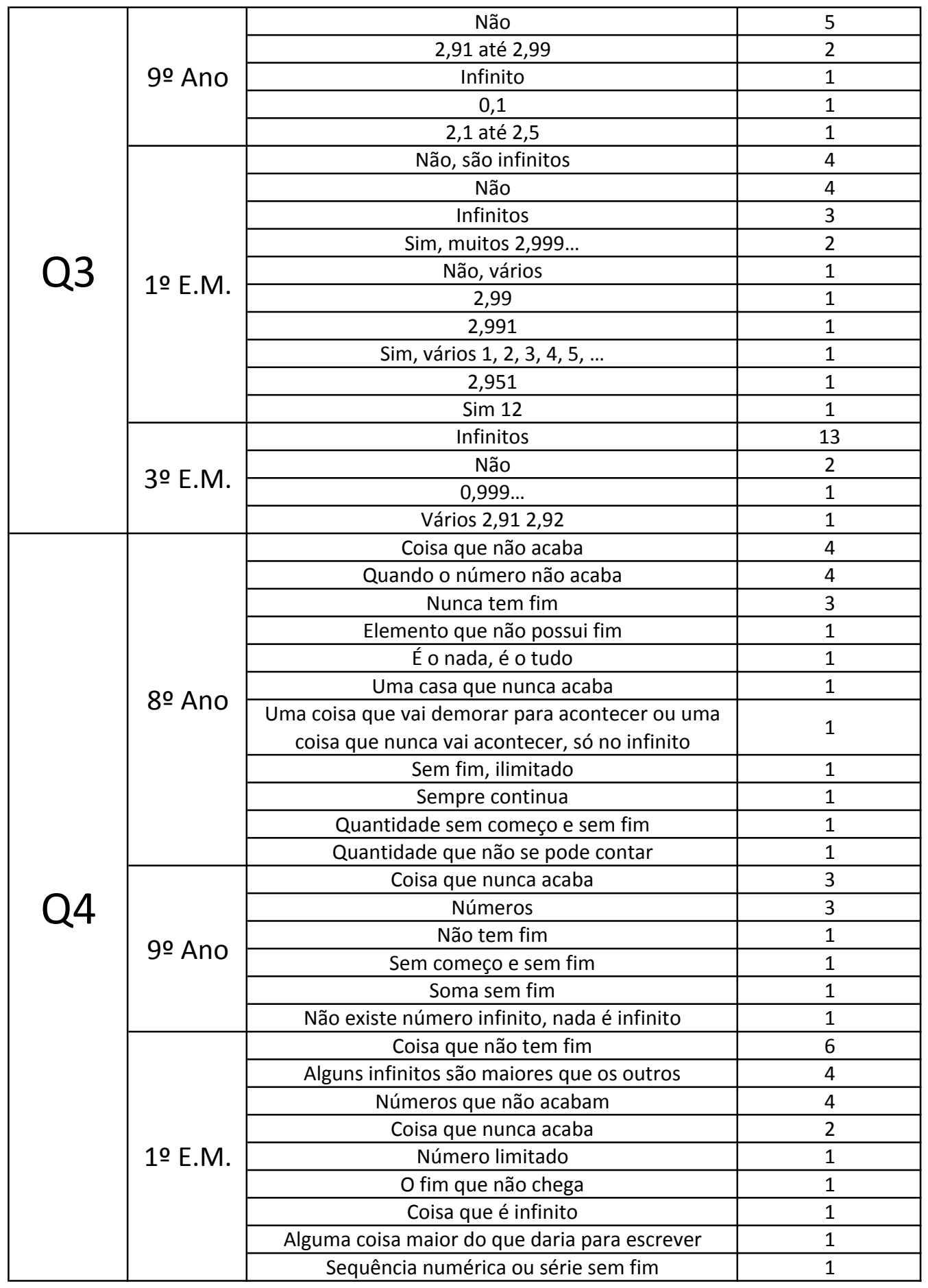

\begin{tabular}{|c|c|c|c|}
\hline & \multirow{9}{*}{ 3으. M. } & Não existe fim & 11 \\
\hline & & Nada, tudo & 1 \\
\hline & & Vácuo & 1 \\
\hline & & Universo & 1 \\
\hline & & Número que nunca acaba & 1 \\
\hline & & Tempo & 1 \\
\hline & & Não tem fim, mas existe começo & 1 \\
\hline & & Grandioso & 1 \\
\hline & & Como nossos pensamentos & 1 \\
\hline
\end{tabular}


Podemos observar que aproximadamente $73,5 \%$ dos alunos responderam corretamente a primeira questão. Dentre esses, chama atenção dois alunos que responderam muitos. Levamos em consideração de que infinitos números são muitos números. Nota-se que muitos alunos tentaram contar um por um a quantidade de números, fazendo por exemplo, $0,18-0,6=0,12$, o que mostra uma defasagem de conhecimentos prévios de números racionais.

Na segunda questão, tivemos aproximadamente 5\% das respostas respondidas corretamente. Percebemos a dificuldade dos alunos em dar uma resposta não esperada. Geralmente quando nos é perguntado: "qual é o maior número...?", queremos dar um número como resposta, e não necessariamente sempre há um maior número, dependerá do contexto. Mesmo assim dois alunos responderam que não tinha e um respondeu: "não tem, pois é infinito", entendemos que existem infinitos números entre 0 e 1 sendo impossível achar um maior que todos. A maioria respondeu que o maior número é 0,999...

Alguns afirmaram ser infinito o maior número, mostrando o erro mais comum: se têm uma ideia clara do significado do termo infinito embora usado como um número. Podemos ver nesses resultados a ideia equivocada do infinito.

É interessante que na terceira questão, a maior parte dos alunos, mesmo aqueles que erraram as questões anteriores, aqui eles conseguem perceber que, dados dois números diferentes, podemos acrescentar uma casa decimal ao menor e encontrar sempre um novo número entre eles. Há também um pouco de confusão por parte de alguns alunos que responderam: "Não tem, pois é infinito".

Na última questão, como diz o ditado, "dá muito pano pra manga". É uma questão um pouco ampla, dando margem a diferentes interpretações. Não foi cobrado aos alunos que falassem sobre o infinito na matemática, por isso surgiram algumas respostas um tanto quanto filosóficas. Porém, vale destacar algumas respostas. Uma delas é a ideia errônea de que o infinito é um número, o que é muito comum entre os alunos. No entanto, também tivemos boas respostas como: "Sempre continua" e "Quantidade que não se pode contar". Essas duas respostas nos remete a dois diferentes tipos de infinito, o potêncial e actual, respectivamente, que exploraremos mais a fundo no próximo capítulo. 


\section{O Infinito potêncial e o infinito Actual}

Basta olhar para qualquer assunto da matemática para perceber que o infinito está presente de algum modo. De uma forma ou de outra, sempre estamos tratando de um ente matemático o qual pertence a algum conjunto. Dessa forma, podemos estudar as propriedades e singularidades desses conjuntos e seus elementos.

Sabemos que a matemática é exata, lógica, possui regras e para um resultado ser verdade precisa ser demonstrado; para isso, temos que mostrá-lo de maneira geral. Mas nem sempre é possível verificar, um por um, determinado resultado, pois podem existir infinitas possibilidades. É aí que muitas vezes entra o infinito de diferentes maneiras. Desse modo, é inevitável falarmos do infinito. Queremos estudar como lidar com o infinito e seu comportamento, o modo como aparece em diferentes situações.

Com isso, surge-nos algumas questões: Mas o que é o infinito? Será o infinito sempre o mesmo? É o infinito ou os infinitos? Há a possibilidade de diferentes infinitos? Uns maiores ou menores que os outros? Isso é o que veremos no desenvolver do nosso trabalho, como tratá-lo de forma correta e coerente.

O infinito aparece de diversas maneiras. No capítulo anterior, vimos o infinito aparecer em pedaços cada vez menores relacionado com distância, com quantidade em que sempre podemos adicionar mais um, diferentes tamanhos e entre outras situações.

Podemos falar que infinito é algo muito grande? Veremos que não é tão simples assim. Um número ou até o universo pode ser muito grande para uma pessoa e não tão grande assim para outra. Por exemplo: o número $10^{10}$ pode ser considerado um número muito grande para muitos. Mas, e se pensarmos no número $10^{1000000}$ ? Com certeza esse segundo é bem maior que o primeiro; porém, também não é grande o suficiente para afirmar que não há outro muito maior que ele. O universo também, muitas vezes, é pensado como algo muito grande e infinito, mas temos que ter muito cuidado ao afirmarmos tais coisas. Portanto, não podemos pensar simplesmente que o infinito é algo muito grande. 
Podemos pensar da mesma forma para algo muito pequeno. O número $10^{-100}$ é um número muito pequeno se comparado ao número 1 , mas o número $10^{-10000000}$ é menor ainda se comparado à $10^{-100}$, e este, por sua vez, pode se tornar razoavelmente grande em relação à $10^{-10000000}$. Então, para falar que algo é muito grande ou muito pequeno é preciso um referencial.

O infinito aparece na dízima periódica, 0,33333..., onde as reticências indicam que o algarismo 3 se repete infinitamente, ou seja, há uma infinidade de números. Também aparece como: aproximação de um número, limite, sequências infinitas, na geometria como aproximação de polígonos para o cálculo de áreas, para indicar que algo não tem fim, entre outras coisas.

Será que com tantos lugares diferentes onde o infinito aparece, ele é sempre o mesmo? No cálculo da área de uma circunferência, podemos aproximar seu valor usando a área de um polígono de infinitos lados infinitamente pequenos.

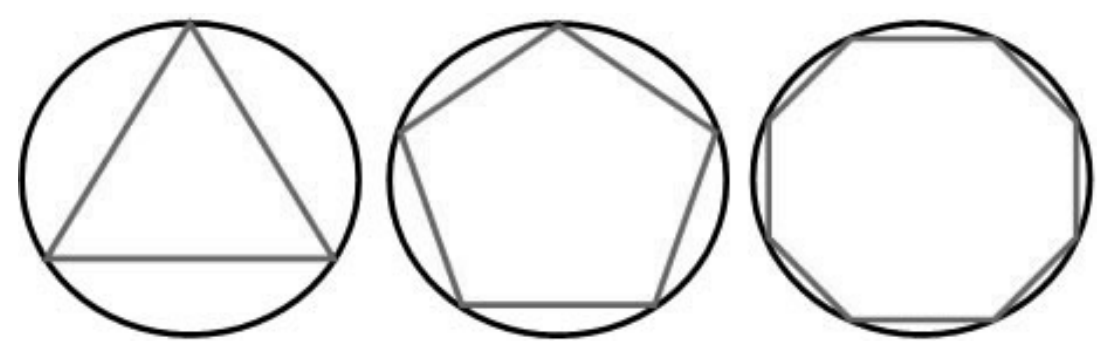

Figura 7: Aproximação da área da circunferência por polígonos.

Neste caso, podemos ver o infinito como uma aproximação (um limite), onde o valor da área do polígono se aproxima da área da circunferência, como quantidade, no caso do número de lados do polígono e como tamanho, no caso da medida dos lados do polígono. Ainda nesse exemplo, podemos pensar que a quantidade de lados do polígono é muito grande, e a medida dos lados desse polígono é muito pequena. Precisamos, então, de dois infinitos? Lembremos também que é comum utilizar dois infinitos na reta real, $(-\infty,+\infty)$.

Esses diferentes tipos de infinito caracteriza o infinito potencial, que é a possibilidade de sempre acrescentar uma unidade a mais. Como na sucessão dos números naturais, em que sempre é possível acrescentar mais um. No sentido de sempre poder ir além, de continuar sem ter um "fim".

Para ilustrar melhor o infinito potencial vejamos alguns exemplos:

Exemplo 4.0.8. Considere as seguintes frações:

$$
\frac{20}{20}=1 ; \frac{20}{10}=2 ; \frac{20}{5}=4 ; \frac{20}{4}=5 ; \frac{20}{2}=10 ; \frac{20}{1}=20 ;
$$




$$
\frac{20}{0,1}=200 ; \frac{20}{0,01}=2000 ; \frac{20}{0,001}=20000 ; \frac{20}{0,0001}=200000 ; \ldots
$$

Observe que na medida em que diminuímos o denominador, o resultado da fração aumenta cada vez mais. Podemos continuar o processo sem ter um fim, ou seja, o resultado da fração pode continuar a crescer indefinidamente. O resultado da fração tende ao infinito cada vez que diminuimos mais o seu denominador. Podemos dizer que o infinito potencial é um candidato para o resultado dessa fração. Da mesma forma para o denominador que tende a zero cada vez mais, mas nunca chega a zero. Esse processo de que o denominador continua a diminuir cada vez mais indefinidamente é uma característica do infinito potencial.

Nesse outro exemplo, veremos como aparece o infinito potencial graficamente.

Exemplo 4.0.9. Considere o gráfico da função $f: \mathbb{R}-\{0\} \rightarrow \mathbb{R}$ dada por $f(x)=\frac{1}{x}$.

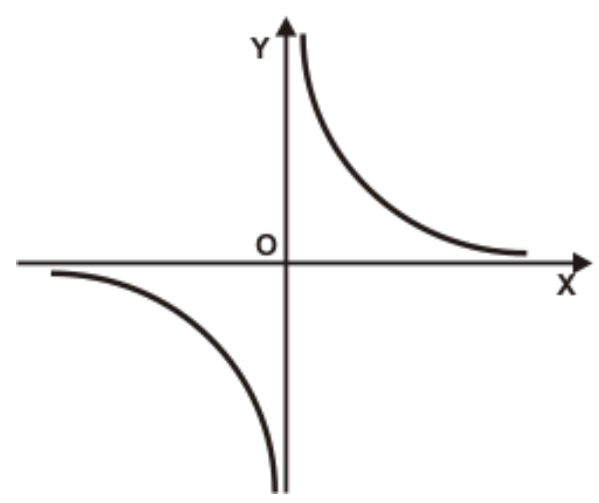

Figura 8: Gráfico da função $f: \mathbb{R}-\{0\} \rightarrow \mathbb{R}$ dada por $f(x)=\frac{1}{x}$.

Observe que quando diminuímos os valores positivos do eixo $x$ cada vez mais pertos de zero, os valores do eixo $y$ aumentam cada vez mais. E quando aumentamos os valores negativos do eixo $x$ cada vez mais próximos de zero, os valores do eixo $y$ diminuem cada vez mais. Este é outro exemplo de infinito potencial, ora é um candidato a $+\infty$, ora é um candidato a $-\infty$.

Dependendo da situação, usamos os símbolos $+\infty$ e $-\infty$ para o infinito potencial, o que significa que podemos sempre "acrescentar mais um...", "ir mais um pouco...", ir além...", chegar perto de...", "tender a...", "aproximar-se de..."; mas nunca realmente chegar, terminar, acabar, igualar.

Uma outra característica diferente para o infinito, é, por exemplo, pensarmos em duas retas paralelas no plano euclidiano. 


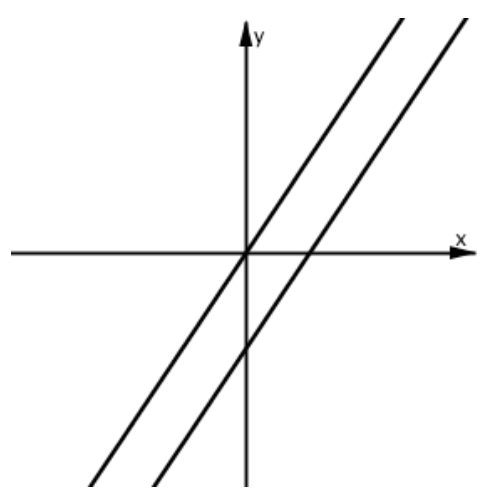

Figura 9: Retas paralelas no plano cartesiano.

Elas continuam indefinidamente e não conseguimos, de modo real, saber para onde vão. Falamos que as retas continuam para o infinito, mas onde será esse infinito? Com essa necessidade de saber onde encontrá-lo, podemos colocar essas duas retas paralelas em perspectiva, num plano projetivo.

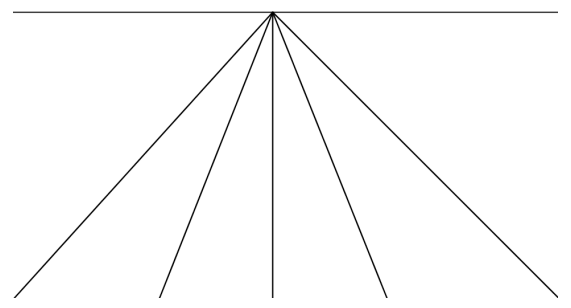

Figura 10: Retas paralelas em perspectiva.

Dessa forma, podemos falar do infinito actual, em que podemos admitir "pontos" no infinito, e que nos possibilita a quantificação e resolução de problemas do mundo real. Podemos dizer, então, que duas retas paralelas se encontram no infinito? Não vamos entrar em detalhes nesta discussão, mas ao leitor interessado indicamos a leitura de Barros e Andrade (2010) ou outro livro sobre geometria não euclidiana.

Agora, considere um quadrado de lado igual a $1 \mathrm{~cm}$.

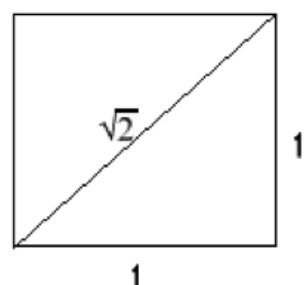

Figura 11: Quadrado de lado $1 \mathrm{~cm}$. 
Esse quadrado possui $\sqrt{2} \mathrm{~cm}$ como medida de sua diagonal. Com uma simples calculadora, temos que $\sqrt{2}=1,41421356237 \ldots$, em que, de acordo com o que já vimos, as reticências seria o infinito potencial, pois sempre podemos ter um digito a mais desse número. Mas ao desenharmos esse quadrado no plano, a diagonal é representada como um segmento de reta com começo e fim, portanto, limitada. Aqui podemos identificar o infinito actual como a representação do número $\sqrt{2}$ da medida da diagonal do quadrado, pois o segmento de reta da diagonal que representa o número real $\sqrt{2}$ possui infinitos pontos. O infinito actual é a representação do infinito como um todo, como uma quantidade. A diagonal do quadrado com aquele tamanho representa o número $\sqrt{2}=1,41421356237 \ldots$ como um todo, com todos os seus dígitos, um tamanho real.

Assim, temos a representação da medida da diagonal em decimal, a qual é um número decimal infinito e sua representação geométrica que é um segmento de reta finito. Vemos aqui a interação do infinito potencial e o infinito actual; por onde um sai, o outro entra.

Considere agora o conjunto de todos os números inteiros positivos $\{1,2,3,4,5, \ldots\}$. Se olharmos para cada elemento desse conjunto como uma sequência em que se pode cada vez mais adicionar mais um elemento, então temos o infinito potencial. Agora, se olharmos para todo o conjunto com infinitos elementos $(\mathbb{N})$, temos o infinito actual. Note que não sabemos exatamente até onde vai os elementos desse conjunto, nem quem são todos eles, mas, olhando para o todo, podemos estudar seu "tamanho".

É com o infinito actual que iremos desenvolver nosso trabalho. Foi Georg Cantor (1845-1918), desenvolvedor da teoria dos conjuntos, que difundiu o infinito actual, dando um novo olhar para o infinito, que até então só era abordado como infinito potencial. 


\section{Conceitos nescessários para estudar o infinito actual}

Neste capítulo é apresentada toda a teoria necessária para o desenvolvimento do nosso trabalho.

\subsection{Um pouco de história}

O matemático alemão Georg Cantor, no final do século XIX, deu continuidade no desenvolvimento matemático intitulado Os paradoxos do infinito de Bernhard Bolzano, um matemático Tcheco, que ele próprio dera início e não continuou. Uma questão intrigava os matemáticos da época: será possível tomar uma parte de um todo e colocá-la em correspondência com o todo? Por exemplo, considere o conjunto dos números inteiros positivos de 1 a 100 e tome uma parte desse conjunto como sendo todos números inteiros positivos de 1 a 10. Naquela época era impossível pensar que poderíamos relacionar cada elemento entre esses dois conjuntos, sem faltar nenhum, formando pares. É lógico que hoje também não. Mas esse exemplo ilustra como os matemáticos na época pensavam, de forma finita, querendo aplicar em conjuntos finitos os mesmos princípios e características dos conjuntos infinitos. Por isso ficavam intrigados e não aceitavam a ideia de que uma parte inteira poderia ter o mesmo "tamanho" ou a mesma "quantidade" de elementos de uma fração dessa parte inteira, ou seja, um pedaço do inteiro. Até então os matemáticos aceitavam apenas o infinito potencial, era impossível pensar no infinito actual, este último era tido como algo divino, somente Deus podia alcançar. Foi então que Cantor descobriu numerosas propriedades dos tamanhos de conjuntos infinitos. Ele encontrou diferentes tamanhos de infinitos. Essas ideias eram muito estranhas na época. Os matemáticos se concentravam no infinito potencial, onde sempre podemos acresentar mais um. O infinito actual como uma quantidade, um tamanho, não era muito aceito. Cantor foi reprovado e muito criticado pelo seu trabalho, chegando a ter sua principal descoberta negada de ser publicada numa das revistas mais renomadas de Matemática na época, a Journal de 
Crelle. Nunca mais Cantor aceitou publicar seus trabalhos nesta revista. Se pararmos para pensar, até hoje, à primeira vista, quando falamos que podemos colocar o conjunto dos números inteiros em correspondência de um para um com o conjunto dos números pares, que é uma parte dos inteiros, por exemplo, parece difícil de se aceitar.

Cantor foi além, mostrou que os números reais não poderia ser colocado em correspondência de um para um com os números naturais. O conjunto dos números reais seria, então, estritamente maior que o conjunto dos números naturais. Temos, então, dois infinitos actuais, um maior que o outro. Mas ele não parou por aí, mostrou também que há uma infinidade de tamanhos, estritamente maiores uns que os outros, de conjuntos infinitos.

A descoberta de Cantor foi um grande avanço na compreensão do infinito actual, que até então, tinha uma certa desconfiança e resistência por parte da maioria dos matemáticos e filósofos da época.

Para entendermos melhor o quanto ainda é difícil lidar com o infinito actual, Cantor mostrou que um segmento de reta e um cubo possuem o mesmo tamanho (do ponto de vista de conjuntos infinitos), ou até mesmo de um espaço de dimensão $n$. Na seção 5.5 é mostrado com detalhes como isso é possível.

Cantor também desenvolveu uma aritmética para o infinito. Com ela, Cantor pode realizar diversas operações com os tamanhos dos conjuntos infinitos. Para leitura sobre este assunto recomendamos Faticoni (2006) e Lieber (2007).

Na próxima seção falaremos um pouco sobre conjuntos e funções que serão de grande importância para o desenvolvimento de nosso trabalho.

\subsection{Algumas noções básicas}

Para iniciarmos, é preciso deixar claro alguns conceitos da teoria de conjuntos já conhecidos e as notações que serão utilizadas, bem como para funções.

Um conjunto é formado por objetos que são chamados de elementos do conjunto. Quando um objeto $x$ é um elemento do conjunto $A$, dizemos que $x$ pertence a $A$ e escrevemos $x \in A$, caso contrário, $x$ não pertence a $A$, e escrevemos $x \notin A$.

Dados dois conjuntos $A$ e $B$, dizemos que $A$ é subconjunto de $B$ quando todos os elementos de $A$ pertencerem ao conjunto $B$. Escrevemos $A \subset B$. Também dizemos que $A$ está contido em $B$. Caso contrário, escrevemos $A \not \subset B$ e dizemos que $A$ não está contido em 
$B$. O conjunto vazio $\emptyset$ é sempre um subconjunto de um conjunto qualquer $A$, e o próprio conjunto $A$ é também um subconjunto dele mesmo. Todos os outros subconjuntos de um conjunto diferentes do vazio e dele mesmo são chamados de subconjuntos próprios.

A união de dois conjunto $A$ e $B$ é o conjunto $A \cup B$, formado pelos elementos de $A$ mais os elementos de $B$. Se um elemento está em $A \cup B$, então podemos afirmar que esse elemento está em $A$, em $B$ ou em ambos.

A interseção dos conjuntos $A$ e $B$ é o conjunto $A \cap B$, formado pelos elementos comuns de $A$ e $B$. Se um elemento está em $A \cap B$, então podemos afirmar que esse elemento está em $A$ e em $B$ ao mesmo tempo.

Caso $A \cap B=\emptyset$, ou seja, os conjuntos $A$ e $B$ não tenham nenhum elemento em comum, eles são ditos disjuntos.

A diferença entre os conjuntos $A$ e $B$ é o conjunto $A-B$ formado pelos elementos de $A$ que não pertencem a $B$.

O produto cartesiano dos conjuntos $A$ e $B$ é o conjunto $A \times B$ cujos elementos são todos os pares ordenados $(a, b)$ onde $a \in A$ e $b \in B$. Por exemplo, sejam os conjuntos $A=\{1,2,5\}$ e $B=\{3,4,5\}$. Então, o produto cartesiano dos conjuntos $A$ e $B$ é o conjunto $A \times B=\{(1,3),(1,4)(1,5),(2,3),(2,4),(2,5),(5,3),(5,4),(5,5)\}$. Veja como fica o gráfico na figura 12 .

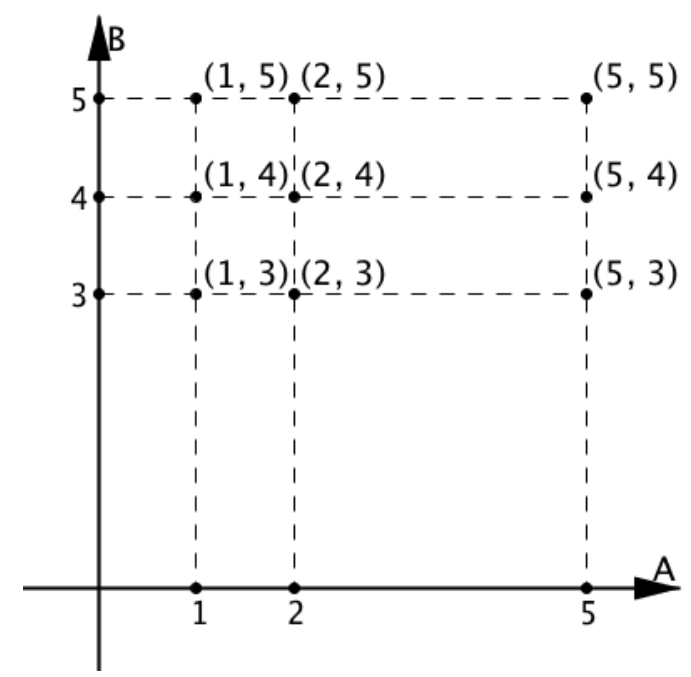

Figura 12: Produto cartesiano $A \times B$.

O conjunto das partes de um conjunto $A$ é um conjunto formado por todos os subconjuntos de $A$, escrevemos $\mathcal{P}(A)$.

Exploraremos um pouco mais a fundo o conjunto das partes de um conjunto. Vejamos 
alguns exemplos:

Exemplo 5.2.1. Sejam os conjuntos $A=\{a, b\}$ e $B=\{a, b, c\}$. Então temos os conjuntos $\mathcal{P}(A)=\{\{a\},\{b\},\{a, b\}, \emptyset\}$ e $\mathcal{P}(B)=\{\{a\},\{b\},\{c\},\{a, b\},\{a, c\},\{b, c\},\{a, b, c\}, \emptyset\}$.

Exemplo 5.2.2. Seja o conjunto $A$ como no exemplo anterior. Então

$$
\begin{gathered}
\mathcal{P}(\mathcal{P}(A))=\{\emptyset,\{a\},\{b\},\{\{a, b\}\},\{\emptyset\},\{\emptyset, a\},\{\emptyset, b\},\{\emptyset,\{a, b\}\},\{a, b\},\{a,\{a, b\}\}, \\
\{b,\{a, b\}\},\{\emptyset, a, b\},\{\emptyset, a,\{a, b\}\},\{\emptyset, b,\{a, b\}\},\{a, b,\{a, b\}\},\{\emptyset, a, b,\{a, b\}\}\} .
\end{gathered}
$$

Exemplo 5.2.3. Seja agora o conjunto $C=\{a,\{a\},\{b\},\{a, b\}\}$. Então

$$
\begin{gathered}
\mathcal{P}(C)=\{\emptyset,\{a\},\{\{a\}\},\{\{b\}\},\{\{a, b\}\},\{a,\{a\}\},\{a,\{b\}\},\{a,\{a, b\}\},\{\{a\},\{b\}\}, \\
\{\{a\},\{a, b\}\},\{\{b\},\{a, b\}\},\{a,\{a\},\{b\}\},\{a,\{a\},\{a, b\}\}, \\
\{a,\{b\},\{a, b\}\},\{\{a\},\{b\},\{a, b\}\},\{a,\{a\},\{b\},\{a, b\}\}\}
\end{gathered}
$$

Observação: No exemplo 5.2.1, o conjunto $A$ possui 2 elementos e $\mathcal{P}(A)$ possui $4=2^{2}$ elementos. Ainda no mesmo exemplo, o conjunto $B$ possui 3 elementos e $\mathcal{P}(B)$ possui $8=2^{3}$ elementos. No exemplo 5.2.2, $\mathcal{P}(\mathcal{P}(A))$ possui $16=2^{4}$ elementos e no exemplo 5.2.3, o conjunto $C$ possui 4 elementos e $\mathcal{P}(C)$ possui $2^{4}$ elementos.

O teorema a seguir mostra que esse resultado é válido em geral.

Teorema 5.2.1. Seja $A$ um conjunto com exatamente $n$ elementos, $n \in \mathbb{N}$. Então, o conjunto $\mathcal{P}(A)$ possui exatamente $2^{n}$ elementos.

Demonstração: Faremos essa demonstração utilizando o princípio de indução. Sabemos que o resultado é válido para $n=0$, pois se um conjunto $A$ é vazio, apenas ele mesmo é seu único subconjunto. Portanto, $\mathcal{P}(A)=1$. Vamos supor válido para um conjunto com $n$ elementos e mostrar que vale para um conjunto com $n+1$ elementos. Se adicionarmos um elemento a mais a um conjunto com $n$ elementos, digamos $a_{0}$, podemos escrever todos os $2^{n}$ subconjuntos desse conjunto sem o $a_{0}$ e depois a cada um desses $2^{n}$ subconjuntos adicionar o elemento $a_{0}$. Fazendo dessa forma, teremos o dobro de subconjuntos, ou seja, $2^{n} .2=2^{n+1}$. Assim, teremos um conjunto com $n+1$ elementos com $2^{n+1}$ subconjuntos.

Para podermos entender o conceito de conjunto infinito, é indispensável o uso de funções. É por isso que traremos algumas definições para ficar bem embasado nosso texto e podermos nos aprofundar melhor nos exemplos dados. 
Definição 5.2.1. Sejam $A$ e $B$ conjuntos dados. Uma função $f: A \rightarrow B$ de $A$ em $B$ é uma relação que permite associar a cada elemento de $x \in A$ um único elemento $f(x) \in B$.

$$
\begin{aligned}
f: A & \rightarrow B \\
x & \mapsto f(x)
\end{aligned}
$$

O conjunto $A$ é chamado de domínio da função $f$ e $B$ de contradomínio.

Dizemos que o conjunto $f(A)=\{b \in B \mid f(a)=b ; a \in A\}$ é o conjunto imagem da função $f$, ou seja, todos elementos do contradomínio que estão relacionados a algum elemento do domínio da função. Dizemos que $f(x)$ é a imagem de $x$ pela $f$.

Dizemos que uma função $f: A \rightarrow B$ é injetora se dados quaisquer $x$ e $y$ em $A$, $f(x)=f(y)$ implicar $x=y$. Equivalentemente, se $x \neq y$, então $f(x) \neq f(y)$.

Em palavras, podemos dizer que uma função é injetora, se não tiver mais de um elemento do domínio se relacionando com um mesmo elemento do contradomínio da função, ou seja, nenhum elemento do domínio terá a mesma imagem que um outro elemento do domínio da função.

Para ilustrar veremos dois exemplos onde a função é injetora e outro onde a função não é injetora.

Exemplo 5.2.4. Seja a função $f: \mathbb{R}-\{1\} \rightarrow \mathbb{R}$ dada por $f(x)=\frac{2 x+1}{x-1}$. Vamos mostrar que essa função é injetora. Sejam $x_{1}, x_{2} \in \mathbb{R}$ tal que $f\left(x_{1}\right)=f\left(x_{2}\right)$. Assim, temos

$$
\begin{aligned}
\frac{2 x_{1}+1}{x_{1}-1} & =\frac{2 x_{2}+1}{x_{2}-1} \\
\left(2 x_{1}+1\right)\left(x_{2}-1\right) & =\left(2 x_{2}+1\right)\left(x_{1}-1\right) \\
2 x_{1} x_{2}-2 x_{1}+x_{2}-1 & =2 x_{1} x_{2}-2 x_{2}+x_{1}-1 \\
-2 x_{1}+x_{2} & =-2 x_{2}+x_{1} \\
3 x_{2} & =3 x_{1} \\
x_{2} & =x_{1}
\end{aligned}
$$

Portanto, a função $f$ é injetora.

Veja no grafico da figura 13, que para valores diferentes de $x$, teremos valores distintos de $y$ associados a eles. 


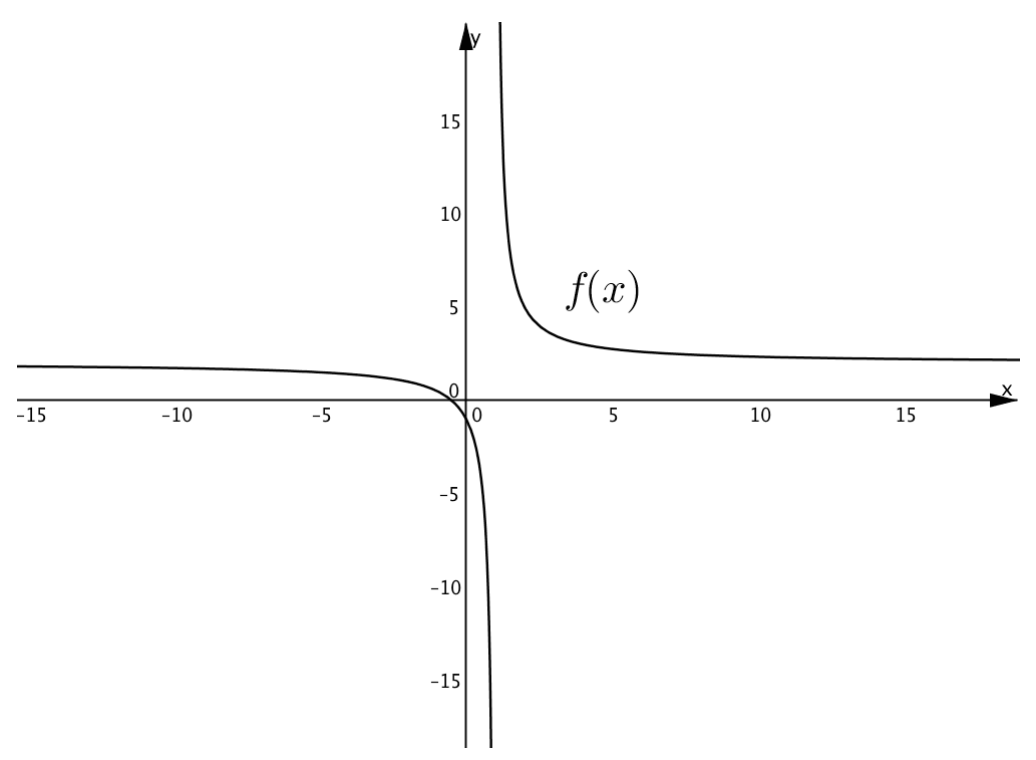

Figura 13: Gráfico da função $f: \mathbb{R}-\{1\} \rightarrow \mathbb{R}-\{2\}$ dada por $f(x)=\frac{2 x+1}{x-1}$.

Exemplo 5.2.5. Seja a função $f: \mathbb{R} \rightarrow \mathbb{R}$ dada por $f(x)=x^{2}$. Veremos que a função dada não é injetora. Para isto, basta encontrarmos um contra exemplo. Aplicando $-2 \mathrm{e}$ 2 na função $f$ temos, $f(-2)=4=f(2)$. Portanto, a função $f$ não é injetora.

Veja no gráfico da figura 14:

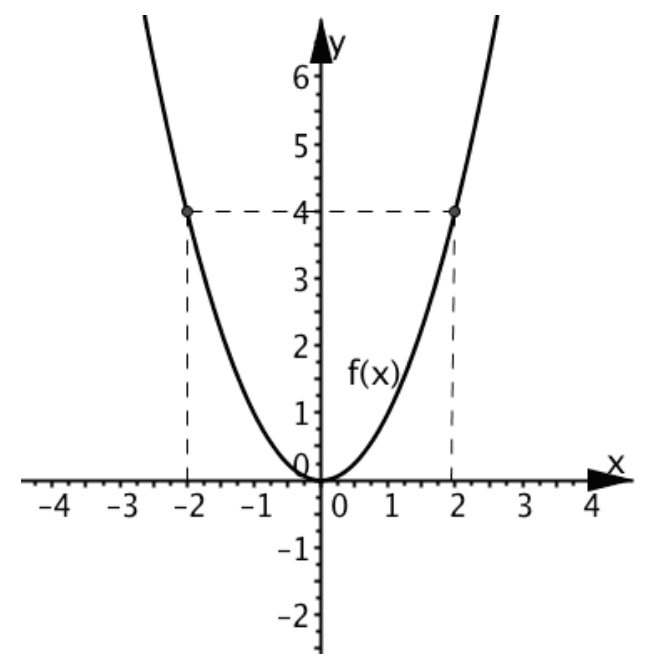

Figura 14: Gráfico da função $f: \mathbb{R} \rightarrow \mathbb{R}$ dada por $f(x)=x^{2}$.

Dizemos que $f: A \rightarrow B$ é sobrejetora se para todo $y \in B$, conseguimos encontrar $x \in A$ tal que $f(x)=y$.

Em palavras, uma função será dita sobrejetora quando todos elementos do contradomínio for imagem de algum elemento do domínio da função, ou seja, todos elementos do contradomínio serão atingidos pelos elementos do domínio por meio da função. 
Vejamos exemplos de funções sobrejetoras e não sobrejetoras.

Exemplo 5.2.6. Tomemos a mesma função do exemplo 5.2.4. Seja $b \in \mathbb{R}-\{2\}$ qualquer. Vamos verificar que essa função é sobrejetora. Vamos encontrar pelo menos um $a \in \mathbb{R}-\{1\}$ tal que $f(a)=b$. Tomemos $a=\frac{b+1}{b-2}$, então

$$
f(a)=\frac{2\left(\frac{b+1}{b-2}\right)+1}{\left(\frac{b+1}{b-2}\right)-1}=\frac{\frac{2 b+2+b-2}{b-2}}{\frac{b+1-b+2}{b-2}}=\frac{3 b}{3}=b
$$

Logo, a função $f$ é sobrejetora.

Observe que no gráfico da figura 13 , dado qualquer valor no eixo y distinto de 2 , sempre existe um valor no eixo $x$ que é seu correspondente.

Exemplo 5.2.7. Tomemos agora a mesma função do exemplo 5.2.5. Vamos verificar que tal função não é sobrejetora de $\mathbb{R}$ em $\mathbb{R}$. Suponha que seja sobrejetora. Para isso, tome $a \in \mathbb{R}, a<0$. Então, como a função é sobrejetora, existe $x \in \mathbb{R}$ tal que $x^{2}=a$. Absurdo, pois $a<0$. Portanto, a função não é sobrejetora.

No gráfico da figura 14, qualquer valor negativo no eixo $y$ que tomemos não teremos um correspondente em $x$.

Dizemos que $f: A \rightarrow B$ é bijetora se $f$ for injetora e sobrejetora. Neste caso, dizemos que existe uma bijeção entre $A$ e $B$.

De modo informal podemos dizer que uma bijeção entre $A$ e $B$ nos diz que, "existe um modo de emparelhar todos os elementos de $A$ com todos os elementos de $B . "$

Se $f: A \rightarrow B$ é uma bijeção de $A$ em $B$, onde $y=f(x)$, com $x \in A$ e $y \in B$, podemos definir uma função $g: B \rightarrow A$ onde $g(y)=x$, com $x \in A$ e $y \in B$, ou seja, a função $g$ faz o caminho inverso da função $f$. Chamamos a função $g$ de função inversa de $f$ e denotamos por $f^{-1}$. A função $f^{-1}: B \rightarrow A$ também determina uma bijeção de $B$ em $A$.

Exemplo 5.2.8. Seja o conjunto $A$ dos números naturais pares e a função $f: \mathbb{N} \rightarrow A$ dada por $f(x)=2 x$.

Vamos mostrar que $f$ é bijetora. Sejam $x_{1}$ e $x_{2}$ dois números naturais quaisquer. Vamos supor que $f\left(x_{1}\right)=f\left(x_{2}\right)$, isso implica que $2 x_{1}=2 x_{2}$, logo $x_{1}=x_{2}$. Portanto, a função $f$ é injetora. Agora, seja $a$ um número natural par qualquer. Como a é par, podemos escreve-lo na forma $a=2 k$, onde $k \in \mathbb{N}$. Portanto, existe um número natural $k$ tal que $f(k)=a$. Portanto, a função $f$ é sobrejetora. Desse modo mostramos que a função $f$ é bijetora. 


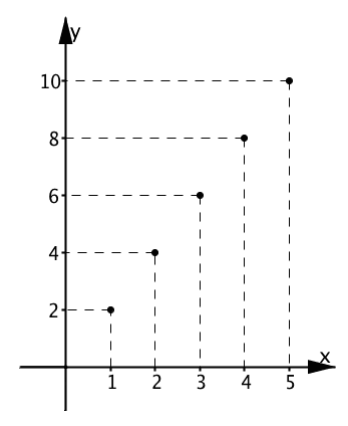

Figura 15: Gráfico da função $f(x)=2 x$.

Observe que no exemplo 5.2.8, como a função $f: \mathbb{N} \rightarrow A$ é bijetora, sua inversa $f^{-1}: A \rightarrow \mathbb{N}$ dada por $f^{-1}(x)=\frac{x}{2}$ também é bijetora, e assim podemos estabelecer uma bijeção de $A$ em $\mathbb{N}$.

Na seção seguinte daremos continuidade a teoria dos conjuntos focando em algumas definições e propriedades que formalizarão o conceito de conjunto finito e infinito.

\subsection{Conjuntos Finitos, Infinitos Enumeráveis e Não Enu- meráveis}

Como dissemos, nesta parte do trabalho falaremos sobre os conjuntos finitos e infinitos, porém, são os conjuntos com infinitos elementos que nos focaremos mais; os quais são classificados como enumeráveis e não enumeráveis.

Para cada $n \in \mathbb{N}$, passaremos a usar a notação $I_{n}=\{p \in \mathbb{N} ; p \leq n\}$, para representar o conjunto finito dos números naturais menores ou iguais a $n$. Ou seja, $I_{1}=\{1\}, I_{2}=\{1,2\}$, $I_{3}=\{1,2,3\}, I_{4}=\{1,2,3,4\}$, e assim por diante, isto é, $I_{n}=\{1,2,3,4, \ldots, n\}$.

Definição 5.3.1. Um conjunto $X$ chama-se finito quando é vazio ou quando existe, para algum $n \in \mathbb{N}$ uma bijeção de $I_{n}$ em $X$.

Decorre desta definição, que cada conjunto $I_{n}$ é finito.

Em outras palavras, podemos dizer que conjuntos finitos são aqueles que conseguimos contar todos seus elementos (um por um), ou seja, associar cada um de seus elementos a um número natural (um elemento em $I_{n}$ ). Diremos que o conjunto vazio é finito, pois não possui nenhum elemento. Intuitivamente, uma bijeção $f: I_{n} \rightarrow X$ significa uma contagem dos elementos de $X$. Pondo $f(1)=x_{1}, f(2)=x_{2}, \ldots, f(n)=x_{n}$, temos $X=\left\{x_{1}, x_{2}, x_{3}, \ldots, x_{n}\right\}$. Esta é a representação ordinária de um conjunto finito. 
Note que se existir duas bijeções $f: I_{n} \rightarrow X$ e $g: I_{m} \rightarrow X$, então, $n=m$. Isto nos garante a seguinte definição. Se $X$ é um conjunto finito, então temos duas possibilidades, $X=\emptyset$ ou existe uma bijeção $f: I_{n} \rightarrow X$ para algum $n \in \mathbb{N}$. No primeiro caso diremos que $X$ possui zero elementos e no segundo que $X$ possui $n$ elementos, ou que o número de elementos de $X$ é $n$. Para mais detalhes indicamos a leitura de Lima (2006).

Vamos ver um exemplo de um conjunto finito de acordo com a definição dada anteriormente.

Exemplo 5.3.1. Considere o conjunto $A=\{x \in \mathbb{Z} \mid-20 \leq x \leq 10\}$. Claramente esse conjunto é finito e possui 31 elementos. Segundo a definiçao acima, basta tomar a função bijetora $f: I_{31} \rightarrow A$ dada por $f(x)=x-21$ para $x \in I_{31}$.

Não é difícil verificar que todo subconjunto, digamos $A$, de um conjunto finito, digamos $B$, é finito, mais ainda, o número de elementos de $A$ não excede o de $B$ e só é igual quando $A=B$. Por outro lado, se existe uma bijeção entre os conjuntos finitos $A$ e $B$, então necessariamente $A$ e $B$ tem o mesmo número de elementos.

Falaremos brevemente de algumas propriedades, que são decorrentes do resultado acima, que nos serão úteis mais adiante.

Se tomarmos uma função $f: X \rightarrow Y$ injetora e se $Y$ for um conjunto finito, então $X$ também será um conjunto finito. É fácil ver que $f$ define uma bijeção entre $X$ e sua imagem $f(X)$. Como $f(X)$ é subconjunto de $Y$ e $Y$ é finito, então, pelo resultado acima, $f(X)$ é finito. Logo, $X$ também é um conjunto finito. Além disso, o número de elementos de $f(X)$, que é igual ao de $X$, não excede o de $Y$.

Por outro lado, se tomarmos agora uma função $g: X \rightarrow Y$ sobrejetora e se $X$ for um conjunto finito, então $Y$ também será um conjunto finito. De fato, como $X$ é finito, tomemos $X=\left\{x_{1}, x_{2}, \ldots, x_{n}\right\}$ para algum $n \in \mathbb{N}$. A imagem de $g$ é o conjunto $g(X)=\left\{g\left(x_{1}\right), g\left(x_{2}\right), \ldots, g\left(x_{n}\right)\right\}$ também finito. Como $g$ é sobrejetora, $g(X)=Y, \operatorname{logo}, Y$ é finito e o seu número de elementos não excede o de $X$.

Definição 5.3.2. Um conjunto $X$ chama-se infinito quando não é finito.

Mais explicitamente, $X$ é infinito quando não é vazio e, além disso, seja qual for $n \in \mathbb{N}$, não existe uma bijeção $f: I_{n} \rightarrow X$.

Podemos dizer que conjuntos infinitos, são aqueles que não conseguimos "contar" todos seus elementos um a um, não conseguimos associar a quantidade de seus elementos a um número natural. 
Galileu Galilei observou que o conjunto dos números naturais $\{1,2,3, \ldots\}$ eram tão numerosos quanto o conjunto dos números quadrados perfeitos $\{1,4,9, \ldots\}$, ou seja, que existe uma bijeção

$$
f:\{1,2,3, \ldots\} \rightarrow\{1,4,9, \ldots\}
$$

dada por

$$
f(x)=x^{2}
$$

Observe que o conjunto dos números quadrados perfeitos $\{1,4,9, \ldots\}$ é um subconjunto próprio do conjunto dos números naturais $\{1,2,3, \ldots\}$, ou seja, está contido mas não é igual; assim, Galileu Galilei observou que é possível colocar todos os elementos de um conjunto em correspondência de um para um com os elementos de um subconjunto próprio, o que parece ser impossível. Esta propriedade é uma característica singular dos conjuntos infinitos que podemos usá-la para caracterizar um conjunto infinito sem mencionar os conjuntos finitos. Isto é o que veremos no seguinte teorema.

Teorema 5.3.1. Um conjunto $A$ é dito infinito se existir uma bijeção entre $A$ e um subconjunto próprio de $A$.

Para o leitor interessado na demonstração desse teorema, veja o livro Análise Real volume 1 de Elon Lages Lima. Vamos ver alguns exemplos de conjuntos infinitos.

Exemplo 5.3.2. O conjunto dos números naturais é um conjunto infinito. Pela definição 5.3.1, vamos mostrar que não existe uma função bijetora $f: \mathbb{N} \rightarrow I_{n}$ qualquer que seja o número $n \in \mathbb{N}$. Faremos a prova por absurdo. Suponha que $f$ seja bijetora. Sem perda de generalidade, vamos admitir que ela já seja sobrejetora e mostrar que não pode ser injetora. De fato, sejam $x_{1}, x_{2}, \ldots, x_{n} \in \mathbb{N}$ tal que $f\left(x_{1}\right)=1, f\left(x_{2}\right)=2, \ldots, f\left(x_{n}\right)=n$. Como $\left\{x_{1}, x_{2}, \ldots, x_{n}\right\}$ é um conjunto finito, esse conjunto possui um maior elemento. Vamos assumir que esse maior elemento seja, por exemplo, $x_{n}$. Logo, se tomarmos $x_{n}+1 \in \mathbb{N}$, teremos $x_{n}+1>x_{n}$, então, $x_{n}+1 \notin\left\{x_{1}, x_{2}, \ldots, x_{n}\right\}$. Mas, por outro lado, como $x_{n}+1 \in \mathbb{N}$ e $f$ é sobrejetora, temos $f\left(x_{n}+1\right)=k \in I_{n}$, e pela definição da $f$ dada anteriormente, $k=f\left(x_{k}\right)$ para algum $k \in I_{n}$ e $x_{k} \in\left\{x_{1}, x_{2}, \ldots, x_{n}\right\}$. Como $x_{n}+1 \notin\left\{x_{1}, x_{2}, \ldots, x_{n}\right\}$, $x_{n}+1 \neq x_{k}$. Assim, $f\left(x_{n}+1\right)=f\left(x_{k}\right)$ e $x_{n}+1 \neq x_{k}$, portanto, $f$ não é injetora e $\mathbb{N}$ não pode ser um conjunto finito, logo, $\mathbb{N}$ é infinito.

Como vimos anteriormente para conjuntos finitos, podemos também estabelecer o seguinte para conjunto infinitos: se $f: X \rightarrow Y$ é injetora e $X$ é infinito, então $Y$ também é; e se $f: X \rightarrow Y$ é sobrejetora e $Y$ é infinito, então $X$ é infinito. (LIMA, 2006) 
Com esses resultados, outros exemplos de conjuntos infinitos são os conjuntos dos números inteiros e racionais, pois ambos contém $\mathbb{N}$.

Já vimos que podemos definir a quantidade de elementos de um conjunto finito. Agora iremos ver como ainda podemos falar em "quantidade" de elementos de um conjunto infinito. Note que não podemos falar que um conjunto infinito tem uma quantidade $x$ de elementos, mas podemos falar do "tamanho" dos conjuntos infinitos e ter conjuntos infinitos maiores uns que os outros.

Definição 5.3.3. Um conjunto $X$ diz-se enumerável, quando é finito ou quando existe uma bijeção do conjunto dos números naturais com $X$. No segundo caso, $X$ diz-se infinito enumerável.

Cada bijeção $f: \mathbb{N} \rightarrow X$ dada na definição anterior chama-se uma enumeração dos elementos do conjunto $X$. De modo grosseiro, dizer que $X$ é enumerável, é querer dizer que podemos enumerar, colocar em ordem seus elementos. Vejamos alguns exemplos.

Exemplo 5.3.3. Veremos que o conjunto dos números naturais pares $(P)$ é infinito enumerável. Para isso basta criarmos uma função que associe os números naturais aos pares da seguinte forma:

$$
\begin{array}{llllll}
\mathbb{N}: & 1 & 2 & 3 & 4 & 5 \\
& \downarrow & \downarrow & \downarrow & \downarrow & \downarrow \\
P: & 2 & 4 & 6 & 8 & 10
\end{array}
$$

Desse modo, basta tomarmos uma função como no exemplo 5.2.8 que é bijetora. Logo, o conjunto dos números pares é infinito enumerável.

De modo análogo é fácil mostrar que o conjunto dos números ímpares $B$ também é enumerável, basta tomarmos a bijeção $f: \mathbb{N} \rightarrow B$ dada por $f(x)=2 x-1$.

Exemplo 5.3.4. (Conjunto $\mathbb{Z}$ enumerável). Vamos ver que o conjunto $\mathbb{Z}$ é enumarável. O interessante é mostrar que podemos ter uma intuição de como podemos enumerar os elementos de $\mathbb{Z}$. Começamos a enumerar a partir do zero, depois $1,-1,2$, -2, e assim por diante, sempre um positivo e um negativo. Dessa forma, conseguimos enumerar todos os elementos de $\mathbb{Z}$. A figura a seguir ilustra melhor essa ideia: 


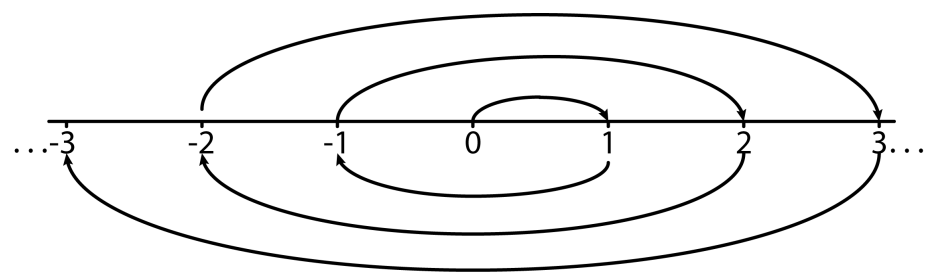

Figura 16: Enumeração dos números inteiros.

De acordo com a definição de conjunto enumerável, para formalizar nossa ideia de enumerar os elementos de $\mathbb{Z}$, construiremos uma função $f: \mathbb{N} \rightarrow \mathbb{Z}$ bijetora. Seja $f$ dada por

$$
f(n)=\left\{\begin{array}{cc}
\frac{n}{2} & \text { se } n \text { for par } \\
\frac{1-n}{2} & \text { se } n \text { for ímpar }
\end{array}\right.
$$

Vamos mostrar primeiro que $f$ é injetora. Sejam $n_{1}$ e $n_{2} \in \mathbb{N}$ tal que $n_{1} \neq n_{2}$. Vamos dividir em três casos:

$1^{\circ}$ Caso: Vamos supor sem perda de generalidade que $n_{1}$ é ímpar e $n_{2}$ é par. Pela definição de $f, f\left(n_{1}\right) \leq 0$ e $f\left(n_{2}\right)>0$, portanto, $f\left(n_{1}\right) \neq f\left(n_{2}\right)$.

$2^{\circ}$ Caso: Se $n_{1}$ e $n_{2}$ forem ambos pares, dividindo ambos os membros da desigualdade $n_{1} \neq n_{2}$ por 2 temos, $\frac{n_{1}}{2} \neq \frac{n_{2}}{2}$, o que implica $f\left(n_{1}\right) \neq f\left(n_{2}\right)$.

$3^{\circ}$ Caso: Se $n_{1}$ e $n_{2}$ forem ambos ímpares, multiplicando ambos os membros da desigualdade $n_{1} \neq n_{2}$ por $-\frac{1}{2}$ e somando $\frac{1}{2}$, temos $\frac{1-n_{1}}{2} \neq \frac{1-n_{2}}{2}$ o que implica $f\left(n_{1}\right) \neq f\left(n_{2}\right)$.

Assim, mostramos que $f$ é injetora. Agora vamos mostrar que $f$ é sobrejetora. Seja $a \in \mathbb{Z}$ qualquer. Vamos mostrar que existe $n \in \mathbb{N}$ tal que $f(n)=a$. Dividiremos em três casos:

$1^{\circ}$ Caso: Se $a=0$, basta tomarmos $n=1, \operatorname{assim} f(n)=f(1)=\frac{1-1}{2}=0$.

$2^{\circ}$ Caso: Se $a>0$, basta tomarmos $n=2 a$, assim $f(n)=f(2 a)=\frac{2 a}{2}=a$.

$3^{\circ}$ Caso: Se $a<0$, basta tomarmos $n=-2 a+1$, assim

$$
f(n)=f(-2 a+1)=\frac{1-(-2 a+1)}{2}=\frac{1+2 a-1}{2}=\frac{2 a}{a}=a .
$$

Observação: Note que nos três casos $n$ está bem definido, ou seja, $n \in \mathbb{N}$.

Assim, mostramos que $f$ é sobrejetora e injetora, logo, $f$ é bijetora. Portanto, o conjunto dos números inteiros $\mathbb{Z}$ é enumerável. 
Exemplo 5.3.5. O conjunto $\mathbb{Z}^{*}$ dos números inteiros diferentes de zero também é enumerável. Basta associarmos os números naturais com os inteiros diferentes de zero da seguinte maneira:

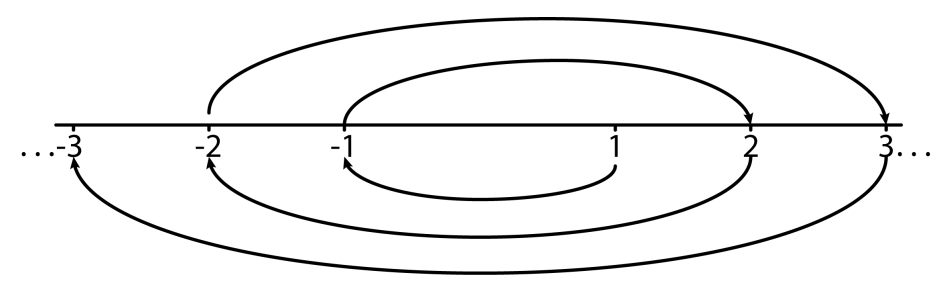

Figura 17: Enumeração dos números inteiros sem o zero.

Para isso, considere a função $f: \mathbb{N} \rightarrow \mathbb{Z}^{*}$ dada por

$$
f(n)=\left\{\begin{array}{cc}
-\frac{n}{2} & \text { se } n \text { for par } \\
\frac{n+1}{2} & \text { se } n \text { for ímpar }
\end{array}\right.
$$

de forma análoga ao que foi feito no exemplo 5.3.4, podemos mostrar que $f$ é bijetora.

Observe que do exemplo 5.3.4 para o exemplo 5.3.5 tiramos apenas o elemento zero do conjunto dos números inteiros e mesmo assim ele continuou enumerável. Veremos que podemos retirar ou adicionar um número finito de elementos de um conjunto enumerável que ele continuará enumerável.

O Paradoxo do Hotel de Hilbert é um exemplo onde os conjuntos enumeráveis cumprem um papel relevante. Cada vez que chegava mais hóspedes, o recepcionista encontrava uma nova função bijetora para associar a quantidade de novos hóspedes (um conjunto infinito enumerável) com a quantidade de quartos do hotel (conjunto dos números naturais).

Podemos concluir que além de $\mathbb{Z}, \mathbb{Q}$ também é um conjunto enumerável. Mas para isso, precisamos de dois resultados cuja demonstração pode ser encontrada em Lima (2006). O primeiro deles é: "Se dois conjuntos $X$ e $Y$ são enumeráveis, então o produto cartesiano $X \times Y$ é enumerável." O segundo é: "Se $X$ é enumerável e $f: X \rightarrow Y$ é sobrejetora, então, $Y$ é enumerável."

Vejamos no exemplo a seguir que $\mathbb{Q}$ é enumerável.

Exemplo 5.3.6. (Conjunto $\mathbb{Q}$ enumerável). Como foi visto nos exemplos 5.3.4 e 5.3.5, $\mathbb{Z}$ e $\mathbb{Z}^{*}$ são enumeráveis, então, $\mathbb{Z} \times \mathbb{Z}^{*}$ é enumerável. Tomando a função $f: \mathbb{Z} \times \mathbb{Z}^{*} \rightarrow \mathbb{Q}$ definida por $f(m, n)=\frac{m}{n}$ com $m \in \mathbb{Z}$ e $n \in \mathbb{Z}^{*}$. Pela definição do conjunto dos números racionais $\mathbb{Q}=\left\{\frac{a}{b} \in \mathbb{Q} \mid a \in \mathbb{Z}\right.$ e $\left.b \in \mathbb{Z}^{*}\right\}$ e da função $f$, é fácil ver que $f$ é sobrejetora. Assim, $\mathbb{Q}$ é enumerável. 
Não é nossa intenção entrar em detalhes sobre os resultados acima usados para concluírmos que $\mathbb{Q}$ é enumerável. Para mais detalhes e resultados, indicamos a leitura de Lima (2006) e Faticoni (2006).

Nosso próximo assunto será de grande importância, pois nos servirá de base para falarmos sobre o "tamanho" de conjuntos com infinitos elementos.

\subsection{Cardinalidade}

A definição de cardinalidade de um conjunto é uma boa maneira de descrever, de mensurar o "tamanho" ou a "quantidade" de elementos de um conjunto infinito, que a princípio não conseguimos contar. Passaremos a escrever no lugar de "quantidade" e "tamanho", o termo cardinalidade.

Sejam $X$ e $Y$ dois conjuntos. Escrevemos $\operatorname{card}(X) \leq \operatorname{card}(Y)$ se existir uma função injetora $f: X \rightarrow Y$, ou seja, a quantidade de elementos de $X$ não excederá a quantidade de elementos de $Y$. Note que se $X \subset Y$, então $\operatorname{card}(X) \leq \operatorname{card}(Y)$. Diremos também que dois conjuntos $X$ e $Y$ têm o mesmo número cardinal se existir uma bijeção $f: X \rightarrow Y$. Escreveremos $\operatorname{card}(X)=\operatorname{card}(Y)$.

Com isso podemos comparar e diferenciar cardinais de diferentes conjuntos. Assim, se dois conjuntos finitos possuem o mesmo número de elementos, eles têm o mesmo número cardinal. Como vimos anteriormente, concluímos que o conjunto $A$ do exemplo 5.3.1 tem o mesmo número cardinal de $I_{31}$, ou seja, 31 elementos.

Para conjuntos infinitos, os conjuntos dos números pares e ímpares, por exemplo, possuem a mesma cardinalidade dos números naturais, pois vimos no exemplo 5.3.3 que existe uma função bijetora entre o conjunto dos números pares e os naturais e os ímpares e os naturais. Vimos também nos exemplos 5.3.4 e 5.3.6 que os conjuntos dos números inteiros e dos números racionais são enumeráveis, de certo modo, há uma bijeção desses conjuntos com os naturais, logo, possuem a mesma cardinalidade entre eles. Portanto, temos que $\operatorname{card}(\mathbb{N})=\operatorname{card}(\mathbb{Z})=\operatorname{card}(\mathbb{Q})$.

Podemos dizer que um conjunto $X$ é infinito enumerável se, e somente se, $\operatorname{card}(X)=$ $\operatorname{card}(\mathbb{N})$. Assim, $\operatorname{card}(\mathbb{N})$ é a classe de todos os conjuntos enumeráveis.

Veremos agora alguns exemplos de conjuntos não enumeráveis, consequentemente, não tem o mesmo número cardinal do conjunto dos números naturais. Veremos adiante que o conjunto dos números reais $\mathbb{R}$ não é enumerável, $\operatorname{logo}, \operatorname{card}(\mathbb{R}) \neq \operatorname{card}(\mathbb{N})$. Mas antes, 
veremos outros exemplos de conjuntos não enumeráveis.

Exemplo 5.4.1. (Conjunto $\mathcal{P}(\mathbb{N})$ não é enumerável). O conjunto das partes de $\mathbb{N}$, dado por $\mathcal{P}(\mathbb{N})$, é um conjunto infinito não enumerável. Para provarmos essa afirmação, iremos mostrar que, para qualquer conjunto $A$, não existe nenhuma bijeção entre $A$ e $\mathcal{P}(A)$. Assim, basta mostrarmos que não existe uma função $f: A \rightarrow \mathcal{P}(A)$ sobrejetora. Sejam a função $f: A \rightarrow \mathcal{P}(A)$ e $x \in A$. A função dada associa cada elemento de $A$ a um subconjunto de $A$ pertencente a $\mathcal{P}(A)$. Em outras palavras, para cada $x \in A, f(x)$ é um conjunto de elementos de $A$. Assim, temos que $f(x) \in \mathcal{P}(\mathrm{A})$ e $f(x) \subset A$. Considere o conjunto $X=\{x \in A \mid x \notin f(x)\}$. É fácil ver que se $x \in f(x)$, então, $x \notin X$, por outro lado, se $x \notin f(x)$, então, $x \in X$. Observe que $X$ é um subconjunto de $A$. Se mostrarmos que $f(x) \neq X$, concluiremos que $f$ não é sobrejetora, pois nem todos elementos de $\mathcal{P}(A)$ será imagem de algum $x \in A$. Isto é imediato, pois pela definição de $X$, não podemos ter um mesmo elemento pertencente a $f(x)$ e a $X$ ao mesmo tempo, assim $f(x) \neq X$. Logo, não existe função $f: A \rightarrow \mathcal{P}(A)$ sobrejetora, com isso, $\operatorname{card}(A) \neq \operatorname{card}(\mathcal{P}(A))$.

Como o que foi feito acima é válido para qualquer conjunto $A$, tomemos então $A=\mathbb{N}$ e concluímos que não existe bijeção entre $\mathbb{N}$ e $\mathcal{P}(\mathbb{N})$. Dessa forma, $\mathcal{P}(\mathbb{N})$ não é enumerável, então

$$
\operatorname{card}(\mathbb{N}) \neq \operatorname{card}(\mathcal{P}(\mathbb{N}))
$$

Além disso, podemos dizer que para qualquer conjunto $A$, tem-se

$$
\operatorname{card}(A)<\operatorname{card}(\mathcal{P}(A))
$$

Basta tomarmos a função injetora $f: A \rightarrow \mathcal{P}(\mathrm{A})$ dada por $f(x)=\{x\}$. De fato, sejam $f\left(x_{1}\right)=f\left(x_{2}\right)$ que implica $\left\{x_{1}\right\}=\left\{x_{2}\right\}$, logo, $x_{1}=x_{2}$. Desse modo temos que $\operatorname{card}(A) \leq \operatorname{card}(\mathcal{P}(\mathrm{A}))$. Como acabamos de mostrar no exemplo 5.4.1 que $\operatorname{card}(A) \neq$ $\operatorname{card}(\mathcal{P}(A))$, concluímos que

$$
\operatorname{card}(A)<\operatorname{card}(\mathcal{P}(A))
$$

para qualquer conjunto $A$.

Vamos ver agora que quaisquer dois segmentos de reta são conjuntos de mesma cardinalidade independente de seu comprimento. Vamos mostrar isso no exemplo a seguir.

Exemplo 5.4.2. Sejam dois segmentos de reta $\overline{A B}$ e $\overline{C D}$. Se os comprimentos de $\overline{A B}$ e $\overline{C D}$ forem iguais não há o que fazer, é fácil ver que eles possuem a mesma cardinalidade. 
Vamos supor então que os segmentos $\overline{A B}$ e $\overline{C D}$ possuem comprimentos diferentes. Vamos colocá-los, sem perda de generalidade, na vertical e paralelos como na figura 18.

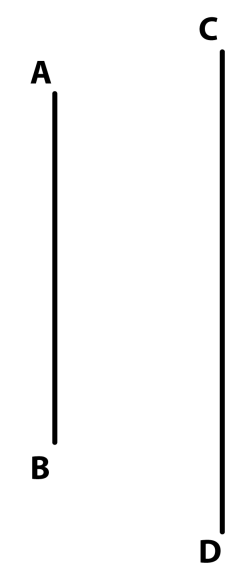

Figura 18: Segmentos $\overline{A B}$ e $\overline{C D}$.

Veremos que esses dois segmentos de reta tem a mesma cardinalidade. De fato, trace uma reta passando por $A$ e $C$ e outra passando por $B$ e $D$. Seja $P$ o ponto de interseção dessas duas retas. Definiremos uma função $f: \overline{A B} \rightarrow \overline{C D}$ de modo que, dado qualquer ponto $x \in \overline{A B}$, trace uma reta passando por $P$ e $x$ interceptando $\overline{C D}$ no ponto $y$. Definiremos $f(x)=y$, ou seja, a imagem de $x \in \overline{A B}$ é $y \in \overline{C D}$. Veja figura 19 .

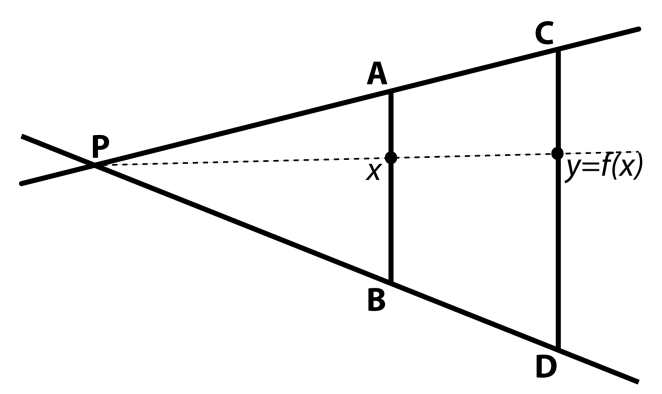

Figura 19: Função $f: \overline{A B} \rightarrow \overline{C D}$

Vamos mostrar que a função $f: \overline{A B} \rightarrow \overline{C D}$ como definida acima é bijetora. Para isso, veremos que a função $f$ é sobrejetora. Tome qualquer ponto $y \in \overline{C D}$. Trace uma reta passando por $y$ e $P$ como na figura 19. Essa reta irá interceptar $\overline{A B}$ em algum ponto $x \in \overline{A B}$, pela definição de $f, f(x)=y$, então a função $f$ é sobrejetora. Para vermos que a função $f$ é injetora, tome dois pontos distintos $x_{1}$ e $x_{2}$ de $\overline{A B}$ de acordo com a figura 20. Trace duas retas, uma passando por $P$ e $x_{1}$ e outra por $P$ e $x_{2}$. Sejam $y_{1}$ e $y_{2}$, respectivamente, os dois pontos de interseçao dessas retas com $\overline{C D}$. 


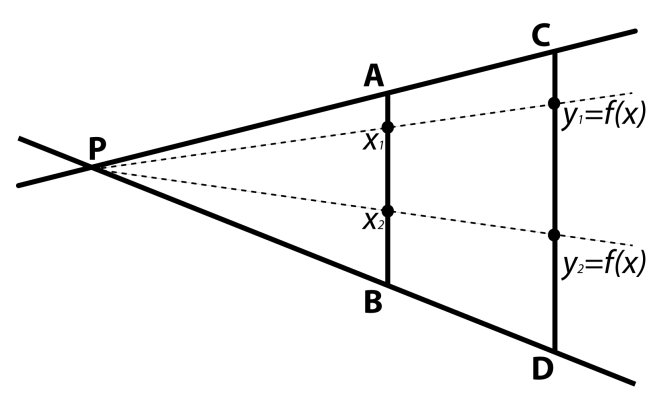

Figura 20: $f: \overline{A B} \rightarrow \overline{C D}$ injetora.

Pela definição de $f, f\left(x_{1}\right)=y_{1}$ e $f\left(x_{2}\right)=y_{2}$ e claramente $y_{1} \neq y_{2}, \operatorname{logo}, f\left(x_{1}\right) \neq f\left(x_{2}\right)$ e assim a função $f$ é injetora. Portanto, vimos que a função $f$ é bijetora e os segmentos $\overline{A B}$ e $\overline{C D}$ tem a mesma cardinalidade.

Como vimos acima, podemos então afirmar que, qualquer segmento de reta tem a mesma cardinalidade, em particular, o conjunto $(0,1)=\{x \in \mathbb{R} \mid 0<x<1\}$.

Veremos agora que não é possível enumerar todos os elementos do intervalo $(0,1)$.

Proposição 5.4.1. O conjunto $(0,1)$ não é enumerável.

Demonstração: Seja $x \in(0,1)$. Podemos escrever $x$ na forma de um número decimal infinito, $x=0, d_{1} d_{2} d_{3} d_{4} \ldots$, onde cada decimal $d_{i}$ do número $x$, é um número inteiro $0 \leq d_{i} \leq 9, i \geq 1$. No caso de decimais finitos como, por exemplo 0,2, colocaremos $0,2000 \ldots, 0,71$, colocaremos $0,71000 \ldots$ e assim por diante. Vamos supor que o conjunto $(0,1)$ seja enumerável. Desse modo, podemos colocar os elementos do conjunto $(0,1)$ em ordem, ou seja, em correspondência de um para um com os números naturais.

$$
\begin{array}{ll}
1^{\mathrm{o}} \text { elemento } & 0, d_{11} d_{12} d_{13} d_{14} \ldots \\
2^{\mathrm{o}} \text { elemento } & 0, d_{21} d_{22} d_{23} d_{24} \cdots \\
3^{\mathrm{o}} \text { elemento } & 0, d_{31} d_{32} d_{33} d_{34} \cdots \\
4^{\mathrm{o}} \text { elemento } & 0, d_{41} d_{42} d_{43} d_{44} \cdots
\end{array}
$$

Pelo método da diagonalização de Cantor, vamos chegar a um absurdo e concluir que o conjunto $(0,1)$ não pode ser enumerável. Para cada decimal $d_{i j}$, com $i=j$, caracterizado 
acima, troque seu valor por qualquer outro diferente dele mesmo e renomei-o por $a_{i j}$.

$$
\begin{array}{ll}
1^{\mathrm{o}} \text { elemento } & 0, a_{11} d_{12} d_{13} d_{14} \ldots \\
2^{\mathrm{o}} \text { elemento } & 0, d_{21} a_{22} d_{23} d_{24} \ldots \\
3^{\mathrm{o}} \text { elemento } & 0, d_{31} d_{32} a_{33} d_{34} \ldots \\
4^{\mathrm{o}} \text { elemento } & 0, d_{41} d_{42} d_{43} a_{44} \ldots
\end{array}
$$

Tome o elemento $0, a_{11} a_{22} a_{33} a_{44} \ldots$ do conjunto $(0,1)$, ele é diferente de todos listados em (5.1). De fato, é diferente do $1^{\circ}$ elemento, pois $d_{11}$ foi trocado por $a_{11}$, é diferente do $2^{\circ}$ elemento, pois $d_{22}$ foi trocado por $a_{22}$ e assim por diante.

Portanto, conseguimos um elemento de $(0,1)$ que está fora da lista (5.1), portanto, não está colocado em correspondência com nenhum número natural. Logo, o conjunto $(0,1)$ não é enumerável.

Uma outra maneira mais intuitiva e menos formal de dizer que um conjunto não é enumerável, é dizer que não se pode colocar seus elementos em sequência, de modo a começar por um primeiro elemento, depois o segundo, o terceiro, ... , onde todos tem um sucessor e um antecessor (exceto o primeiro). Desse modo, é fácil ver que os elementos do conjunto $(0,1)$ não podem ser colocados em ordem (enumerados). Por exemplo, qual seria o sucessor de 0,2? Poderia ser o 0,21, 0,201, 0,2001, 0,20001, ... , ou seja, não é possível, pois há infinitos números reais entre dois números reais.

Vimos que quaisquer segmentos de reta tem a mesma cardinalidade e sabe-se que o segmento de reta dado pelo intervalo $(0,1)$ não é enumerável, então, quaisquer segmentos de reta não são enumeráveis. Com isso podemos dizer que os conjunto $(0,1)$ e $\left(-\frac{\pi}{2}, \frac{\pi}{2}\right)$ tem a mesma cardinalidade e não são enumeráveis. Vamos então mostrar que $\mathbb{R}$ não é enumerável mostrando que possui a mesma cardinalidade do segmento de reta dado pelo intervalo $\left(-\frac{\pi}{2}, \frac{\pi}{2}\right)$, ou seja, encontrando uma função $f:\left(-\frac{\pi}{2}, \frac{\pi}{2}\right) \rightarrow \mathbb{R}$ bijetora. Veja o exemplo a seguir.

Exemplo 5.4.3. Considere a função $f:\left(-\frac{\pi}{2}, \frac{\pi}{2}\right) \rightarrow \mathbb{R}$ dada por $f(x)=\operatorname{tg}(x)$. O gráfico dessa função é dado pela figura 21.

É fácil de ver que a função $f$ é bijetora. O gráfico da figura 21 nos mostra isto. Podemos tomar quaisquer dois elementos diferentes do domínio que eles terão imagens diferentes, e se tomarmos qualquer elemento do contra domínio, sempre há um elemento no domínio que chega à ele pela função $f$. 


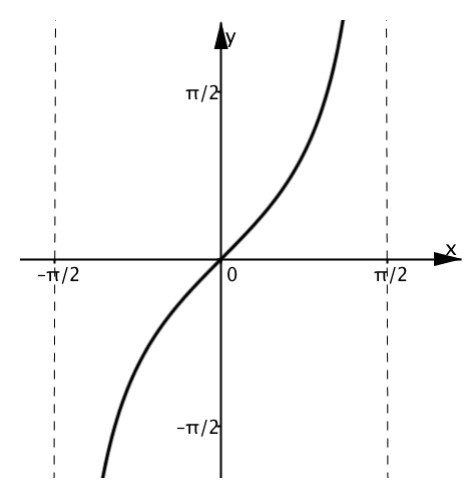

Figura 21: Gráfico da função $f:\left(-\frac{\pi}{2}, \frac{\pi}{2}\right) \rightarrow \mathbb{R}$ dada por $f(x)=\operatorname{tg}(x)$.

Vamos mostrar mais formalmente que a função $f:\left(-\frac{\pi}{2}, \frac{\pi}{2}\right) \rightarrow \mathbb{R}$ dada por $f(x)=\operatorname{tg}(x)$ é bijetora. Vamos começar mostrando que a função dada é sobrejetora, ou seja, dado $y \in \mathbb{R}$ qualquer, existe $x \in\left(-\frac{\pi}{2}, \frac{\pi}{2}\right)$ tal que $t g(x)=y$. Iremos separar em três casos:

$1^{\circ}$ Caso: Se $y>0$. Tome um ponto $T$ na reta tangente ao círculo trigonométrico de raio 1 de tal forma que $\overline{A T}=y$ como mostra a figura 22 .

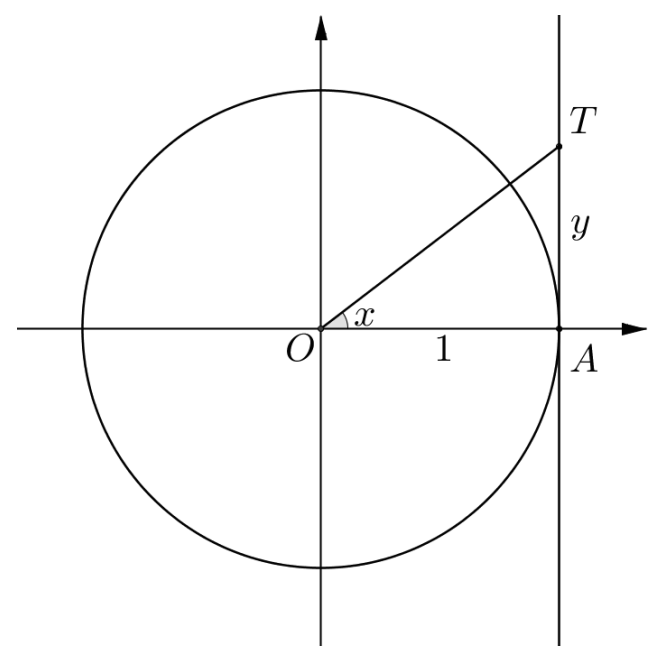

Figura 22: Círculo trigonométrico caso 1.

Considere o triângulo $O A T$ e $x$ o ângulo $T \hat{O} A$ medido em radianos. Pela construção do triângulo temos que $x \in\left(0, \frac{\pi}{2}\right)$. Calculando a tangente do ângulo $x$ temos, $\operatorname{tg}(x)=\frac{y}{1}=y$, ou seja, para qualquer números real $y>0$ temos um números real $x \in\left(0, \frac{\pi}{2}\right)$ associado à ele.

$2^{\mathbf{o}}$ Caso: Se $y<0$. Tome um ponto $T^{\prime}$ na reta tangente ao círculo trigonométrico de raio 1 de tal forma que $\overline{A T^{\prime}}=|y|$ como mostra a figura 23 . 


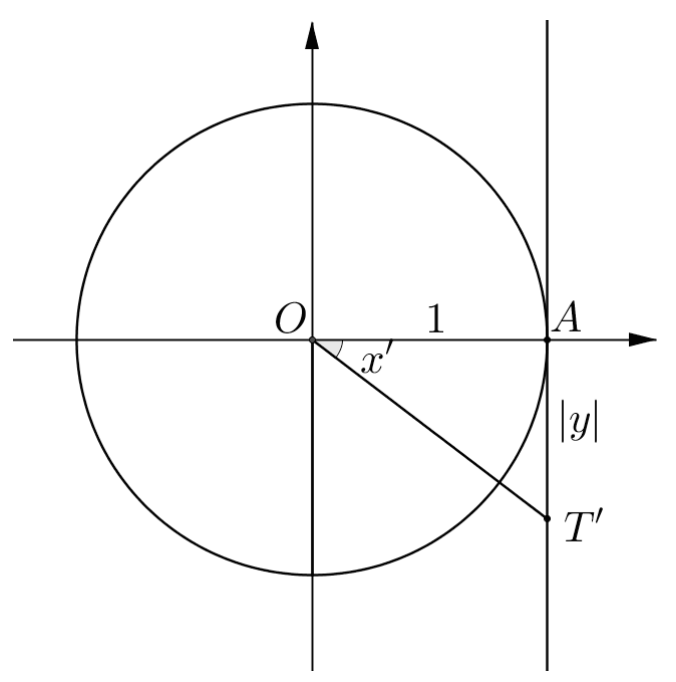

Figura 23: Círculo trigonométrico caso 2.

Considere o triângulo $O A T^{\prime}$ e $x^{\prime}$ o ângulo $T^{\prime} \hat{O} A$ medido em radianos. Pela construção do triângulo temos que $x^{\prime} \in\left(-\frac{\pi}{2}, 0\right)$. Calculando a tangente do ângulo $x^{\prime}$ temos, $\operatorname{tg}\left(x^{\prime}\right)=\frac{|y|}{1}=|y|$, ou seja, para qualquer números real $y<0$ temos um números real $x^{\prime} \in\left(-\frac{\pi}{2}, 0\right)$ associado à ele.

$3^{\circ}$ Caso: Se $y=0$, basta tomarmos $x=0$ que teremos $\operatorname{tg}(0)=0$.

Portanto, pelos três casos mostramos que a função $f$ é sobrejetora.

Agora vamos mostrar que a função dada é injetora. De fato, tomemos $f\left(x_{1}\right)=f\left(x_{2}\right)$, ou seja, $\operatorname{tg}\left(x_{1}\right)=\operatorname{tg}\left(x_{2}\right)$ para quaisquer $x_{1}$ e $x_{2}$. Desenhe dois triângulos retângulos. Um deles com catetos medindo 1 e $\left|\operatorname{tg}\left(x_{1}\right)\right|$ e o outro com catetos medindo 1 e $\left|\operatorname{tg}\left(x_{2}\right)\right|$, como mostra a figura 24 .
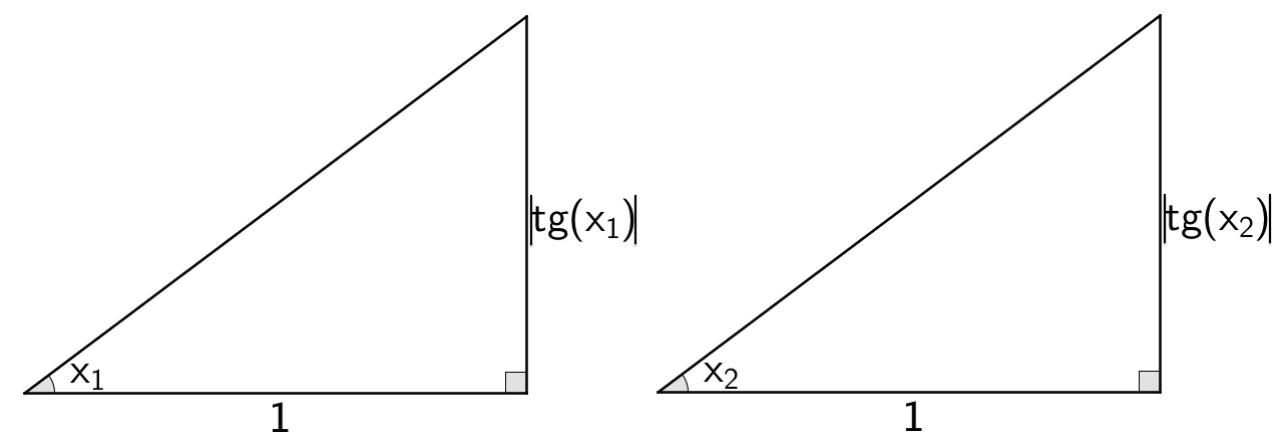

Figura 24: Triângulos retângulos.

Pelo caso de congruência $L A L$, os dois triângulos são congruentes, então, $x_{1}=x_{2}$. Portanto, a função $f$ é injetora.

Assim, a função $f:\left(-\frac{\pi}{2}, \frac{\pi}{2}\right) \rightarrow \mathbb{R}$ dada por $f(x)=\operatorname{tg}(x)$ é bijetora. 
Com o que vimos no exemplo anterior, podemos enunciar e provar o seguinte teorema.

Teorema 5.4.1. O conjunto dos números reais $\mathbb{R}$ não é enumerável.

Demonstração: Pelo exemplo 5.4.3, a função $f:\left(-\frac{\pi}{2}, \frac{\pi}{2}\right) \rightarrow \mathbb{R}$ dada por $f(x)=t g(x)$ é bijetora. Logo, o conjunto dos números reais $\mathbb{R}$ possui a mesma cardinalidade do conjunto $\left(-\frac{\pi}{2}, \frac{\pi}{2}\right)$, que por sua vez não é enumerável, logo, o conjunto dos números reais não é enumerável.

Na próxima seção, iremos mostrar o resultado mais intrigante da descoberta de Cantor, sobre o qual ele mesmo escreveu a Dedekind: "Eu posso ver, mas não acredito."

\subsection{O cubo e o intervalo de reta tem o "mesmo número de elementos".}

Vimos que todo segmento de reta (um intervalo real) tem a mesma cardinalidade dos números reais (reta contínua), e mais, possui uma cardinalidade diferente dos números naturais, pois não são enumeráveis. Agora nós iremos além, vamos ver que um segmento unitário $(S)$, um quadrado unitário $(Q)$ e um cubo unitário $(C)$ tem o mesmo número cardinal, ou ainda, tem o mesmo "número" de pontos entre seus interiores. Mostrando isso podemos concluir um fato que contradiz nossa intuição. A cardinalidade de um conjunto não depende da sua geometria e sua dimensão.

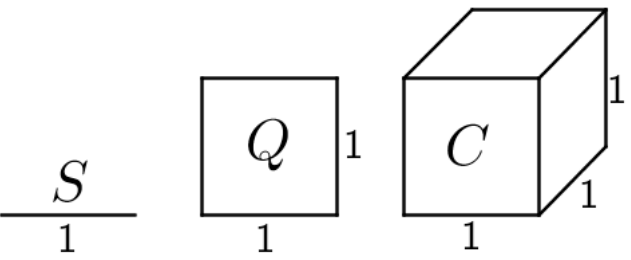

Figura 25: Segmento, quadrado e cubo unitários.

Proposição 5.5.1. $\operatorname{card}(S)=\operatorname{card}(Q)=\operatorname{card}(C)$, onde $S=\{x \in \mathbb{R} \mid 0 \leq x \leq 1\}$, $Q=\left\{(x, y) \in \mathbb{R}^{2} \mid 0 \leq x, y \leq 1\right\}$ e $C=\left\{(x, y, z) \in \mathbb{R}^{3} \mid 0 \leq x, y, z \leq 1\right\}$.

Demonstração: É fácil de ver que $S \subset Q \subset C$ de modo que pela observação feita na página 44 temos

$$
\operatorname{card}(S) \leq \operatorname{card}(Q) \leq \operatorname{card}(C)
$$

Com isso, basta mostrarmos que $\operatorname{card}(C) \leq \operatorname{card}(S)$ e usar a desigualdade (5.2) para concluir que $\operatorname{card}(S)=\operatorname{card}(Q)=\operatorname{card}(C)$. 
Para mostrarmos que $\operatorname{card}(C) \leq \operatorname{card}(S)$, construiremos uma função injetora de $C$ em $S$. Para cada $(x, y, z)$ no interior de $C$, seja

$$
\begin{aligned}
& x=0, x_{1} x_{2} x_{3} \ldots \\
& y=0, y_{1} y_{2} y_{3} \ldots \\
& z=0, z_{1} z_{2} z_{3} \ldots
\end{aligned}
$$

a representação decimal infinita de $x, y$ e $z$, respectivamente, onde $0 \leq x_{i} \leq 9$, $0 \leq y_{i} \leq 9$ e $0 \leq z_{i} \leq 9$ para cada $i \in \mathbb{N}$.

Antes de proceder com a demonstração, precisaremos lembrar alguns fatos importantes.

1. Cada número real tem uma representação decimal infinita. Exemplo:

$$
\begin{aligned}
& \frac{1}{4}=0,25000 \ldots \\
& \frac{1}{3}=0,33333 \ldots
\end{aligned}
$$

2. Alguns números possuem duas representações decimal infinita. Exemplo:

$$
\begin{aligned}
1,000 \ldots & =0,999 \ldots \\
0,354000 \ldots & =0,353999 \ldots
\end{aligned}
$$

3. Como foi dito no item 1, todo número real admite uma representação decimal infinita. Mas ainda, existem duas possíveis situações: a representação é única ou existem unicamente duas representações, uma finalizando em uma sequência infinita de zeros e a outra finalizando com uma sequência infinita de noves. Exemplo:

$$
0,15000 \ldots=0,14999 \ldots
$$

Números como

$$
0,57898989 \ldots
$$

tem uma única representação.

4. Também é possível provar que se $0, x_{1} x_{2} x_{3} \ldots=0, y_{1} y_{2} y_{3} \ldots$, são duas representações decimais infinitas, tal que $0 \leq x_{i} \leq 9$ e $0 \leq y_{i} \leq 9$, para cada $i \in \mathbb{N}$ e se 
(a) $0, x_{1} x_{2} x_{3} \ldots=0, y_{1} y_{2} y_{3} \cdots$

(b) $0, x_{i} x_{i+1} x_{i+2} \ldots<1$ e $0, y_{i} y_{i+1} y_{i+2} \ldots<1$ para todo $i \in \mathbb{N}$

então, $x_{n}=y_{n}$ para todo $n \geq 1$.

Note que a condição do item (b) está garantindo que ambas representações decimais não finalizam em um sequência infinita de noves.

As provas dos itens 3 e 4 serão feitas nos apêncides B e C respectivamente.

Podemos agora retomar a demonstração. Do cubo $C$ retiremos o conjunto de todas as triplas $(x, y, z)$ para os quais $x, y$ e $z$ admitem mais de uma representação decimal infinita. Chamemos este conjunto de $K$. Mais precisamente, $K=\{(x, y, z) \in$ $C ; x$ ou $y$ ou $z$ possuem duas representações decimal infinita\}

É possível provar que o subconjunto dos números reais que possuem duas representações decimais infinitas, é um conjunto enumerável. Logo, podemos afirmar que

$$
\operatorname{card}(C)=\operatorname{card}(C-K)
$$

Sendo assim, podemos definir a função injetora $f: C \rightarrow S$ definida em $C-K$ como segue: para cada $x, y$ e $z$ em $C-K$ seja

$$
\begin{aligned}
& x=0, x_{1} x_{2} x_{3} \ldots \\
& y=0, y_{1} y_{2} y_{3} \ldots \\
& z=0, z_{1} z_{2} z_{3} \ldots
\end{aligned}
$$

a expansão decimal infinital (única) de $x, y$ e $z$. Defina

$$
f(x, y, z)=0, x_{1} y_{1} z_{1} x_{2} y_{2} z_{2} x_{3} y_{3} z_{3} \ldots
$$

note-se que como os números $x, y$ e $z$ estão em $C-K$, o número $f(x, y, z)$ terá uma única representação decimal infinita, logo $f$ é de fato um função. Por exemplo, para

$$
\begin{aligned}
& x=0,4532222 \ldots \\
& y=0,9272731 \ldots \\
& z=0,1333333 \ldots
\end{aligned}
$$


teremos

$$
f(0,4532222 \ldots, 0,9272731 \ldots, 0,1333333 \ldots)=0,491523373223273233213 \ldots
$$

Para finalizar, bastará mostrar que $f$ é injetora. Mas isto segue do $4^{\circ}$ item anterior, $\log 0$

$$
\operatorname{card}(C)=\operatorname{card}(C-K) \leq \operatorname{card}(S) .
$$

Isto junto com a desigualdade (5.2) conclui a prova.

Podemos ir além, a reta real tem a mesma cardinalidade do plano $\left(\mathbb{R}^{2}\right)$, do espaço $\left(\mathbb{R}^{3}\right)$ e até mesmo de qualquer espaço de dimensão $n\left(\mathbb{R}^{n}\right)$. Isto é, se traçarmos um segmento de reta qualquer, este segmento "terá o mesmo número de pontos" de uma quadrado qualquer, que por sua vez "terá o mesmo número de pontos" que um cubo qualquer. Isso pode ir contra nosso senso comum, mas o infinito nos proporciona situações que parecem ser duvidosas e embaraçosas. Como já vimos, historicamente era embaraçoso pensarmos em colocar todos elementos de um conjunto em correspondência de um para um com todos os elementos de seu próprio subconjunto. É o que acabamos de ver, se considerarmos o conjunto de todos os pontos do espaço, podemos colocá-los em correspondência de um para um com todos os pontos de uma reta por exemplo, que é um subconjunto próprio do espaço, ou seja, está "dentro" do próprio espaço e possuem a mesma "quantidade" de elementos. É estranho pensar que mesmo tirando um pedaço de um todo, ainda sim este pedaço terá o mesmo "tamanho" do todo.

Depois de vermos conjuntos infinitos enumeráveis e infinitos não enumeráveis, a pergunta que fica é a seguinte: Se temos conjuntos infinitos de cardinalidades diferentes, como ordená-los? Será que existe uma ordem? Uma hierarquia? Para responder a essas perguntas precisaremos estabelecer o seguinte: Dados os conjuntos $X, Y$, diremos que $\operatorname{card}(X)<\operatorname{card}(Y)$ quando existir uma função injetora $f: X \rightarrow Y$ mas não existir uma função sobrejetora $f: X \rightarrow Y$. Isso nos quer dizer que, para que possamos afirmar que $\operatorname{card}(X)<\operatorname{card}(Y)$, precisamos encontrar pelo menos uma função injetora $f: X \rightarrow Y$ e provar que não existe nenhuma função $f: X \rightarrow Y$ sobrejetora.

Sendo assim, mostramos que o conjunto dos números reais $\mathbb{R}$ não é enumerável usando o fato de que não conseguimos colocar todos os números reais em correspondência de um para um com os números naturais. Sempre há um número real sem correspondência com algum número natural, ou seja, não existe uma função $f: \mathbb{N} \rightarrow \mathbb{R}$ sobrejetora. Por outro 
lado, é fácil ver que existem mais de uma função $f: \mathbb{N} \rightarrow \mathbb{R}$ injetora. Por exemplo, a função $f: \mathbb{N} \rightarrow \mathbb{R}$ dada por $f(x)=x$, é injetora. Portanto, vimos que existe uma função $f: \mathbb{N} \rightarrow \mathbb{R}$ injetora e que não existe uma função $f: \mathbb{N} \rightarrow \mathbb{R}$ sobrejetora. Assim, concluímos que $\operatorname{card}(\mathbb{N})<\operatorname{card}(\mathbb{R})$. Resumidamente, juntando alguns dos exemplos dados até aqui sobre a cardinalidade de conjuntos infinitos, temos:

$$
\operatorname{card}(\mathbb{N})=\operatorname{card}(\mathbb{Z})=\operatorname{card}(\mathbb{Q})<\operatorname{card}(\mathbb{R})=\operatorname{card}\left(\mathbb{R}^{2}\right)=\operatorname{card}\left(\mathbb{R}^{3}\right)=\operatorname{card}\left(\mathbb{R}^{n}\right)
$$

Temos mostrado até o momento a existência de dois conjuntos com infinitos elementos de "tamanhos" diferentes, os que tem a mesma cardinalidade dos números naturais e os que tem a mesma cardinalidade dos números reais como na desigualdade (5.4).

Afirmamos que o número cardinal de $\mathbb{N}$ é o menor dos números cardinais. De fato, é possível provar que todo conjunto infinito $X$ contém um subconjunto infinito enumerável $^{1}$. Isso nos mostra que para todo conjunto infinito $X$, tem-se $\operatorname{card}(\mathbb{N}) \leq \operatorname{card}(X)$. Assim, o número cardinal dos números naturais é o menor dos números cardinais, consequentemente, podemos dizer que o "tamanho" dos conjuntos infinitos enumeráveis são os menores dos conjuntos infinitos.

Lembrando que já provamos que $\operatorname{card}(\mathbb{N})<\operatorname{card}(\mathcal{P}(\mathbb{N}))$ e que $\operatorname{card}(\mathbb{N})<\operatorname{card}(\mathbb{R})$, fica-nos uma pergunta: Qual é a relação entre $\operatorname{card}(\mathbb{R})$ e $\operatorname{card}(\mathcal{P}(\mathbb{N}))$ ? A resposta está no seguinte teorema.

Teorema 5.5.1. $\operatorname{card}(\mathbb{R})=\operatorname{card}(\mathcal{P}(\mathbb{N}))$.

Demonstração: Mostraremos que

$$
\operatorname{card}(0,1)=\operatorname{card}(\mathcal{P}(\mathbb{N}))
$$

já que $\operatorname{card}(\mathbb{R})=\operatorname{card}(0,1)$. Para isso, vamos definir uma função $f:(0,1) \rightarrow \mathcal{P}(\mathbb{N})$ injetora para concluir que

$$
\operatorname{card}(0,1) \leq \operatorname{card}(\mathcal{P}(\mathbb{N}))
$$

Em seguida, definiremos outra função $g: \mathcal{P}(\mathbb{N}) \rightarrow(0,1)$ também injetora para concluir que

$$
\operatorname{card}(\mathcal{P}(\mathbb{N})) \leq \operatorname{card}(0,1)
$$

Com as inequações (5.5) e (5.6) teremos mostrado que $\operatorname{card}(0,1)=\operatorname{card}(\mathcal{P}(\mathbb{N}))$, ou seja, $\operatorname{card}(\mathbb{R})=\operatorname{card}(\mathcal{P}(\mathbb{N}))$.

\footnotetext{
${ }^{1}$ Este é um teorema que não demonstraremos para não perdermos o foco do nosso objetivo. Para o leitor interessado, ler o livro "Curso de Análise - vol.1" de Elon Lages Lima.
} 
Vamos definir uma função injetora $f$ de $(0,1)$ em $\mathcal{P}(\mathbb{N})$. Para cada número real $x \in(0,1)$ iremos escrevê-lo como um número decimal binário

$$
x=b_{1} \cdot \frac{1}{2}+b_{2} \cdot \frac{1}{2^{2}}+b_{3} \cdot \frac{1}{2^{3}}+\ldots=0, b_{1} b_{2} b_{3} \cdots
$$

onde $b_{1}, b_{2}, b_{3}, \ldots \in\{0,1\}$.

Por exemplo,

$$
\begin{gathered}
\frac{1}{2}=1 \cdot \frac{1}{2}+0 \cdot \frac{1}{2^{2}}+0 \cdot \frac{1}{2^{3}}+\ldots=0,10 \overline{0} \\
\frac{1}{3}=0 \cdot \frac{1}{2}+1 \cdot \frac{1}{2^{2}}+0 \cdot \frac{1}{2^{3}}+1 \cdot \frac{1}{2^{4}}+\ldots=0,01 \overline{01} \\
\frac{5}{8}=1 \cdot \frac{1}{2}+0 \cdot \frac{1}{2^{2}}+1 \cdot \frac{1}{2^{3}}+0 \cdot \frac{1}{2^{4}}+0 \cdot \frac{1}{2^{5}}+\ldots=0,1010 \overline{0}
\end{gathered}
$$

Vamos associar cada decimal à um número natural da forma

$$
\begin{array}{ccccc}
1 & 2 & 3 & 4 & \ldots \\
\downarrow & \downarrow & \downarrow & \downarrow & \\
b_{1} & b_{2} & b_{3} & b_{4} & \ldots
\end{array}
$$

Para cada $x \in(0,1)$, seja o subconjunto $f(x)=U_{x} \subset \mathbb{N}$ definido por

$$
\left\{\begin{array}{l}
n \in U_{x} \text { se } b_{n}=1 \\
n \notin U_{x} \text { se } b_{n}=0
\end{array}\right.
$$

Por exemplo, $\frac{1}{3}=0,0101 \overline{01}$, associando seus decimais com os números naturais temos

$$
\begin{array}{ccccccc}
1 & 2 & 3 & 4 & 5 & 6 & \ldots \\
\downarrow & \downarrow & \downarrow & \downarrow & \downarrow & \downarrow & \\
0 & 1 & 0 & 1 & 0 & 1 & \ldots
\end{array}
$$

Então, $f\left(\frac{1}{3}\right)=U_{\frac{1}{3}}=\{2,4,6, \ldots\}$.

Um outro exemplo é se $x=0,101001 \overline{0}$, então, $f(x)=U_{x}=\{1,3,6\}$.

Temos que ter o cuidado nos casos onde há duas ou mais maneiras de escrevermos um número real na sua forma decimal binária. Por exemplo,

$$
\frac{1}{2}=1 \cdot \frac{1}{2}+0 \cdot \frac{1}{2^{2}}+0 \cdot \frac{1}{2^{3}}+0 \cdot \frac{1}{2^{4}}+\ldots=0,1 \overline{0}
$$




$$
\frac{1}{2}=0 \cdot \frac{1}{2}+1 \cdot \frac{1}{2^{2}}+1 \cdot \frac{1}{2^{3}}+1 \cdot \frac{1}{2^{4}}+\ldots=0,0 \overline{1}
$$

Nestes casos tomaremos a forma que tiver a menor quantidade de $1^{\prime} s$, assim, $\frac{1}{2}=0,1 \overline{0}$ e $f\left(\frac{1}{2}\right)=\{1\}$.

Definida a função $f:(0,1) \rightarrow \mathcal{P}(\mathbb{N})$ como acima, vamos mostrar que ela é injetora. Sejam $x, y \in(0,1), x \neq y$, na forma decimal binária

$$
\begin{aligned}
& x=0, b_{1} b_{2} b_{3} \ldots \\
& y=0, c_{1} c_{2} c_{3} \ldots
\end{aligned}
$$

Como supomos $x \neq y$, temos $b_{n} \neq c_{n}$ para algum $n \in \mathbb{N}$. Vamos supor sem perda de generalidade que $b_{n}=1$ e $c_{n}=0$. Pela definição de $f$ temos

$$
n \in f(x)=U
$$

$\mathrm{e}$

$$
n \notin f(y)=V .
$$

Logo, $U$ e $V$ não possuem os mesmos elementos, então

$$
f(x)=U \neq V=f(y) .
$$

Com isso, concluímos que a função $f:(0,1) \rightarrow \mathcal{P}(\mathbb{N})$ assim definida é injetora, portanto,

$$
\operatorname{card}(0,1) \leq \operatorname{card}(\mathcal{P}(\mathbb{N}))
$$

Agora vamos definir uma função injetora $g$ de $\mathcal{P}(\mathbb{N})$ em $(0,1)$. Escreveremos cada subconjunto de $\mathbb{N}$ como uma sequência binária. Mais precisamente, para cada $U \in \mathcal{P}(\mathbb{N})$ lhe corresponderá a sequência binária $b_{0} b_{1} b_{2} b_{3} \ldots$ como segue

$$
b_{n}=\left\{\begin{array}{lll}
1 & \text { se } & n \in U \\
0 & \text { se } & n \notin U
\end{array}\right.
$$

Por exemplo, o conjunto $U=\{0,2,4,6, \ldots\}$ tem como correspondência a sequência binária

$$
1010 \overline{10}
$$

pois 


$$
\begin{aligned}
& b_{0}=1 \text { pois } \quad 0 \in U \\
& b_{1}=0 \text { pois } 1 \notin U \\
& b_{2}=1 \text { pois } 2 \in U \\
& b_{3}=0 \text { pois } 3 \notin U
\end{aligned}
$$

$\mathrm{O}$ conjunto $\{3\}$ corresponde à $0001 \overline{0}$, por outro lado, se $U$ corresponde à $0101 \overline{01}$, então, $U=\{1,3,5, \ldots\}$. Se $U$ corresponde à $000011 \overline{1}$, então, $U$ contém todos números naturais maiores que três.

Assim, cada conjunto $U \in \mathcal{P}(\mathbb{N})$ será identificado com um sequência binária $U=$ $b_{0} b_{1} b_{2} b_{3} \ldots$ Com isso, considere a função $g: \mathcal{P}(\mathbb{N}) \rightarrow(0,1)$ dada por

$$
g(U)=0, b_{0} b_{1} b_{2} b_{3} \cdots
$$

Por exemplo,

$$
\begin{gathered}
g(01 \overline{0})=0,01=\frac{1}{100} \\
g(11 \overline{1})=0,11 \overline{1}=\frac{1}{9} \\
g(10 \overline{10})=0,10 \overline{10}
\end{gathered}
$$

Vamos mostrar que $g$ é injetora. Sejam $U, V \in \mathcal{P}(\mathbb{N}), U \neq V$.

$$
\begin{aligned}
& U=b_{0} b_{1} b_{2} b_{3} \cdots \\
& V=c_{0} c_{1} c_{2} c_{3} \cdots
\end{aligned}
$$

Para algum $n \in \mathbb{N}$ temos $b_{n} \neq c_{n}$, então,

$$
f(U)=0, b_{0} b_{1} b_{2} b_{3} \ldots \neq c_{0} c_{1} c_{2} c_{3} \ldots=f(V) .
$$

Com isso, concluímos que a função $g: \mathcal{P}(\mathbb{N}) \rightarrow(0,1)$ é injetora, portanto,

$$
\operatorname{card}(\mathcal{P}(\mathbb{N})) \leq \operatorname{card}(0,1)
$$

Assim, mostramos o que precisávamos como dito no começo dessa demonstração. Consequentemente $\operatorname{card}(\mathbb{R})=\operatorname{card}(\mathcal{P}(\mathbb{N}))$. 
Será que existe ainda outros conjuntos com cardinalidade diferente dos números naturais e reais? A resposta é sim. Vimos que se um conjunto finito $A$ possui $n$ elementos, o conjunto das partes de $A, \mathcal{P}(A)$, terá $2^{n}$ elementos. É fácil ver que $n<2^{n}$ para qualquer $n \in \mathbb{N}$. Isto nos mostra que $\operatorname{card}(A)<\operatorname{card}(\mathcal{P}(A))$. Se continuarmos tomando as partes das partes de $A$ indefinidamente e denotando por

$$
\begin{aligned}
\mathcal{P}(\mathcal{P}(A)) & =\mathcal{P}^{2}(A)=2^{2^{n}} \\
\mathcal{P}(\mathcal{P}(\mathcal{P}(A))) & =\mathcal{P}^{3}(A)=2^{2^{2^{n}}} \\
\mathcal{P}(\mathcal{P}(\mathcal{P}(\mathcal{P}(A)))) & =\mathcal{P}^{4}(A)=2^{2^{2^{2^{n}}}}
\end{aligned}
$$

teremos a seguinte desigualdade

$$
n<2^{n}<2^{2^{n}}<2^{2^{2^{n}}}<2^{2^{2^{2^{n}}}}<\ldots
$$

equivalente a uma sequência infinita de cardinais finitos

$$
\operatorname{card}(A)<\operatorname{card}(\mathcal{P}(A))<\operatorname{card}\left(\mathcal{P}^{2}(A)\right)<\operatorname{card}\left(\mathcal{P}^{3}(A)\right)<\operatorname{card}\left(\mathcal{P}^{4}(A)\right)<\ldots
$$

Os próximos dois teoremas são fundamentais para concluirmos nosso trabalho.

Teorema 5.5.2. $\operatorname{card}(\mathbb{N})<\operatorname{card}(\mathcal{P}(\mathbb{N}))$.

Demonstração: Vimos na página 45 que para qualquer conjunto $A$ temos $\operatorname{card}(A)<\operatorname{card}(\mathcal{P}(A))$. Basta tomarmos $A=\mathbb{N}$ e teremos $\operatorname{card}(\mathbb{N})<\operatorname{card}(\mathcal{P}(\mathbb{N}))$.

Teorema 5.5.3. Há uma sequência infinita $\alpha_{0}<\alpha_{1}<\alpha_{2}<\alpha_{3}<\ldots$ de cardinais infinitos.

Demonstração: Sejam $\alpha_{0}=\operatorname{card}(\mathbb{N})$ e $\alpha_{1}=\operatorname{card}(\mathcal{P}(\mathbb{N}))$, então, pelo Teorema 5.5.2 temos

$$
\alpha_{0}<\alpha_{1}
$$

Agora sejam $\alpha_{2}=\operatorname{card}\left(\mathcal{P}^{2}(\mathbb{N})\right), \alpha_{3}=\operatorname{card}\left(\mathcal{P}^{3}(\mathbb{N})\right), \ldots$.Pelo que vimos na página 45, tomemos $A=\mathcal{P}(\mathbb{N})$, logo, $\mathcal{P}(A)=\mathcal{P}^{2}(\mathbb{N})$, então

$$
\alpha_{1}<\alpha_{2}
$$


Das desigualdades (5.7) e (5.8) temos

$$
\alpha_{0}<\alpha_{1}<\alpha_{2}
$$

Em geral, colocando $A=\mathcal{P}^{n}(\mathbb{N})$ temos $\mathcal{P}(A)=\mathcal{P}^{n+1}(\mathbb{N})$, desse modo, denotando $\alpha_{n}=$ $\operatorname{card}\left(\mathcal{P}^{n}(A)\right)$ e $\alpha_{n+1}=\operatorname{card}\left(\mathcal{P}^{n+1}(A)\right)$, temos

$$
\alpha_{n}<\alpha_{n+1}
$$

Portanto, conseguimos construir uma sequência infinita de cardinais infinitos

$$
\alpha_{0}<\alpha_{1}<\alpha_{2}<\ldots<\alpha_{n}<\alpha_{n+1}<\ldots
$$

equivalente a

$$
\operatorname{card}(\mathbb{N})<\operatorname{card}(\mathcal{P}(\mathbb{N}))<\operatorname{card}\left(\mathcal{P}^{2}(\mathbb{N})\right)<\operatorname{card}\left(\mathcal{P}^{3}(\mathbb{N})\right)<\ldots
$$

A desigualdade (5.9) nos diz que temos infinitos números cardinais. Para isso, tomando um conjunto infinito $X$ qualquer, temos um número cardinal. Se tomarmos o conjuntos das partes de $X$, teremos um outro número cardinal estritamente maior que o anterior. Continuando com esse procedimento, podemos tomar o conjunto das partes das partes de $X$ e teremos um novo número cardinal estritamente maior que os dois anteriores. Desse modo, se continuarmos tomando sucessivamente o conjunto das partes do conjunto tomado anteriormente, conseguimos encontrar sempre um número cardinal estritamente maior que o encontrado anteriormente, e podemos fazer isso infinitas vezes. Portanto, temos quantos forem necessários, conjuntos infinitos de tamanhos diferentes.

Sabe-se que no conjunto dos números naturais $(\mathbb{N})$ existe uma relação de ordem muito bem caracterizada: se $m, n \in \mathbb{N}$, então uma das seguintes condições é válida:

$$
m<n \text { ou } n<m \text { ou } n=m \text {. }
$$

Sabe-se também que esta relação de ordem está definida no conjunto dos números reais $(\mathbb{R})$, mas existe uma diferença importantíssima entre a relação de ordem $<$ em $\mathbb{N}$ e em $\mathbb{R}$. O conjunto $\mathbb{N}$ com a relação de ordem $<$, é um conjunto bem ordenado, já o conjunto $\mathbb{R}$ não. Para entender melhor, vamos lembrar a definição de conjunto bem ordenado.

Definição 5.5.1. Seja $A$ um conjunto onde está definido uma relação de ordem <. Diz-se 
que $A$ é bem ordenado em relação a $<$ se for verdade a seguinte propriedade: Cada subconjunto de $A$ contém um único menor elemento. Equivalentemente, para cada elemento $x \in A$, existe um único elemento $x+1 \in A$ tal que

$$
\text { se } y \in A \text { e se } x<y \text {, então } x+1<y
$$

O elemento $x+1$ é chamado o sucessor de $x$.

O conjunto dos números reais não é bem ordenado com a relação usual de ordem $<$. De fato, se fosse, qual seria o sucessor de $\frac{1}{2}$ ?

É possível provar que "o conjunto dos números cardinais é bem ordenado com a seguinte relação de ordem: $\operatorname{card}(A) \leq \operatorname{card}(B)$; se existe uma função injetora de $A$ em $B$." Sendo assim, podemos considerar o sucessor de $\operatorname{card}(\mathbb{N})$.

Cantor usou a letra $\aleph$ (lê-se: álefe) do alfabeto hebraico e denotou o $\operatorname{card}(\mathbb{N})$, que é o menor dos números cardinais infinitos, como $\aleph_{0}$ (lê-se: álefe zero). O próximo infinito é denotado por $\aleph_{1}$, o seguinte por $\aleph_{2}$ e assim por diante.

Vimos no teorema 5.2.1 que se um conjunto possui $n$ elementos, o conjunto das partes terá $2^{n}$ elementos. Com isso, como $\operatorname{card}(\mathbb{N})=\aleph_{0}$, é usual denotar ${ }^{2}$ o $\operatorname{card}(\mathcal{P}(\mathbb{N}))=$ $\operatorname{card}(\mathbb{R})$ por $2^{\aleph_{0}}$, isto é, $\operatorname{card}(\mathcal{P}(\mathbb{N}))=2^{\aleph_{0}}$. Então, da desigualdade (5.9), temos a seguinte desigualdade

$$
\aleph_{0}<2^{\aleph_{0}}<2^{2^{\aleph_{0}}}<2^{2^{2^{\aleph_{0}}}} \ldots
$$

Por outro lado, sabe-se que

$$
\aleph_{0}=\operatorname{card}(\mathbb{N})<\operatorname{card}(\mathbb{R})
$$

$\log \mathrm{O}$

$$
\aleph_{1} \leq \operatorname{card}(\mathbb{R}) .
$$

Lembre que $\aleph_{1}$ denota o seguinte infinito cardinal depois de $\aleph_{0}$. Observando a desigualdade anterior, uma questão bastante natural aparece:

$$
\aleph_{1}=\operatorname{card}(\mathbb{R}) ?
$$

Ou existe algum conjunto cuja cardinalidade é maior que $\aleph_{1}$ e menor que $\operatorname{card}(\mathbb{R}) ?$ Du-

\footnotetext{
${ }^{2}$ Esclarecemos que isto é uma notação, não interpretar como a potência de 2 a um cardinal infinito.
} 
rante muito tempo esta questão intrigou os matemáticos, só em 1963 o matemático Paul J. Cohen respondeu esta questão, ele mostrou que não é possível provar ou negar que $\aleph_{1}=\operatorname{card}(\mathbb{R})$.

A afirmação de que $\aleph_{1}=\operatorname{card}(\mathbb{R})$ é conhecida como a hipótese do contínuo. O que os estudos até então apontam é que mesmo aceitar ou não a hipótese do contínuo não torna a teoria dos conjuntos contraditória, ela apenas se mantém indiferente. Isso é algo muito incômodo do ponto de vista lógico; como pode a indecisão de uma igualdade ser verdadeira ou falsa não influenciar em uma teoria? A indecisão dessa questão não nos impede de ir mais longe. Ainda há estudos para comprovar ou não a veracidade da hipótese do contínuo.

\subsection{Observações Gerais}

Para encerrarmos a parte teórica do nosso trabalho, não poderíamos deixar de comentar sobre a aritmética dos números cardinais. Podemos falar em "somar" e "multiplicar" números cardinais a outros números cardinais e números reais, porém essa "soma" e essa "multiplicação" não é a usual conhecida para números reais, muito menos goza de todas as propriedades que conhecemos. Para entendermos um pouco como funciona essa aritmética para os números cardinais, mostraremos alguns exemplos.

Vimos que $\operatorname{card}(\mathbb{N})$ é denotado por $\aleph_{0}$. Podemos somar qualquer número real $k$ a $\aleph_{0}$. Assim, podemos mostrar que ${ }^{3}$

$$
\aleph_{0}+k=\aleph_{0}
$$

É fácil mostrar também que

$$
k . \aleph_{0}=\aleph_{0} .
$$

Além da soma e multiplicação por um número real, podemos somar e multiplicar entre os números cardinais. Desse modo, temos que

$$
\aleph_{0}+\aleph_{0}=\aleph_{0}
$$

e que

$$
\aleph_{0} \cdot \aleph_{0}=\aleph_{0} .
$$

Você pode estar se perguntando: qualquer operação com $\aleph_{0}$ resultará em $\aleph_{0}$ ? A

\footnotetext{
${ }^{3}$ Aqui deve ser considerado que, se $\operatorname{car} d(A)=\alpha$ e $\operatorname{card}(B)=\beta$ são cardinais infinitos, então $\operatorname{card}(A \cup$ $B)=\alpha+\beta$.
} 
resposta é não. Como vimos, no decorrer desta seção, não temos apenas o número cardinal $\aleph_{0}$. Assim, podemos escrever que

$$
\aleph_{0}<2^{\aleph_{0}}=\aleph_{1}
$$

Mas cuidado! As operações não são as usuais que estamos acostumados. Acabamos de ver que

$$
\aleph_{0}+2=\aleph_{0}
$$

e

$$
\aleph_{0}+4=\aleph_{0}
$$

então, das duas equações acima temos que

$$
\aleph_{0}+2=\aleph_{0}+4
$$

o que nos daria

$$
2=4
$$

o que é um absurdo. Por isso não podemos nos esquecer que é preciso ter cuidado ao falarmos da aritmética dos números cardinais, senão podemos chegar a contradições como visto acima.

O leitor interessado em se aprofundar no assunto e nas demonstrações dos resultados, recomendamos a leitura dos livros The Mathematics of infinity de Faticoni e Infinity de Lieber.

Com isso encerramos a parte teórica do nosso trabalho. Vimos que é possível "contar" a quantidade de elementos de conjuntos infinitos e que eles não possuem sempre a mesma "quantidade" de elementos pelo fato de serem infinitos. 


\section{O simbolo $\infty$}

Neste capítulo tratamos um pouco da curiosidade do símbolo $\infty$ usado para nos referirmos ao infinito.

O surgimento de símbolos e fórmulas veio para tornar mais clara e precisa a matemática, afim de se evitar contradições, interpretações ambíguas e tornar a matemática uma linguagem universal; e com isso abrir novos horizontes, tanto no sentido de comunicação entre povos diferentes como no sentido de novas descobertas. Por outro lado, hoje em dia, para a maioria dos leigos e estudantes, essa simbologia moderna e rebuscada da matemática a torna um pouco difícil de se compreender.

Quando, na virada do século XVIII, Isaac Newton (1643 - 1727) e Wilhelm Leibniz (1646 - 1716) desenvolveram o cálculo diferencial e integral, houve uma evolução muito grande na sistematização de símbolos e fórmulas matemáticas, pois havia a necessidade de precisar as teorias que iam sendo descobertas.

O inglês John Wallis (1616 - 1703) foi um estudioso que simplificou e modernizou a escrita da matemática na época. Foi o primeiro a usar o símbolo $\infty$ para se tratar do infinito. O problema era que o infinito empregava diversos significados, tanto filosóficos, teológicos, como matemáticos. Enquanto Bonaventura Cavalieri (1598-1647), aluno de Galileu Galilei, dividia uma superfície plana por uma quantidade finita de pedaços, Wallis introduz o uso de um número infinito de paralelogramos de igual tamanho infinitamente pequeno, $\frac{1}{\infty}$, em que $\infty$ representa o infinito.

Há especulações de que Wallis sabia que além do símbolo romano $\mathbf{M}$ ser usado para representar o número 1000, era usado também o símbolo

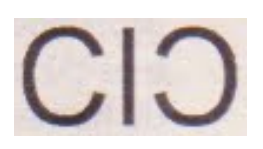

Figura 26: Símbolo romano para representar números grandiosos.

para representar um número muito grande. A partir daí, talvez Wallis teria usado 
uma versão cursiva do $\mathbf{M}$, com o símbolo acima e o ômega,

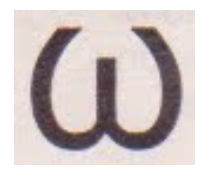

Figura 27: Ômega, última letra do alfabeto grego.

a última letra grega, e criado o símbolo $\infty$ lembrando a curva leminiscata, onde não se tem fim ao percorrê-la, ou seja, um caminho sem fim.

O símbolo tornou-se parte integrante da linguagem matemática amparada pelo crescimento do cálculo diferencial e integral, sempre se referindo a algo infinitamente pequeno, e não mais dando espaço para outras interpretações do tipo filosóficas ou teológicas.

Mais tarde, Georg Cantor (1845 - 1918) com sua teoria dos conjuntos, usaria outro símbolo, o $\aleph_{0}$, para distinguir um segundo tipo de infinito, o infinito actual. 


\section{Uma proposta didática}

Neste capítulo, apresentamos uma abordagem didática do tema trabalhado na pesquisa. Analisaremos de forma suscinta diferentes maneiras de como o infinito pode ser apresentado e discutido dentro da sala de aula do Ensino Médio.

Partiremos da ideia cultural de que o aluno chega ao ensino médio com uma noção básica sobre o infinito e suas particularidades, limitação essa própria da idade escolar. Sendo assim, é imprescindível que o professor esteja bem preparado e que tenha claro para si as concepções de infinito para que traga atividades pedagógicas instrutivas e de simples compreensão sobre o assunto.

Percebemos pelo nosso questionário que os alunos possuem a ideia errada de que o infinito é um número ou de que simplesmente é algo muito grande. Quando questionados sobre a quantidade de números entre 0,18 e 0,6, por exemplo, muitos tentam contar, outros afirmam ser infinito; mas infinito no sentido de um número muito grande, um lugar muito distânte. Com isso, queremos propor exemplos simples para serem dados em sala de aula a fim de esclarecer esses conceitos equivocados que os alunos possuem. Feito isso, podemos ir um pouco além, espandindo o conceito de infinito trazendo novas situações que os façam pensar.

O mais comum é a ideia do infinito potencial que, em poucas palavras, é algo que não tem fim, que sempre podemos continuar. É mais fácil para o aluno lidar com esse tipo de infinito, pois é mais intuitivo e presente no cotidiano. Já o infinito actual é um tipo de infinito distante para o aluno. É com ele que queremos trabalhar e mostrar aos alunos o conceito correto de infinito e que é possível ter diferentes infinitos.

Para começarmos, vamos falar sobre como contar o número de elementos de conjuntos finitos e infinitos. 


\subsection{Número de elementos}

Nesta seção, buscaremos dar a ideia de contagem, ou seja, como contamos a quantidade de elementos de um conjunto finito? Desde o surgimento da humanidade há necessidade de contagem. No começo o homem ia marcando em um pedaço de osso ou em uma vara, ou fazendo nós em uma corda ou ainda juntando pedras para contar a quantidade de ovelhas que possuia, por exemplo.

Então ele associava aquela quantidade marcada a quantidade de animais, podendo assim, saber a quantidade de que possuia. Essa ideia primitiva e muito simples é essencial para entendermos o infinito. Vamos ver alguns exemplos de como podemos ilustrar essa ideia aos alunos.

Exemplo 7.1.1. Hoje com o nosso sistema de numeração é fácil contarmos quantas letras possui o alfabeto. O que fazemos instantaneamente é associar o número 26 com a soma de cada uma das letras.

Até ai tudo bem, mas temos situações que não são tão simples assim contar a quantidade de elementos de um certo conjunto finito. Vamos aos próximos exemplos.

Exemplo 7.1.2. Um fazendeiro possui muitas cabeças de gado a se perder de vista no horizonte. Possuidor de uma área de $2000 \mathrm{~m}^{2}$ exclusiva para o gado, precisando saber a quantidade de gado que possui, resolve contá-las. Contando uma a uma ele até poderá conseguir, mas levará muito tempo e pode correr o risco de se perder no meio da contagem. Então, pensando um pouco, e vendo que um gado em média ocupa aproximadamente uma área de $2 m^{2}$ e que toda a área reservada ao gado está ocupada, basta ele dividir o valor total da área destinada aos animais por esse último valor obtendo $2000 \mathrm{~m}^{2} / 2 \mathrm{~m}^{2}=1000$ cabeças de gado.

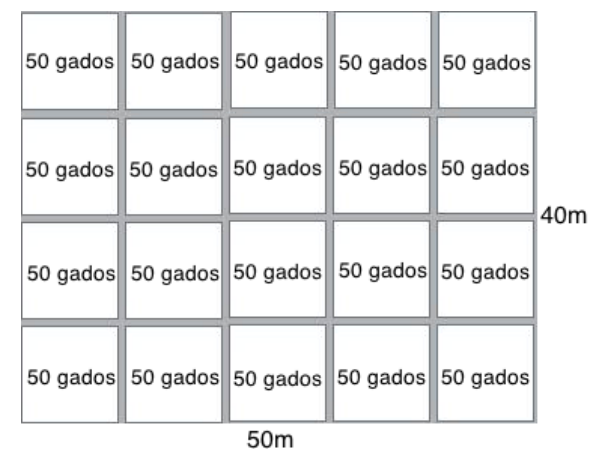

O exemplo acima mostra que podemos associar a quantidade de elementos de um conjunto a outro para descobrirmos o total de elementos de um deles já conhecendo do 
outro. Essa associação não é única, mas deve ser de modo que cada elemento de um conjunto seja associado a um único elemento do outro conjunto de modo que nenhum elemento fique sobrando. Então, podemos dizer que cada metro quadrado da área destinada ao gado represente os elementos do conjunto que chamaremos $A$. Sabendo a quantidade de elementos que o conjunto $A$ possui e que podemos associar cada elemento dele a uma única cabeça de gado sem que reste nenhum gado e nenhum metro quadrado, então sabemos que o conjunto $A$ e o conjunto das cabeças de gado possuem a mesma quantidade de elementos; podendo assim, concluir a quantidade de gado (aproximada).

Exemplo 7.1.3. O dono de uma granja de ovos precisa saber todo dia a quantidade de ovos que produz. Porém, ele perderia um bom tempo para contar ovo por ovo todos os dias. Para resolver esse problema, ele conta apenas a quantidade de caixas de ovos que ele embala, e sabendo que em cada caixa há 12 ovos, basta ele multiplicar a quantidade de caixas do dia por 12 e facilmente ele chega no número de ovos produzidos.

Neste outro exemplo estamos associando cada elemento do conjunto de ovos com um espaço dentro de uma caixa do conjunto de caixas.

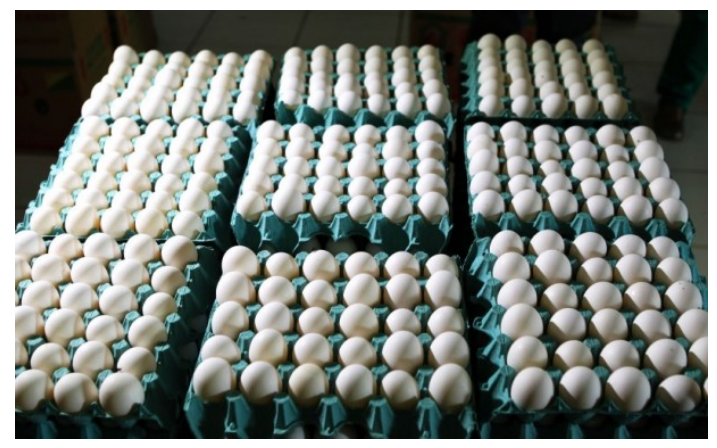

Assim, é fácil encontrar a quantidade de elementos de qualquer conjunto finito, basta estabelecer uma relação de um para um com outro conjunto finito que já é conhecido sua quantidade de elementos.

Como já falamos, os alunos acabam se equivocando quando se deparam com uma quantidade muito grande e o infinito. No próximo exemplo podemos perceber essa confusão.

Exemplo 7.1.4. Peça a alguém para contar a quantidade de grãos de areia existente na praia de Copacabana. Praticamente todas as pessoas responderam que é impossível ou que são infinitos grãos. Isso é um grande equívoco, pois a quantidade de grãos de areia por maior que seja, é um número finito, e então possível de se contar. Lógicamente que ninguém conseguirá contar grão por grão, mas por estimativa é possível estabelecer um 
número muito grande, mas finito, por meio de uma relação entre cada grão de areia com um elemento de um outro conjunto finito que se conheça previamente a sua quantidade de elementos, representando assim a quantidade de grão de areia.

Usando o exemplo acima, sugerimos que o professor leve uma caixa de sapato (por exemplo) cheia de areia e desafie os alunos a contarem a quantidade de grãos dentro da caixa. Deixe que os alunos tentem um pouco. Em seguida, mostre que é possível estimar a quantidade de grãos contida na caixa. Basta espalharmos de forma homogênea uma quantidade pequena de grãos sobre uma mesa lisa, de modo que fique apenas um grão ao lado do outro, sem que nenhum fique em cima do outro. Delimite um quadrado de $1 \mathrm{~cm}$ de lado e com a ajuda de uma lupa, conte os grãos de areia presentes neste quadrado. Feito isso, calcule quantos quadrados de $1 \mathrm{~cm}$ de lado cabem na área da base da caixa de sapato e multiplique essa quantidade pelo números de grãos encontrado no quadrado. Em seguida, multiplique o resultado pela medida da altura da caixa descobrindo o total de grãos dentro da caixa. Mesmo sendo um processo trabalhoso, vê-se que é possível calcular a quantidade total de grão de areia, e essa quantidade é representada por um número finito.

Com esses tipos de situações podemos desmistificar essa relação do infinito com um número muito grande. Vamos nos aprofundar mais sobre o assunto na próxima seção.

\subsection{O infinito como um "número" grande?}

Podemos pensar em situações que nossa intuição nos engana a respeito de quantidades muito grandes que fogem do nosso domínio. Uma delas é a do exemplo 7.1.4 da seção anterior, outra é sobre distâncias muito grandes que são difíceis de se imaginar como na distância do planeta Terra ao Sol, das distâncias entre galáxias, ou contar os números naturais pelo resto da vida. São situações que se pararmos para pensar um pouco podemos chegar a um número como resposta, um valor finito. Então, por maiores que sejam esses números, não podemos afirmar que é infinito.

Vamos mostrar aos alunos que não há algo físico suficientemente grande que não possa ser contado e que não é necessariamente tão grande como parece, vamos ver o seguinte exemplo.

Exemplo 7.2.1. Pergunte aos alunos qual é o maior número que eles conseguem pensar. Em seguida, peça que cada um deles tente falar um número maior que o do colega. 
Não é preciso pensar muito, basta somar 1 ao número falado que esse novo número será maior que o anterior. Assim, não há um número maior que todos ou tão grande que não conseguimos um maior. Agora, podemos escolher o maior dos números falados e que seja considerado por todos da turma como muito grande. Podemos afirmar que esse número pode não ser tão grande como parece. Na verdade, pode ser considerado um número bem pequeno. Mas como isso é possível? Vamos pensar no número um quatrilhão

$$
1.000 .000 .000 .000 .000=10^{15}
$$

Praticamente para qualquer coisa do nosso dia a dia esse número seria absurdamente muito grande. Mas se tomarmos o número

$$
10^{100}
$$

ou seja, o dígito 1 seguido de cem zeros. O número $10^{15}$ já não parece ser tão grande assim, conseguimos mostrar um número muito maior que ele. O número em questão é um número especial, $10^{100}$ é chamado de Googol ${ }^{1}$.

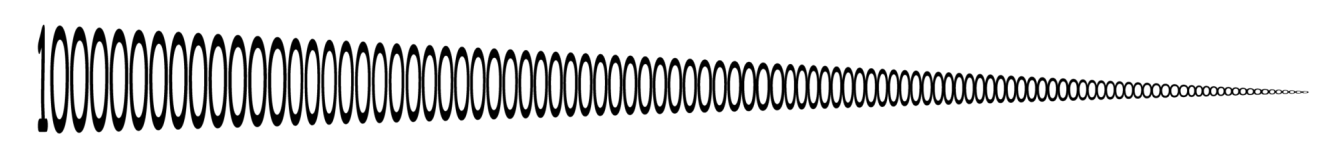

Para termos a noção do quão grande é esse número, se contarmos a quantidade de átomos em todo o universo, não daria um googol, ou então, se pensarmos no surgimento do universo há aproximadamente 14 bilhões de anos, ou aproximadamente 4, 7.10 ${ }^{17}$ segundos, não daria nem um googol de milésimos de segundo. Note que mesmo muito grande, um googol é um número finito. Temos também o número chamado de googolplex, que nada mais é que dez elevado a um googol

$$
10^{\text {googol }}
$$

ou seja, o dígito 1 seguido de um googol de zeros.

Esses números imensos, ou astronômicos, como queiram chamar, servem para diferenciarmos um número muito grande do infinito. Queremos concluir que mesmos esses números gigantescos são tão pequenos quanto o número 1 quando comparados com o infinito. Assim, não há quantidade finita em todo o universo que podemos chamar de infinito.

Pode-se propor o seguinte exercício aos alunos.

\footnotetext{
${ }^{1} \mathrm{O}$ matemático Edward Kasner, da Universidade da Columbia, pediu ao seu sobrinho de oito anos que inventasse um nome para dar a um número muito grande, mas que não fosse infinito, então surgiu o termo googol, que foi apresentado no livro "Matemática e Imaginação".
} 
Exemplo 7.2.2. (Contando sempre). Pergunte aos alunos qual é o maior número que uma pessoa consegue contar durante toda a sua vida. Pode ser que muitos repondam infinitos, ou muitos, ou vários, ou um número muito grande, etc. É possível mostrar que esse número é pequeno. Suponha que uma pessoa a partir dos 10 anos inicie contando os números até sua morte (em média 75 anos), sendo que, suporemos que cada número leve 1 segundo para ser falado. Obviamente existirão números que levam mais de um segundo para serem falados, mas suporemos isto por comodidade. Até que número chegaria? Supondo que uma pessoa conte durante 65 anos, como um ano tem 365 dias, um dia tem 24 horas, uma hora tem 60 minutos e um minuto tem 60 segundos, então, teremos que essa pessoa chegará a contar, apenas até o número 2.049.840.000 (dois bilhões, quarenta e nove milhões e oitocentos e quarenta mil). Não é um número tão grande como pode parecer a princípio, há muitas coisas do cotidiano que são maiores que esse número que podem servir de exemplo para convencer os alunos que o número encontrado não é tão grande como parece; por exemplo o número de estrelas no céu, a quantidade de grãos de areia já visto, quantidade de átomos, etc.

\section{3 "Contando" o infinito}

Depois de falarmos de como contar o número de elementos de um conjunto finito e ver que não há um número tão grande que possa ser comparado ao infinito, vamos ver como podemos "contar" o número de elementos de um conjunto infinito.

Não podemos contar todos elementos de um conjunto infinito um a um, mas então, será possível contar todos os elementos de um conjunto infinito? A ideia é bem simples. Se conseguirmos colocar cada elemento de um conjunto infinito enfileirados, ou seja, ordenados como numa fila, um atrás do outro, em sequência, podemos então, enumerá-los. Isso significa que podemos associar cada elemento dessa fila com os números naturais, por exemplo: o primeiro elemento é associado com o número um, o segundo elemento é associado com o número dois, o terceiro elemento é associado com o número três, e assim por diante. 
Desse modo podemos dizer que há uma associação de um para um do conjunto infinito em questão com os números naturais, ou ainda, há uma associação biunívoca entre esses conjuntos. Assim como foi feito nos exemplos 7.1.2, 7.1.3 e 7.1.4 para calcular a quantidade de elementos de conjuntos finitos, podemos fazer algo semelhante para conjuntos infinitos, associando cada elemento de um conjunto infinito com um elemento do conjunto dos números naturais. Portanto, concluímos que se conseguimos essa associação de um conjunto infinito com o conjunto dos números naturais, esse conjunto tem a mesma "quantidade" de elementos dos números naturais.

Para exemplificar essa ideia aos alunos, é interessante voltarmos na página 40 e perguntar a eles, qual dos dois conjuntos tem mais elementos? O dos números naturais ou dos quadrados perfeitos? Depois de alguns minutos para que eles pensem e respondam, explicar a ideia de Galileu, de associar os elementos de cada conjunto um a um. Mostrando assim que ambos os conjuntos possuem a mesma "quantidade" de elementos.

Recomendamos também que o leitor use os exemplos 5.3.3, 5.3.4 e 5.3.6 para mostrar aos alunos como temos que ter cuidado ao falarmos da "quantidade" de elementos de conjuntos infinitos, pois mesmo parecendo que uns tem mais elementos que outros, podemos facilmente estar enganados.

Deixamos a critério do professor e de sua criatividade o uso dos exemplos citados acima para tornar a situação mais lúdica e motivadora para os alunos. Vejamos um exemplo.

Exemplo 7.3.1. Podemos pensar no conjunto dos numeros naturais como uma quantidade de pessoas e o conjunto dos números pares como a numeração das poltronas de um teatro. Imagine essas pessoas em fila na porta de fora do teatro esperando para entrar e se acomodar em cada poltrona. A primeira pessoa irá se sentar na poltrona de número dois, a segunda pessoa irá se sentar na poltrona de número quatro, a terceira pessoa irá se sentar na poltrona de número seis, ou seja, cada pessoa irá se sentar na poltrona cujo número é o dobro de sua posição na fila. Assim, podemos saber em qual assento qualquer pessoa está sentada; por exemplo: a pessoa de posição 30 na fila está sentada na poltrona de número 60, a pessoa de posição 47 na fila está sentada na poltrona de número 94 . Também podemos saber qual pessoa está em qualquer poltrona; por exemplo: na poltrona de número 12 está a pessoa da posição 6 na fila, na poltrona 506 está a pessoa da posição 253 na fila. 


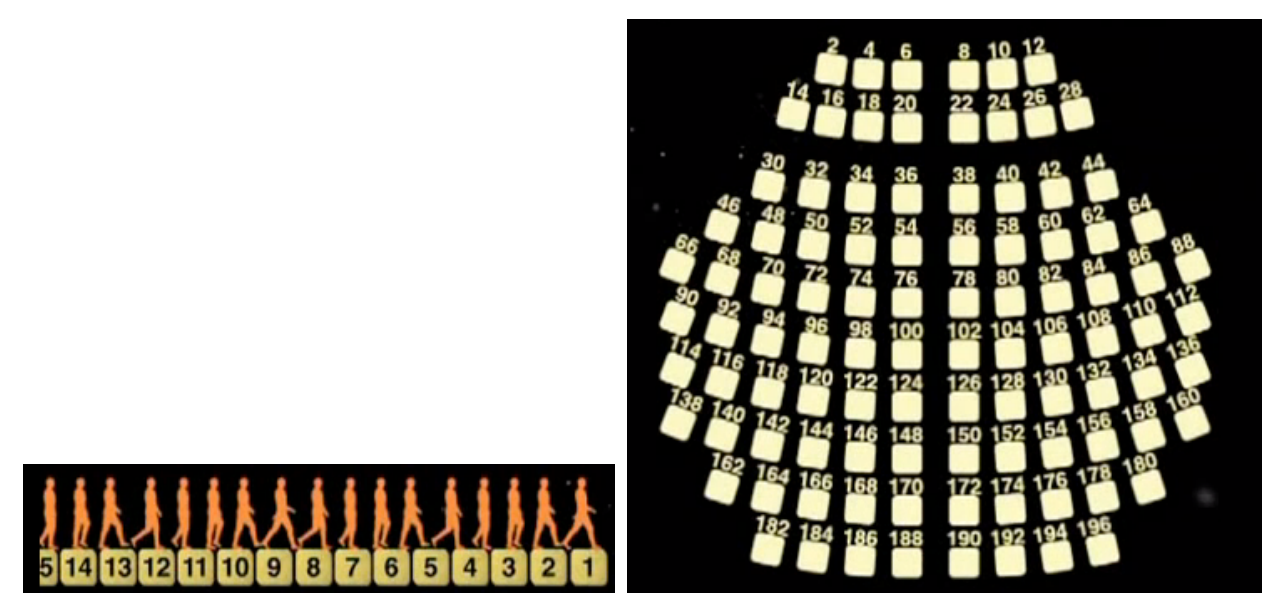

Todas as pessoas terão sua poltrona garantida, e toda poltrona terá uma pessoa ocupando-a, portanto, podemos concluir que os números naturais e os pares possuem a mesma "quantidade" de elementos. Podemos também usar como motivação o problema do Hotel de Hilbert.

Vale lembrar que o professor deve sempre alertar os alunos na hora de comparar, ou associar os elementos entre dois conjunto infinitos, pois como já vimos, o infinito nos engana a todo o momento. Será que não há nenhum conjunto infinito que não conseguimos colocá-los em fila de modo a associá-los aos números naturais como fizemos até agora? É preciso ter certeza que podemos associar um a um os elementos entre dois conjuntos infinitos.

Neste momento, depois de fazer vários exemplos onde podemos enumerar vários conjuntos infinitos e mostrar aos alunos conjuntos diferentes que são difíceis de imaginar que possuem a mesma "quantidade" de elementos, é precisor frisar que também existem conjuntos infinitos que não é possível enumerá-los, como foi feito até agora.

Um exemplo disso é o conjunto dos números reais, que não é possível de ser enumerado, ou seja, não conseguimos colocar todos seus elementos em ordem, numa fila, um depois do outro. Podemos trabalhar com os alunos da seguinte maneira.

Exemplo 7.3.2. Considere o conjunto dos números reais e tente colocá-los em ordem, como numa fila. Para isso, temos que ter um primeiro elemento e o sucessor dele, depois o sucessor do segundo e assim por diante. Isso quer dizer, por exemplo, que o número real 2,7 ocupará alguma posição nessa fila e terá um sucessor. Podemos dizer que o número 2, 8 seja o sucessor do 2, 7 na fila? Será que não há outro? E quanto ao número 2,79? E o 2,71? E o 2,700001? Percebe que seria impossível achar um sucessor para o número 2,7 ou qualquer outro que seja? Temos infinitos números reais entre dois números reais 
quaisquer, bastar somá-los e dividí-los por dois que encontramos um novo número entre eles. Essa tentativa de ordenar os números reais nos da uma intuição de que não é possível enumerá-los de maneira a termos o primeiro elemento, o segundo, o terceiro, etc... Porém, há um método bastante simples que fica mais claro que é impossível enumerar o conjunto dos números reais.

No próximo exemplo utilizamos o famoso método da diagonal desenvolvido por Cantor para mostrar que o conjunto dos números reais não pode ser enumerado.

Exemplo 7.3.3. Vamos supor que há um modo de enumerarmos o conjunto dos números reais. Assim, vamos colocar todos os números entre 0 e 1 em uma ordem qualquer como na tabela abaixo.

\begin{tabular}{|c|c|}
\hline $\mathbb{N}$ & \\
\hline 1 & $0,23647 \ldots$ \\
2 & $0,09848 \ldots$ \\
3 & $0,10982 \ldots$ \\
4 & $0,28364 \ldots$ \\
5 & $0,65915 \ldots$ \\
$\vdots$ & $\vdots$ \\
\hline
\end{tabular}

Estamos supondo que todos os números reais entre 0 e 1 estão listados na tabela acima e numerados de acordo com os números naturais. Vamos tomar o número 0,29965 ... obtido pelo primeiro dígito decimal do primeiro número, pelo segundo dígito decimal do segundo número, pelo terceiro dígito decimal do terceiro número e assim por diante. Agora, mude cada dígito desse número obtendo um novo número, por exemplo: 0,31728 . . Observe que esse segundo número é diferente do primeiro da tabela, pois seu primeiro dígito foi alterado, é diferente do segundo número da tabela, pois seu segundo dígito foi alterado, é diferente do terceiro número da tabela, pois seu terceiro dígito foi alterado, e assim por diante. Logo, podemos concluir que o número 0,31728 . . não está listado na tabela, pois acabamos de ver que ele será diferente de todos, pois seu $n$-ésimo dígito será diferente do $n$-ésimo número da tabela para qualquer número natural $n$. Portanto, não conseguimos listar todos os números reais e associá-los aos números naturais. Concluímos então que não podemos enumerar o conjunto dos números reais.

Note que na listagem da tabela no exemplo anterior sobram infinitos números reais sem serem listados, ou seja, conseguimos associar todos os números naturais com alguns dos números reais e mesmo assim sobram infinitos números. Podemos dizer então que, o conjunto infinito dos números reais é maior que o conjunto infinito dos números naturais. 
Assim, abusando um pouco da linguagem, podemos dizer aos alunos que há infinitos "maiores" que os outros. Por tal motivo, não podemos mais falar de "número" de elementos, e sim de cardinalidade. O exemplo 5.4.2 e a proposição 5.5.1 podem ser propostos como desafios para os alunos, de maneira informal, para que eles possam enchergar como dois conjuntos diferentes podem ter a mesma cardinalidade.

\subsection{Diferença entre o infinito potencial e actual}

Nesta seção traremos algumas sugestões de como apresentar aos alunos a diferença entre o infinito potencial e o infinito actual.

Um exemplo simples que o professor pode usar para introduzir a diferença entre os infinitos é o exemplo 7.2.2. Essa possibilidade de sempre poder dizer um número maior que o anterior (seu sucessor no caso dos naturais) é o que caracteriza o infinito potencial. Podemos pensar na totalidade dos números naturais, dos quais não conseguimos contar todos, como vimos no exemplo, é o que chamamos de infinito actual.

Vamos lembrar do Hotel de Hilbert, onde tínhamos um hotel com infinitos quartos numerados pelos números naturais. Peça para cada aluno pensar em um quarto do hotel que tenha o maior número de todos. Em seguida peça que eles falem os números pensados e mostre que não é possível dizer o maior número, pois sempre podemos dizer o número que foi falado somado de 1 que será maior. Podemos sempre pensar em um número maior, pois são infinitos números, não tem fim, esse infinito é caracterizado como infinito potencial.

Agora, o mais intrigante é tentar falarmos na "quantidade" de quartos desse hotel. Instigue os alunos a pensarem se não é possível pensar nessa questão. Deixe bem claro que não podemos dar um valor finito, pois são infinitos quartos e já vimos que o infinito não é um número, porém, podemos explicar aos alunos que há os números cardinais (números transfinitos) que são usados para falar da "quantidade" de infinitos elementos. Desse modo, a "quantidade" de quartos do hotel de Hilbert é um número cardinal que caracteriza o infinito actual.

Outra situação interessante para mostrar aos alunos é o exemplo do Aquiles e a tartaruga. O professor pode escrever as seis primeiras distâncias percorridas pelo Aquiles no quadro e perguntar se alguém tem alguma ideia se ele conseguirá alcançar a tartaruga. Deixe claro que as distâncias somadas são cada vez menores, parecendo que Aquiles nunca alcançará a tartaruga. Mostre que aqui aparece o infinito potencial. É importante 
também explicar ao aluno que na época do surgimento desse problema, só era pensado o infinito potencial, por isso era considerado um problema sem resolução. Por outro lado, com o surgimento da ideia do infinito actual foi possível dar uma explicação lógica para o problema.

Além dessas situações que podemos ver a diferença entre o infinito potencial e actual, temos também a aproximação da área da circunferência por polígonos e outros exemplos vistos no capítulo 4. Fica a cargo do professor usar os vastos e ricos conteúdos na matemática, e até no cotidiano, e encontrar outras situações onde podemos diferenciar o infinito potencial e actual.

Para encerrarmos, traremos um exemplo interessante mostrando uma particularidade do infinito actual estudado neste capítulo e em toda esta dissertação e do que somos capazes de fazer com ele.

Exemplo 7.4.1. Imagine um segmento de $1 \mathrm{~cm}$ de comprimento. Podemos colocar tudo o que já foi escrito em livros pela humanidade e mais o que ainda virá a ser escrito dentro deste segmento, associando cada palavra ou frase a um número entre 0 e 1 deste segmento. Vamos numerar a letra $A$ por 01 , a letra $B$ por 02 e assim por diante como no esquema

$\begin{array}{cccccccccccccc}01 & 02 & 03 & 04 & 05 & 06 & 07 & 08 & 09 & 10 & 11 & 12 & 13 & 14 \\ \downarrow & \downarrow & \downarrow & \downarrow & \downarrow & \downarrow & \downarrow & \downarrow & \downarrow & \downarrow & \downarrow & \downarrow & \downarrow & \downarrow \\ A & B & C & D & E & F & G & H & I & J & K & L & M & N\end{array}$

$\begin{array}{ccccccccccccc}15 & 16 & 17 & 18 & 19 & 20 & 21 & 22 & 23 & 24 & 25 & 26 & 27 \\ \downarrow & \downarrow & \downarrow & \downarrow & \downarrow & \downarrow & \downarrow & \downarrow & \downarrow & \downarrow & \downarrow & \downarrow & \downarrow \\ O & P & Q & R & S & T & U & V & W & X & Y & Z & -\end{array}$

Note que adicionamos um espaço e numeramos por 27. Desse modo, podemos associar a palavra "infinito" ao número

$$
0,0914060914092015
$$

ou seja, sempre começando por $0, \ldots$ pois os números deste segmento estão entre 0 e 1.

Podemos associar a frase "Infinito na matemática" a um ponto deste segmento da seguinte maneira

0, 09140609140920152814012813012005130120090301. 
Assim, podemos associar qualquer palavra, frase, texto e até mesmo um livro inteiro a um único número real entre 0 e 1 . Como temos infinitos números entre 0 e 1 e a forma que associamos cada palavra a esses números é única, podemos colocar tudo o que a humanidade já escreveu dentro deste segmento de comprimento igual a $1 \mathrm{~cm}$ e ainda sobrará muito espaço para colocar todo o restante que ainda será escrito.

Este é um bom exemplo para ilustrar do que somos capazes de fazer com o infinito actual. Há inúmeros outros exemplos e situações interessantes envolvendo o infinito, basta usarmos nossa criatividade para surpreender nossos alunos e mostrar como a matemática é interessante e desafiadora. Mas para isso, é preciso ter o conceito de infinito ou de qualquer outro assunto muito bem claro, caso contrário estamos fadados a esbarrarmos em situações contraditórias e absurdas. 


\section{Conclusão}

Vimos neste trabalho um pouco do quão grande e importante é a aplicação do infinito na matemática e como é sutíl falarmos dele. São diversas situações que nos deparamos e nos enganamos a respeito do infinito. São diversas situações que parecem não fazer sentido, não ter lógica, mas que com a compreensão correta sobre o infinito, há explicações concretas.

O questionário realizado nos mostra e nos confirma um cenário de que os alunos não tem, na maioria das vezes, a ideia e não fazem o uso correto do infinito. Muitas vezes encontramos o uso do termo infinito de maneira equivocada e o conceito de infinito deturpado. Diante disso, fomos inspirados a escrever essa dissertação a fim de trazer, de uma maneira menos formal e mais didática, para que o professor interessado possa se atualizar e passar a seus alunos a maneira correta de falar sobre o infinito.

É importante que se tenha o pleno domínio dos conceitos aqui trabalhados como as noções básicas da teoria dos conjuntos e de funções de maneira geral. É extremamente necessário entender a diferença entre o infinito potencial e actual, pois como vimos neste trabalho, há uma interação entre eles. Também no seu contexto histórico, a necessidade do uso do infinito para o desenvolvimento da matemática.

Entendemos que todos os pontos levantados aqui são de suma importância para a formação e desenvolvimento profissional do professor, para que ele posse ao aluno de forma correta o uso do infinito em suas diversas aplicações, bem como o uso correto dos termos envolvidos. Fazer com que o aluno tenha uma visão clara do que é o infinito na matemática e como isso pode influenciar no seu dia-a-dia. 


\section{Referências}

ÁVILA, G. As séries infinitas. Revista do professor de matemática. São Paulo, n. 30, p. 10-17, 1996.

BARROS, A. A.; ANDRADE, P. F. Introdução à Geometria Projetiva. Textos universitários. Rio de Janeiro: SBM, 2010.

DELAHAYE, J. P. O infinito é um paradoxo na matemática? Revista Scientific American Brasil: As diferentes faces do infinito, São Paulo, n. 15, p. 15-23, 2006, Edição Especial.

FATICONI, T. G.The Mathematics of Infinity: A Guide to Great Ideas. $1^{\text {a }}$ Edição. New Jersey: Wiley-Interscience, 2006.

GOFF, J. P. Da perspectiva ao infinito geométrico. Revista Scientific American Brasil: As diferentes faces do infinito, São Paulo, n. 15, p. 25-31, 2006, Edição Especial.

GUIDORIZZI, H. L. Um curso de cálculo. 5 Edição. São Paulo: LTC Editora, 2002. Vol. 4.

LIEBER, L. R. Infinity. New York: Paul Dry Books, 2007.

LIMA, E. L. Análise real: Funções de uma variável. $8^{\mathrm{a}}$ Edição. Rio de Janeiro: Coleção Matemática Universitária - IMPA, 2004. Vol. 1.

LIMA, E. L. Curso de análise. $12^{\circ}$ Edição. Rio de Janeiro: Projeto Euclides - IMPA, 2006. Vol. 1.

MARTÍneZ, J. L. A ciência do infinito. Revista Scientific American Brasil: As diferentes faces do infinito, São Paulo, n. 15, p. 7-13, 2006, Edição Especial.

REMÉNYI M. A história do símbolo. Revista Scientific American Brasil: As diferentes faces do infinito, São Paulo, n. 15, p. 32-33, 2006, Edição Especial.

VELLEMAN, D. J. How to prove it: A Structured Approach. $2^{\circ}$ edição. Cambridge: Cambridge University Press, 2006. 


\section{$A P \hat{E} N D I C E A$}

Neste apêndice lembraremos alguns fatos básicos sobre a convergência e divergência de séries e veremos alguns exemplos que foram mencionados ao longo do texto e que são importantes.

Se tentarmos adicionar os termos de uma sequência infinita $\left\{a_{n}\right\}_{n=1}^{+\infty}$, obteremos uma expressão da forma

$$
a_{1}+a_{2}+a_{3}+\ldots+a_{n}+\ldots
$$

que é denominada uma série infinita (ou apenas uma série) e é denotada, por abreviação, pelo símbolo

$$
\sum_{i=1}^{+\infty} a_{i}
$$

Dada uma série $\sum_{i=1}^{+\infty} a_{i}=a_{1}+a_{2}+a_{3}+\ldots$, denote por $s_{n}$ sua $n$-ésima soma parcial:

$$
s_{n}=\sum_{i=1}^{n} a_{i}=a_{1}+a_{2}+\ldots+a_{n} .
$$

Se a sequência $\left\{s_{n}\right\}$ for convergente e $\lim _{n \rightarrow \infty} s_{n}=s$ existir como um número real, então a série $\sum_{i=1}^{+\infty} a_{i}$ é denominada convergente, e escrevemos

$$
a_{1}+a_{2}+\ldots+a_{n}+\ldots=s \quad \text { ou } \quad \sum_{i=1}^{+\infty} a_{i}=s .
$$

O número $s$ é chamado soma da série. Caso contrário, a série é dita divergente.

Exemplo A.0.2. Mostraremos que a série geométrica $\sum_{k=0}^{+\infty} r^{k}$, com $|r|<1$, é convergente e tem como soma $\frac{1}{1-r}$. 
Sabemos que

$$
\sum_{k=0}^{n} r^{k}=1+r+r^{2}+\ldots+r^{n}=\frac{1-r^{n+1}}{1-r} .
$$

Como $|r|<1, \lim _{n \rightarrow \infty} r^{n+1}=0$. Daí

$$
\lim _{n \rightarrow \infty} \sum_{k=0}^{n} r^{k}=\lim _{n \rightarrow \infty} \frac{1-r^{n+1}}{1-r}=\frac{1}{1-r}
$$

Logo, a série dada é convergente e tem como soma $\frac{1}{1-r}$. Em outras palavras,

$$
\sum_{k=0}^{+\infty} r^{k}=\frac{1}{1-r}
$$

Lembraremos agora algumas propriedades elementares de séries.

\section{Propriedade A.0.1.}

(a) Seja k um número real dado. Se $\sum_{i=1}^{+\infty} a_{i}$ for convergente, então $\sum_{i=1}^{+\infty} k a_{i}$ será convergente $e$

$$
\sum_{i=1}^{+\infty} k a_{i}=k \sum_{i=1}^{+\infty} a_{i}
$$

(b) $S e \sum_{i=1}^{+\infty} a_{i} e \sum_{i=1}^{+\infty} b_{i}$ forem convergentes, então $\sum_{i=1}^{+\infty}\left(a_{i} \pm b_{i}\right)$ será convergente e

$$
\sum_{i=1}^{+\infty}\left(a_{i} \pm b_{i}\right)=\sum_{i=1}^{+\infty} a_{i} \pm \sum_{i=1}^{+\infty} b_{i}
$$

A prova desta propriedade pode ser encontrada em Guidorizzi (2002, p.17).

Critério de Comparação: Sejam as séries $\sum_{n=1}^{+\infty} a_{n}$ e $\sum_{n=1}^{+\infty} b_{n}$. Suponhamos que exista um número natural $k$ tal que, para todo $n \geq k, 0 \leq a_{n} \leq b_{n}$. Nestas condições, tem-se:

1. Se $\sum_{n=1}^{+\infty} b_{n}$ é convergente, então, $\sum_{n=1}^{+\infty} a_{n}$ é convergente.

2. Se $\sum_{n=1}^{+\infty} a_{n}$ é divergente, então, $\sum_{n=1}^{+\infty} b_{n}$ é divergente.

A prova deste critério de comparação pode ser encontrada em Guidorizzi (2002, p.44).

É fácil ver também a seguinte propriedade, e deixamos a prova dela como um exercício para o leitor. 
Propriedade A.0.2. Se $\sum_{n=1}^{+\infty} a_{n}$ é uma série convergente de termos não negativos, tal que, $a_{n}>0$ para algum valor de $n$, então

$$
0<\sum_{n=1}^{+\infty} a_{n}
$$

Como uma consequência direta desta propriedade, temos o seguinte:

Propriedade A.0.3. Se $\sum_{n=1}^{+\infty} a_{n} e \sum_{n=1}^{+\infty} b_{n}$ são séries convergentes de termos não negativos, então, se $a_{n} \leq b_{n}$ para todo $n$ e se $a_{n}<b_{n}$ para ao menos um valor de $n$, então

$$
\sum_{n=1}^{+\infty} a_{n}<\sum_{n=1}^{+\infty} b_{n}
$$

Exemplo A.0.3. Vamos mostrar com mais detalhes porque a série harmônica é divergente. Vimos no exemplo 2.3.2 a seguinte desigualdade

$$
\sum_{n=1}^{+\infty} \frac{1}{n}=1+\frac{1}{2}+\frac{1}{3}+\frac{1}{4}+\frac{1}{5}+\ldots>1+\frac{1}{2}+\frac{1}{2}+\frac{1}{2}+\ldots
$$

ou seja, cada termo da série harmônica é maior ou igual que a série do segundo termo da desigualdade, que é uma série divergênte. Deste modo, pelo critério de comparação, a série harmônica $\sum_{n=1}^{+\infty} \frac{1}{n}$ é divergente.

O próximo exemplo será muito importante para o apêndice B.

Exemplo A.0.4. Afirmamos que 0,999 $\ldots=1$. De fato, como

$$
0,999 \ldots=\frac{9}{10}+\frac{9}{10^{2}}+\ldots=\sum_{n=1}^{+\infty} \frac{9}{10^{n}}
$$

Vamos mostrar que a série $\sum_{n=1}^{+\infty} \frac{9}{10^{n}}$ converge para 1. Note que é uma série geométrica de razão $\frac{1}{10}$. Deste modo, pelo o que foi visto no exemplo A.0.2, temos que

$$
\sum_{n=1}^{+\infty} \frac{9}{10^{n}}=\frac{\frac{9}{10}}{1-\frac{1}{10}}=1
$$

Assim, concluímos que $0,999 \ldots=1$. 


\section{$A P \hat{E} N D I C E B$}

Iremos fazer a prova do item 3 da demonstração da proposição 5.5.1 que nos diz o seguinte:

Todo número real admite uma representação decimal infinita. Mas ainda, existem duas possiveis situações: a representação é única ou existem unicamente duas representações, uma finalizando em uma sequência infinita de zeros e a outra finalizando com uma sequência infinita de noves.

\section{Prova:}

Seja $x$ um número real dado. Por comodidade, suporemos que $x \geq 0$. O outro caso é similar. Se $x=m, 000 \ldots$ é uma expansão decimal de $x$ (com $m>0)$, então, é fácil verificar que $m-1,999 \ldots$ é outra expansão decimal para $x$.

Por outro lado, se

$$
x=m, m_{1} m_{2} \ldots m_{n-1} m_{n} 000 \ldots
$$

é uma expansão decimal para $x$, é fácil verificar que

$$
m, m_{1} m_{2} \ldots m_{n-1}\left(m_{n}-1\right) 999 \ldots
$$

é uma outra expansão decimal para $x$.

Veremos agora a situação mais interessante. Suponhamos que o número $x$ admite duas representações decimais infinita, digamos

$$
m, m_{1} m_{2} m_{3} \ldots
$$

e

$$
n, n_{1} n_{2} n_{3} \ldots
$$

Vejamos os seguintes casos a considerar. 
Caso 1: $m<n$.

Neste caso, suponhamos que algum dos $m_{1}, m_{2}, m_{3}, \ldots$ seja estritamente menor que 9. Se isto for verdade, teremos que

$$
x=m, m_{1} m_{2} m_{3} \ldots=m+\sum_{i=1}^{+\infty} \frac{m_{i}}{10^{i}}<m+\sum_{i=1}^{+\infty} \frac{9}{10^{i}}=m+1 \leq n \leq x
$$

Note que na penúltima desigualdade, como $m$ e $n$ são números naturais e $m<n$, então, $m+1$ não pode passar de $n$, será no máximo $n$, e pelo exemplo A.0.4 no apêndice $\mathrm{A}, \sum_{i=1}^{+\infty} \frac{9}{10^{i}}=1$.

Juntando os extremos da desigualdade acima, vemos que temos um contradição. Esta contradição é originada pela suposição de que algum dos $m_{i}$ é estritamente menor que 9. Logo, nosso caso 1 teremos que: se

$$
x=m, m_{1} m_{2} m_{3} \ldots=n, n_{1} n_{2} n_{3} \ldots
$$

com $m<n$, então, necessariamente

$$
m, m_{1} m_{2} m_{3} \ldots=m, 999 \ldots
$$

e

$$
x=m+1=n
$$

de onde temos então que

$$
x=m, 999 \ldots=n=n, 000 \ldots
$$

Caso 2: $m=n$.

Neste segundo caso, seja

$$
t=\min _{i}\left\{m_{i} \neq n_{i}\right\}
$$

isto é, $t$ é o menor índice em $i$ no qual $m_{i} \neq n_{i}$. Por comodidade consideramos que $m_{t}<n_{t}$ (a outra situação será similar).

Suponhamos que neste segundo caso seja verdade que

$$
m_{j}<9 \text { para algum } j>t
$$


Sob esta suposição neste segundo caso e pela propriedade A.0.3 (vide apêndice A), obtemos

$$
\begin{gathered}
x=m+\sum_{i=1}^{+\infty} \frac{m_{i}}{10^{i}}=m+\sum_{i=1}^{t} \frac{m_{i}}{10^{i}}+\sum_{i=t+1}^{+\infty} \frac{m_{i}}{10^{i}}=n+\sum_{i=1}^{t-1} \frac{n_{i}}{10^{i}}+\frac{m_{t}}{10^{t}}+\sum_{i=t+1}^{+\infty} \frac{m_{i}}{10^{i}} \\
<n+\sum_{i=1}^{t-1} \frac{n_{i}}{10^{i}}+\frac{m_{t}}{10^{t}}+\sum_{i=t+1}^{+\infty} \frac{9}{10^{i}}=n+\sum_{i=1}^{t-1} \frac{n_{i}}{10^{i}}+\frac{m_{t}}{10^{t}}+\frac{1}{10^{t}}=n+\sum_{i=1}^{t-1} \frac{n_{i}}{10^{i}}+\frac{\left(m_{t}+1\right)}{10^{t}} \\
\leq n+\sum_{i=1}^{t-1} \frac{n_{i}}{10^{i}}+\frac{n_{t}}{10^{t}}=n+\sum_{i=1}^{t} \frac{n_{i}}{10^{i}}=n, n_{1} n_{2} \ldots n_{t} \leq x
\end{gathered}
$$

portanto, os extremos e a desigualdade extrita no processo intermediário chegamos a uma contradição. Logo,

$$
m_{i}=9 \text { para todo } i>t
$$

Assim, temos que

$$
x=m, m_{1} m_{2} \ldots m_{t} 999 \ldots=n, n_{1} n_{2} \ldots n_{t} n_{t+1} \ldots
$$

com

$$
m=n, m_{i}=n_{i} \text { para todo } i=1,2, \ldots, t-1 \text { onde } t=\min _{i}\left\{m_{i} \neq n_{i}\right\} .
$$

Vejamos agora que

$$
n_{i}=0 \text { para todo } i>t
$$

De fato, se

$$
n_{i}>0 \text { para algum } i>t,
$$

então, pela propriedade A.0.3 do apêndice A

$$
\begin{gathered}
x=n, n_{1} n_{2} \ldots n_{t-1} n_{t} n_{t+1} \ldots=n+\sum_{i=1}^{t-1} \frac{n_{i}}{10^{i}}+\frac{n_{t}}{10^{t}}+\sum_{i=t+1}^{+\infty} \frac{n_{i}}{10^{i}} \\
>n+\sum_{i=1}^{t-1} \frac{n_{i}}{10^{i}}+\frac{n_{t}}{10^{t}}
\end{gathered}
$$

pois $n_{i}>0$ para algum $i>t$. E pela condição de $t$ neste segundo caso, teremos

$$
n+\sum_{i=1}^{t-1} \frac{n_{i}}{10^{i}}+\frac{n_{t}}{10^{t}}=m+\sum_{i=1}^{t-1} \frac{m_{i}}{10^{i}}+\frac{n_{t}}{10^{t}} .
$$

Por outro lado, como estamos supondo que $m_{t}<n_{t}$, então, $m_{t}+1 \leq n_{t}$, assim

$$
m+\sum_{i=1}^{t-1} \frac{m_{i}}{10^{i}}+\frac{n_{t}}{10^{t}} \geq m+\sum_{i=1}^{t-1} \frac{m_{i}}{10^{i}}+\frac{m_{t}+1}{10^{t}}=m+\sum_{i=1}^{t-1} \frac{m_{i}}{10^{i}}+\frac{m_{t}}{10^{t}}+\frac{1}{10^{t}}
$$




$$
=m+\sum_{i=1}^{t} \frac{m_{i}}{10^{i}}+\sum_{i=t+1}^{+\infty} \frac{9}{10^{i}} \geq x .
$$

Juntando os extremos e a desigualdade extrita que aparece no meio, teremos uma contradição, $\log o$

$$
n_{i}=0 \text { para todo } i>t
$$

assim

$$
x=m, m_{1} m_{2} \ldots m_{t-1} m_{t} 999 \ldots=n, n_{1} n_{2} \ldots n_{t-1} n_{t} 000 \ldots
$$

com

$$
m=n, m_{i}=n_{i} \text { para todo } i=1,2, \ldots, t-1 \text { e } m_{t}+1=n_{t} .
$$

Provando assim a afirmação também neste segundo caso. 


\section{$A P \hat{E} N D I C E C$}

Iremos fazer a prova do item 4 da demonstração da proposição 5.5.1 que nos diz o seguinte:

Se $0, x_{1} x_{2} x_{3} \ldots=0, y_{1} y_{2} y_{3} \ldots$, são duas representações decimais infinitas, tal que $0 \leq x_{i} \leq 9$ e $0 \leq y_{i} \leq 9$, para cada $i \in \mathbb{N}$ e se

(a) $0, x_{1} x_{2} x_{3} \ldots=0, y_{1} y_{2} y_{3} \ldots$

(b) $0, x_{i} x_{i+1} x_{i+2} \ldots<1$ e $0, y_{i} y_{i+1} y_{i+2} \ldots<1$ para todo $i \in \mathbb{N}$

então, $x_{n}=y_{n}$ para todo $n \geq 1$.

\section{Prova:}

A prova será feita por indução em $n$. Por hipótese

$$
0, x_{1} x_{2} x_{3} \ldots=0, y_{1} y_{2} y_{3} \ldots
$$

Provaremos que sob as condições colocadas, $x_{n}=y_{n}$ para todo $n \geq 1$. Vejamos que $x_{1}=y_{1}$. Multiplicando em ambos os membros de (C.1) por 10 obtemos

$$
x_{1}, x_{2} x_{3} x_{4} \ldots=y_{1}, y_{2} y_{3} y_{4} \ldots
$$

que pode ser escrito como

$$
x_{1}+0, x_{2} x_{3} x_{4} \ldots=y_{1}+0, y_{2} y_{3} y_{4} \cdots
$$

Por comodidade, denotemos $0, x_{2} x_{3} x_{4} \ldots$ e $0, y_{2} y_{3} y_{4} \ldots$ por $a$ e $b$, respectivamente. Isto é,

$$
a=0, x_{2} x_{3} x_{4} \ldots \text { e } b=0, y_{2} y_{3} y_{4} \ldots
$$

Já que por hipótese

$$
0, x_{2} x_{3} x_{4} \ldots<1 \text { e } 0, y_{2} y_{3} y_{4} \ldots<1
$$


então,

$$
0 \leq a<1 \text { e } 0 \leq b<1
$$

de onde

$$
-1<a-b<1
$$

Por outro lado, com estas novas representações

$$
x_{1}+a=y_{1}+b
$$

assim

$$
x_{1}-y_{1}=b-a .
$$

Como $x_{1}-y_{1}$ é um número inteiro, então $b-a$ é um número inteiro que, pelo descrito acima, é maior que -1 e menor que 1 . Deste modo, concluímos que $b-a=0$ e, consequentemente, $x_{1}=y_{1}$.

Consideremos agora a seguinte hipótese de indução: seja $n>1$ um número natural e

$$
x_{1}=y_{1}, x_{2}=y_{2}, \ldots, x_{n-1}=y_{n-1} .
$$

Provaremos que sobre esta hipótese $x_{n}=y_{n}$.

De fato, de modo similar à primeira etapa, multiplicando por 10 em ambos os membros da igualdade (C.1) teremos

$$
x_{1}, x_{2} x_{3} x_{4} \ldots=y_{1}, y_{2} y_{3} y_{4} \cdots
$$

de onde

$$
x_{1}+0, x_{2} x_{3} x_{4} \cdots=y_{1}+0, y_{2} y_{3} y_{4} \cdots
$$

já que $x_{1}=y_{1}$ (hipótese de indução), então,

$$
0, x_{2} x_{3} \ldots=0, y_{2} y_{3} \ldots
$$

Multiplicando em ambos os membros por 10 obtemos

$$
x_{2}+0, x_{3} x_{4} \cdots=y_{2}+0, y_{3} y_{4} \cdots
$$

Como $x_{2}=y_{2}$ (hipótese de indução), concluímos que

$$
0, x_{3} x_{4} \ldots=0, y_{3} y_{4} \ldots
$$


Repetindo este argumento, pois por hipótese de indução

$$
x_{1}=y_{1}, x_{2}=y_{2}, \ldots, x_{n-1}=y_{n-1},
$$

concluímos que

$$
0, x_{n} x_{n+1} \ldots=0, y_{n} y_{n+1} \ldots
$$

Usando novamente o argumento da primeira etapa podemos concluir que $x_{n}=y_{n}$.

Assim,

$$
x_{n}=y_{n} \text { para todo } n>1 \text {. }
$$

